MICHELLE DE OLIVEIRA COUTINHO

RESPONSABILIDADE SOCIAL EM PROJETOS DE CONSTRUÇÃO CIVIL

São Paulo

2019 


\title{
RESPONSABILIDADE SOCIAL EM PROJETOS DE CONSTRUÇÃO CIVIL
}

\author{
Dissertação apresentada à Escola \\ Politécnica da Universidade de São Paulo \\ para obtenção do título de Mestre em \\ Ciências.
}

Área de concentração: Engenharia de Construção Civil e Urbana.

Orientador: Professor Livre-Docente Silvio Burrattino Melhado.

\section{São Paulo}


Autorizo a reprodução e divulgação total ou parcial deste trabalho, por qualquer meio convencional ou eletrônico, para fins de estudo e pesquisa, desde que citada a fonte.

Este exemplar foi revisado e corrigido em relação à versão original, sob responsabilidade única do autor e com a anuência de seu orientador.

São Paulo, de de

Assinatura do autor:

Assinatura do orientador:

Catalogação-na-publicação

Coutinho, Michelle de Oliveira

Responsabilidade Social em Projetos de Construção Civil / M. O. Coutinho -- versão corr. -- São Paulo, 2019. $116 \mathrm{p}$.

Dissertação (Mestrado) - Escola Politécnica da Universidade de São Paulo. Departamento de Engenharia de Construção Civil.

1.Responsabilidade Social 2.Projetos de Construção Civil 3.Gestão das Partes Interessadas 4.Gestão dos Recursos Humanos 5.Gestão de Riscos I.Universidade de São Paulo. Escola Politécnica. Departamento de Engenharia de Construção Civil Il.t. 


\section{AGRADECIMENTOS}

Agradeço ao professor Silvio Burrattino Melhado por me acolher e orientar quando eu já quase não tinha esperança de conseguir terminar o mestrado. Suas palavras de apoio e incentivo foram fundamentais para eu seguir adiante.

À professora Brenda Leite, por me incentivar e motivar a não desistir do mestrado. E por ser um exemplo de mulher forte.

Às amigas Mariana e Débora Chazanas que me apoiaram compartilhando o dia a dia da vida em São Paulo.

Aos colegas Marie e Alan, colegas de aulas na USP, que também correm atrás de seus sonhos de serem Doutores na melhor universidade do país.

Aos membros da banca de qualificação e defesa, professores Francisco Cardoso, Roque Rabecchini e Ricardo Oviedo Haito, pelas sugestões de melhoria na pesquisa.

Agradeço ao Bureau Veritas e aos colegas de trabalho pelo aprendizado e experiências profissionais enriquecedoras e pelo apoio para a realização deste mestrado. O lema do BV também passou a ser o meu em muitas ocasiões: "Move forward with confidence".

Às pessoas as quais devo o mérito deste trabalho: a minha mãe Yara Maria e as minhas irmãs queridas Bartira e Juliana Coutinho. Por elas sempre lutarei com força para cuidar e dar bons exemplos.

MUITO OBRIGADA! 
"Não se limite. Muitas pessoas se limitam ao que elas pensam que podem fazer. Você pode ir tão longe quanto sua mente permite. O que você acredita, lembre-se, você pode conseguir." Mary Kay Ash, empreendedora e filantropa. 


\section{RESUMO}

Os projetos de construção civil são de modo geral impactantes na sociedade, uma vez que afetam a vida das pessoas envolvidas, tanto positiva quanto negativamente. Os benefícios de projetos deste tipo são inegáveis, visto que geram emprego, renda e desenvolvimento. Todavia, os aspectos negativos também são consideráveis, pois alteram dramaticamente o meio ambiente. Hoje, vários autores defendem a ideia de que os projetos de construção civil devem incorporar valores éticos e sociais, porque deste modo, podem manter os melhores funcionários, melhorar a produtividade e evitar problemas legais. Dentro desta visão, o objetivo desta pesquisa teve como objetivo principal entender como empresas ligadas a projetos de construção civil desenvolvem e operacionalizam o tema responsabilidade social em seus projetos. Traçando um panorama das ações desenvolvidas, das dificuldades encontradas e avaliando se o tema está inserido no planejamento e orçamento dos projetos. O desenvolvimento do trabalho foi realizado em três etapas: a primeira, uma revisão sistemática da literatura; a segunda, a aplicação de questionários online (survey) sobre o tema e a terceira etapa foi o tratamento análises estatísticas dos dados obtidos. Como resultado, foi identificado que as empresas ligadas a projetos de construção civil seguem a tendência empresarial geral, ou seja, atuam fortemente no entorno de suas obras. Em seus projetos, as ações de responsabilidade social são endereçadas aos funcionários e às comunidades locais, com grande atenção para questões de capacitação e educação; em seguida, há destaque para questões de direitos humanos; e, por último, questões de meio ambiente. As ações de responsabilidade social são contempladas no planejamento e orçamento de $51 \%$ dos projetos. Verificou-se que existem diferentes motivações iniciais para a atuação na área social dos projetos, variando de acordo com a localização geográfica do respondente. No Brasil, a grande maioria das empresas ligadas à projetos são motivadas pela crença de que as suas ações podem fazer a diferença nas comunidades dos entornos das obras.

Palavras-chave: Responsabilidade Social, Empresa de Construção Civil, Projetos de Construção Civil, Gestão das Partes Interessadas, Gestão de Recursos Humanos, Gestão de Riscos 


\begin{abstract}
Construction projects are generally impacting on society as they affect the lives of the people involved, both positively and negatively. The benefits of such projects are undeniable as they generate jobs, income and development. However, the negative aspects are also considerable, as they dramatically change the environment. Today, several authors defend the idea that civil construction projects must incorporate ethical and social values, because in this way, they can maintain the best employees, improve productivity and avoid legal problems. Within this vision, the main objective of this research was to understand how companies linked to civil construction projects develop and operationalize the theme social responsibility in their projects. Outlining the actions developed, the difficulties encountered and evaluating whether the theme is part of the planning and budgeting of the projects. The development of the work was carried out in three stages: the first, a systematic review of the literature; the second, the application of online questionnaires (survey) on the subject and the third stage was the statistical analysis of the data obtained through the survey. As a result, it was identified that the companies involved in civil construction projects follow the general business trend, that is, they act strongly in the surroundings of their works. In their projects, social responsibility actions are addressed to employees and local communities, with great attention to training and education issues; then there is a focus on human rights issues; and, finally, environmental issues. The social responsibility actions are contemplated in the planning and budgeting of $51 \%$ of the projects. It was verified that there are different initial motivations for the performance in the social area of the projects, varying according to the geographical location of the respondent. In Brazil, the great majority of the companies involved with projects are motivated by the belief that their actions can make a difference in the communities of the work environment.
\end{abstract}

Keywords: Social Responsibility, Construction Company, Construction Projects, Stakeholder Management, Human Resources Management, Risk Management 


\section{RÉSUMÉ}

Les projets de construction civile ont généralement un impact sur la société, dans la mesure où ils affectent la vie des personnes impliquées, tant de manière positive que négative. Les avantages de tels projets sont indéniables, car ils créent des emplois, génèrent des revenus et participe au développement de la société. Cependant, les aspects négatifs sont également considérables, puisqu'ils modifient radicalement l'environnement. Aujourd'hui, plusieurs auteurs défendent l'idée que les projets de construction civile doivent incorporer des valeurs éthiques et sociales, pour pouvoir ainsi conserver les meilleurs employés, améliorer la productivité et éviter les problèmes juridiques. Dans cette vision, l'objectif principal de cette recherche était de comprendre comment les entreprises liées aux projets de construction civile développent et opérationnalisent le thème de la responsabilité sociale dans leurs projets. Une analyse décrivant les actions développées, les difficultés rencontrées et déterminant si le thème fait partie de la planification et de la budgétisation des projets, a donc été faite. Les travaux se sont déroulés en trois étapes: la première consistait en une revue systématique de la littérature; dans la deuxième, une application de questionnaires en ligne (survey) sur le sujet a été réaliser et ; la troisième étape a concerné l'analyse statistique des données obtenues par l'enquête. Comme résultat, il a été identifié que les entreprises impliquées dans des projets de construction civile suivent la tendance générale des affaires, c'est-à-dire qu'elles agissent fortement autour de leurs travaux. Dans leurs projets, des actions de responsabilité sociale sont dirigées vers les employés et les communautés locales, avec une grande attention portée aux questions de formation et d'éducation ; ensuite, l'accent est mis sur les questions relatives aux droits de l'homme; et, enfin, les problèmes environnementaux. Les actions de responsabilité sociale sont envisagées dans la planification et la budgétisation de $51 \%$ des projets. II a été vérifié qu'il existe différentes motivations initiales pour la réalisation du domaine social des projets, qui varient en fonction de la localisation géographique du répondant. Au Brésil, la grande majorité des entreprises impliquées dans les projets sont motivées par la conviction que leurs actions peuvent faire une différence dans les communautés de l'environnement des oeuvres.

Mots-clés: Responsabilité Sociale, Entreprise de Construction, Projets de Construction, Gestion des Parties Prenantes, Gestion des Ressources Humaines, Gestion des Risques 


\section{LISTA DE ABREVIATURAS E SIGLAS}

$\begin{array}{ll}\text { ABNT } & \text { Associação Brasileira de Normas Técnicas } \\ \text { CDP } & \text { Carbon Disclosure Program } \\ \text { ESG } & \text { Environmental, Social and Governance } \\ \text { GRI } & \text { Global Reporting Initiative } \\ \text { ISO } & \text { International Organization for Standardization } \\ \text { LEED } & \text { Leadership in Energy and Environmental Design } \\ \text { MTE } & \text { Ministério do Trabalho e Emprego } \\ \text { OIT } & \text { Organização Internacional do Trabalho } \\ \text { ONG } & \text { Organização Não Governamental } \\ \text { OSCIP } & \text { Organização da Sociedade Civil de Interesse Público } \\ \text { RAIS } & \text { Relação Anual de Informações Sociais } \\ \text { RH } & \text { Recursos Humanos } \\ \text { SAG } & \text { Strategic Advisory Group } \\ \text { SGA } & \text { Sistema de Gestão Ambiental } \\ \text { SGRS } & \text { Sistema de Gestão de Responsabilidade Social } \\ \text { SSI } & \text { Swedish Standards Institute } \\ \text { TBL } & \text { Triple Bottom Line }\end{array}$




\section{LISTA DE QUADROS}

Quadro 1 - Definições de Risco

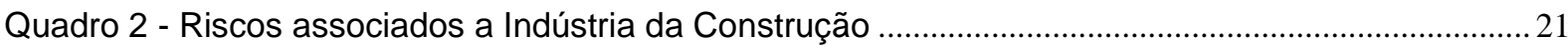

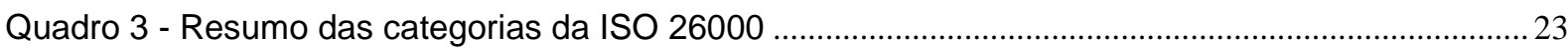

Quadro 4 - Relação da Análise de Conteúdo com as Categorias de Responsabilidade Social ............54

\section{LISTA DE TABELAS}

Tabela 1- Número de publicações por periódico e por ano

Tabela 2 - Lista de artigos mais relevantes de acordo com o índice de impacto e número de citações

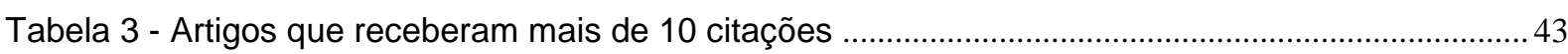

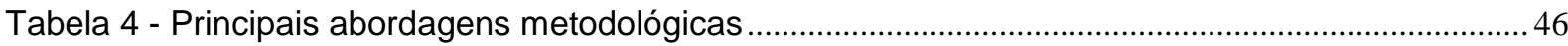

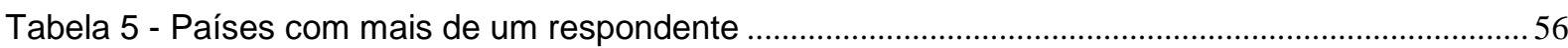

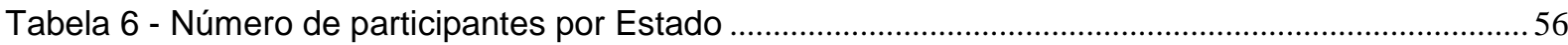

Tabela 7 - Categoria das ações de Responsabilidade Social realizadas nos projetos ............................ 66

Tabela 8 - Estoque de trabalhadores na Construção Civil Segundo o grau de instrução - Brasil 2017*

Tabela 9 - Categorias de ações de Responsabilidade Social versus tipo de projetos - Todos os respondentes

Tabela 10 - Categorias de ações de Responsabilidade Social versus tipo de projetos - Respondentes do Brasil 


\section{LISTA DE FIGURAS}

Figura 1 - Etapas e métodos de pesquisa 5

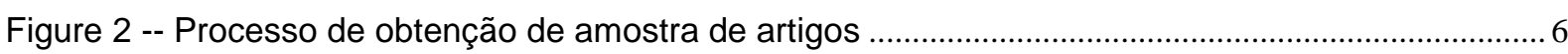

Figure 3 - Síntese do processo de importação e tratamento dos dados da Survey ................................. 11

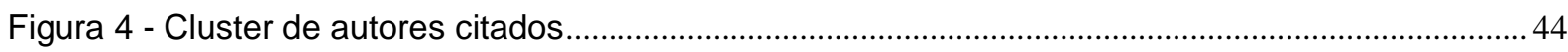

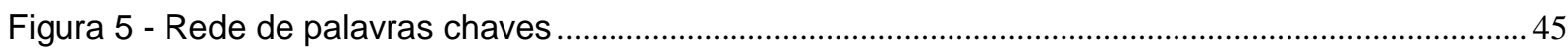

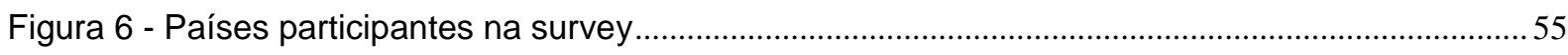

Figura 7 - Distribuição geográfica dos participantes da survey no Brasil .................................................56

Figura 8 - Distribuição dos respondentes por tipo de projeto de atuação ..................................................57

Figura 9 - Nível de conhecimento do termo "Responsabilidade Social" .................................................58

Figura 10 - Categorias consideradas Responsabilidade Social ...............................................................58

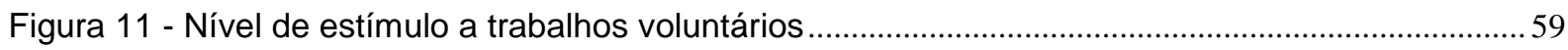

Figura 12 - Nível de estímulo a trabalhos voluntários quando a Responsabilidade Social integra a Visão Estratégica.

Figura 13 - Percentual de empresas que contemplam ações de Responsabilidade Social no planejamento e orçamento de seus projetos versus tamanho da empresa..

Figura 14 - Volume de investimento em ações de Responsabilidade Social nos projetos versus tamanho da empresa.

Figura 15 - Nível de divulgação das ações de Responsabilidade Social nos projetos versus tamanho

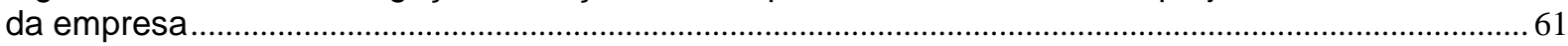

Figura 16 - Métodos de divulgação das ações de Responsabilidade Social dos projetos ....................... 62

Figura 17 - Percentual de empresas que possuem ações de Responsabilidade Social em seus projetos.

Figura 18 - Percentual de empresas que possuem ações de Responsabilidade Social em seus projetos - Comparação Brasil versus Exterior.

Figura 19 - Percentual de empresas que possuem ações de responsabilidade social em seus projetos: Comparação por segmento de atuação.

Figura 20 - Motivações das empresas para investir em ações de Responsabilidade Social em seus projetos.

Figura 21 - Principais dificuldades para implantação de ações de Responsabilidade Social nos projetos.

Figura 22 - As ações de Responsabilidade Social nos projetos integram a visão estratégica da empresa?.

Figura 23 - As ações de Responsabilidade Social estão contempladas no planejamento e orçamentos dos projetos? - Para empresas que responderam "Sim" sobre a integração com a visão estratégica. 73 Figura 24 - As ações de Responsabilidade Social estão contempladas no planejamento e orçamento

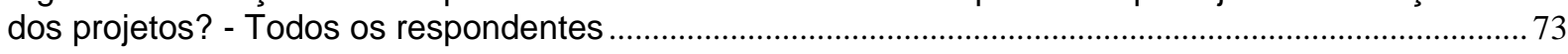

Figura 25 - Responsáveis por decidir as ações de Responsabilidade Social dos projetos .....................74

Figura 26 - Volume de investimentos em ações de Responsabilidade Social nos projetos no ano de 2017 (em Reais)

Figure 27 - Comparação dos volumes de investimentos com o ano de 2016 ............................................75

Figure 28 - Parceiros para a realização de ações de Responsabilidade Social nos projetos ................. 76

Figura 29 - Critério para escolha dos beneficiários das ações de Responsabilidade Social nos projetos

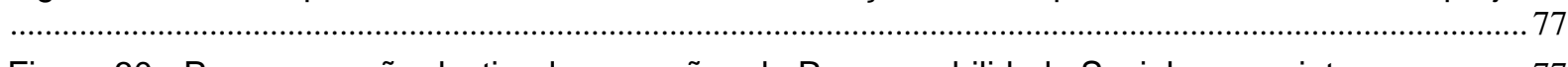

Figura 30 - Para quem são destinadas as ações de Responsabilidade Social nos projetos................... 77

Figura 31 - Nível de conhecimento em referências normativas, indicadores e métodos de mensuração

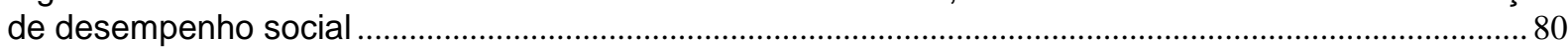

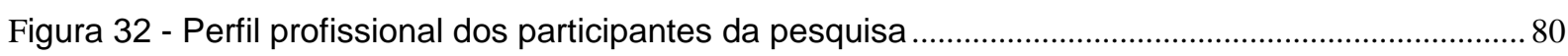




\section{SUMÁRIO}

1 INTRODUÇÃO

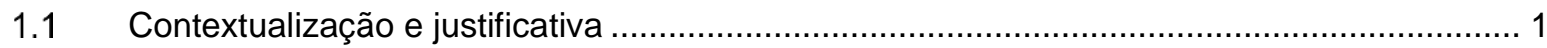

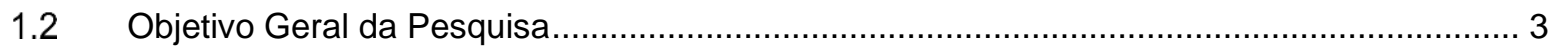

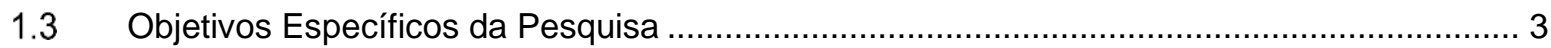

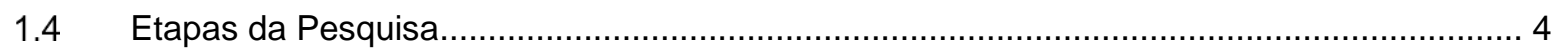

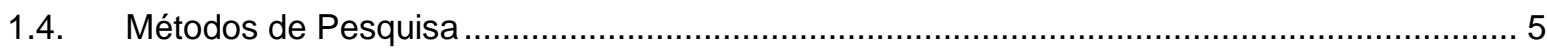

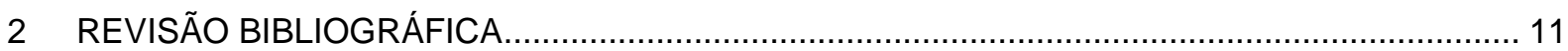

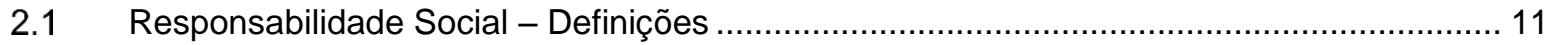

2.2 Responsabilidade Social em Projetos de Construção Civil ................................................... 13

2.2.1 Gestão de Stakeholders em Projetos de Construção Civil .............................................. 15

2.2.2 Gestão de Recursos Humanos em Projetos de Construção Civil ...................................... 17

2.2.3 Gestão de Riscos em Projetos de Construção Civil ......................................................... 19

2.3 Teoria e estratégia em Responsabilidade Social na Construção Civil ................................ 22

2.4 Referências normativas e Indicadores da responsabilidade social ...................................... 24

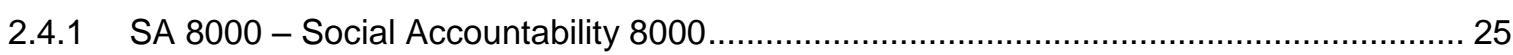

2.4.2 AA 1000 - Institute of Social and Ethical Accountability - ISEA .................................... 26

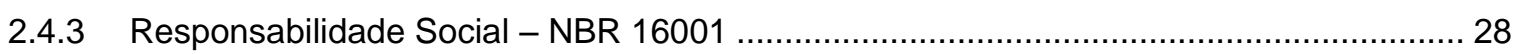

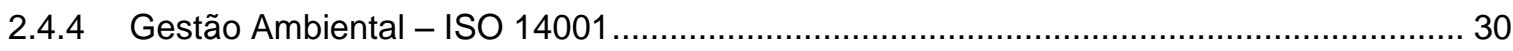

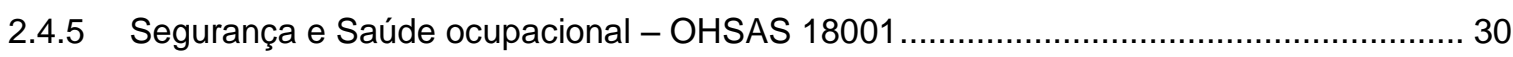

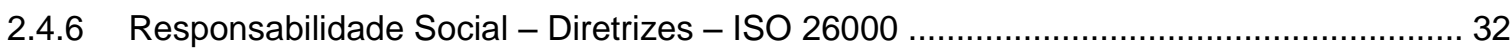

2.5 Estratégias para mensuração do Desempenho Social .................................................. 33

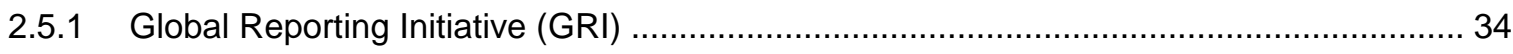

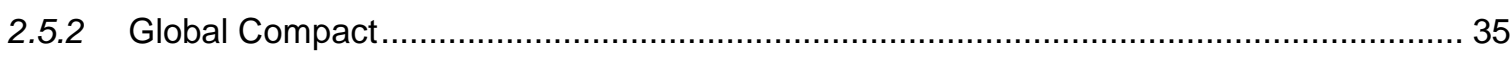

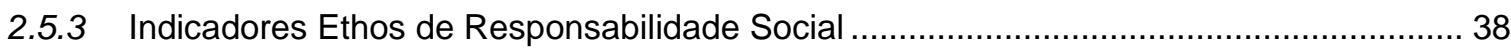

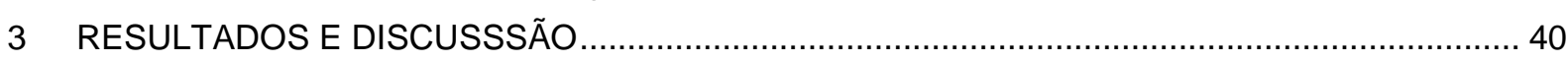

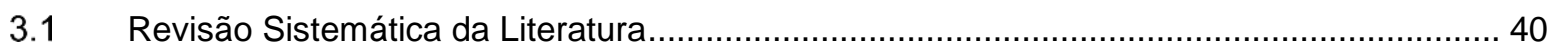

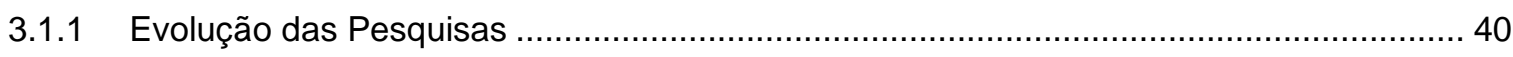

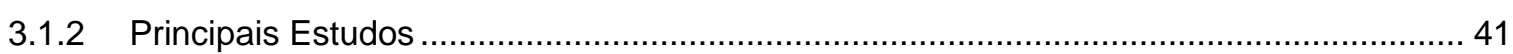

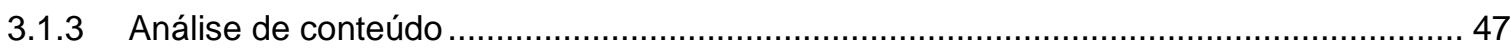

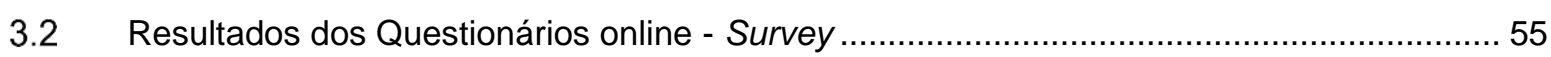

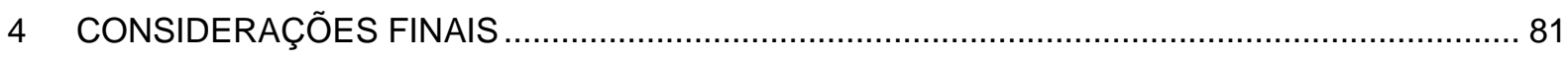

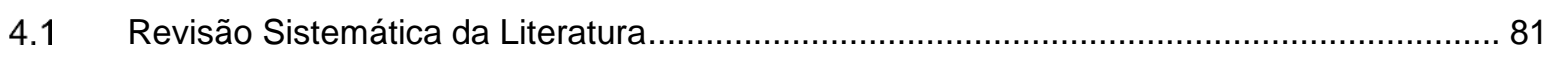

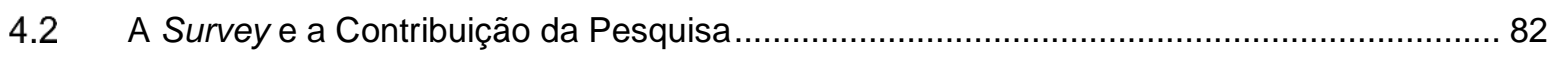

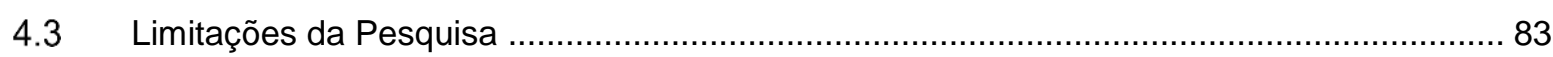

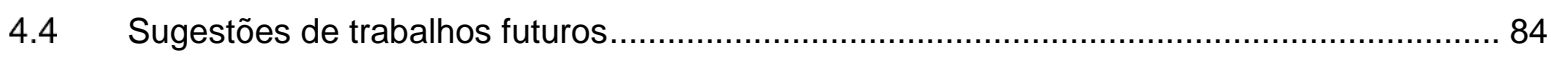

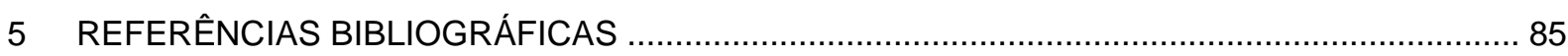

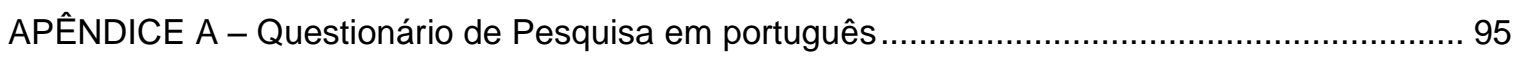

APÊNDICE B - Questionário de Pesquisa em espanhol ......................................................... 103

APÊNDICE C - Questionário de Pesquisa em inglês ............................................................. 110

APÊNDICE D - Link para a planilha de dados originais ............................................................ 116 


\section{INTRODUÇÃO}

\subsection{Contextualização e justificativa}

As atividades da indústria da construção civil exercem grande influência na sociedade e no meio ambiente, por este motivo, têm recebido grande atenção de acadêmicos e do setor industrial. Esse setor é um dos grandes causadores de impactos ambientas no planeta. Suas atividades geram diferentes tipos de poluição: sonora, da água e do ar, além de consumir grandes parcelas de recursos naturais não renováveis e gerar grandes quantidades de resíduos (BARTHORPE, 2010; TURK, 2009). Globalmente, o setor da construção civil demanda $10 \%$ do fornecimento mundial de energia; é responsável por cerca de $40 \%$ das emissões de gases de efeito estufa, consumindo de 40 a 50\% de matérias-primas naturais, além de demandar $12 \%$ da água do mundo (NAÇÕES UNIDAS, 2017). A implementação de responsabilidade social na indústria da construção civil é importante para demonstrar o esforço para se manter o equilíbrio entre objetivos econômicos, ambientais e sociais.

O conceito de responsabilidade social corporativa não é recente, sendo o termo proposto pela primeira vez na década de 1950 (BOWEN, 1953; FREDERICK, 1994) e desde então a temática tem evoluído. Sendo que os principais assuntos estão relacionados a questões sociais, ambientais, éticas e stakeholders (DAHLSRUD, 2008). Acadêmicos têm focado em níveis institucionais, organizacionais ou individuais para analisar diferentes aspectos das ações e políticas de responsabilidade social corporativa (AGUINIS; GLAVAS, 2012).

Comparado com a quantidade existente de trabalhos sobre responsabilidade social corporativa, a responsabilidade social em projetos de construção civil é ainda um campo pouco desenvolvido (ZENG et al., 2015). De acordo com a definição de Davis (1973), a responsabilidade social em um empreendimento deve significar ir além de metas de qualidade, tempo e custo. Os stakeholders, ou seja, as partes interessadas dos projetos, devem considerar e responder a problemas sociais e ambientais contemporâneos ainda dentro de seu ciclo de vida. Sendo projetos de construção civil as concepções, edificações e ou/montagem de diferentes estruturas, 
que seguem o seguinte ciclo de vida: iniciação, planejamento, execução e encerramento. Sendo assim, questões de responsabilidade social devem ser implementadas em projetos de construção, incluindo medidas, políticas ou atividades que abordem problemas ambientais e sociais.

No setor da construção civil, os projetos mantêm as atividades de negócios da empresa, pois este segmento é fortemente baseado na existência e manutenção de projetos (LOOSEMORE; BRIDGEMAN, 2017). Assim, os projetos são importantes plataformas para a indústria da construção civil desenvolver responsabilidade social. É importante levar em consideração o que asseveram alguns pesquisadores, os quais dizem que sustentabilidade é uma questão preocupante em vários setores e que as empresas ligadas a projetos de construção não se constituem exceções. E mais, alguns autores defendem a ideia de que empresas que desenvolvem projetos devem incorporar valores éticos e sociais, pois desse modo podem manter os melhores funcionários, melhorar sua produtividade e evitar problemas legais (MONEVA; RIVERA-LIRIO; MUÑOZ-TORRES, 2007; ZUO et al., 2012).

Diante dessa realidade é importante que as empresas de construção civil, apontadas em pesquisas como aquelas que menos investem em ações sociais, sendo tradicionalmente consideradas vilãs no quesito meio ambiente, estejam dispostas a oferecer produtos e serviços de qualidade, mas que preservem o meio ambiente e contribuam para o desenvolvimento social. Assim, algumas empresas que atuam com projetos de construção civil, seguindo a tendência de outras indústrias, vêm apostando e acreditando que suas atividades devem ter objetivos maiores que seu próprio crescimento. Por essa razão, fazem questão de participar do desenvolvimento dos locais onde atuam e das pessoas que neles vivem, investindo em seu bem-estar, assim como em cultura, educação e preservação do meio ambiente (TINOCO, 2012).

Projetos relacionados à construção civil são de modo geral impactantes na sociedade, tanto positiva quanto negativamente. Trazem benefícios econômicos, gerando emprego e renda para os trabalhadores envolvidos. Os aspectos negativos estão relacionados ao impacto ambiental, geração de resíduos e altos índices de acidentes de trabalho (ZENG et al., 2015). Todavia, esses projetos são de extrema importância, pois seus resultados geram produtos com longo ciclo de vida. Futuras gerações serão influenciadas pelas decisões feitas hoje em termos de construções. 
Sendo assim, questões ligadas à responsabilidade social devem ser consideradas (SARKIS; MEADE; PRESLEY, 2012). Na fase de projetos não se tem muitos estudos sobre responsabilidade social. Considerando os impactos nocivos a longo prazo sobre a sociedade e o meio ambiente a partir de projetos de construção, esta pesquisa pretende ser uma contribuição para se elevar os níveis de conhecimentos sobre responsabilidade social em nível de projetos de construção civil (LIN; HO; SHEN, 2017).

Embora seja evidente que exista um interesse crescente e variado na pesquisa sobre responsabilidade social na construção civil, a heterogeneidade da pesquisa nesta área significa que ainda não há um consenso, e tem-se pouca ideia de como as empresas desenvolvem e operacionalizam as ações de responsabilidade social em seus projetos. Sendo assim, o presente trabalho vem para contribuir com a lacuna existente nessa temática, especialmente no âmbito de projetos.

\subsection{Objetivo Geral da Pesquisa}

A presente pesquisa tem como objetivo principal entender como empresas ligadas a projetos de construção civil desenvolvem e operacionalizam o tema responsabilidade social em seus projetos.

\subsection{Objetivos Específicos da Pesquisa}

Visando atender o objetivo geral, a presente pesquisa tem os seguintes objetivos específicos:

1. Verificar se as partes interessadas do setor da construção civil conhecem os preceitos de responsabilidade social; 
2. Averiguar se empresas de construção civil desenvolvem ações de responsabilidade social nos seus diferentes projetos e que tipo de ações são realizadas;

3. Conhecer principais dificuldades encontradas, no caso de nenhum tipo de ação ser desenvolvida nos projetos;

4. Examinar se as empresas do setor têm incorporado ações de responsabilidade social de forma estratégica em seus negócios, através da inserção das ações no planejamento e orçamento dos projetos;

5. Averiguar quanto é gasto anualmente em média pelas empresas com ações de responsabilidade social;

6. Analisar quem são os parceiros nas ações de responsabilidade social das empresas que atuam com projetos de construção civil;

7. Verificar para quem são direcionadas as ações de responsabilidade social, quando elas existem em nível de projeto;

8. Examinar se as empresas ligadas a projetos de construção civil conhecem e implementam normas, orientações e indicadores de desempenho da área social.

\subsection{Etapas da Pesquisa}

A presente pesquisa foi desenvolvida em três grandes etapas. A etapa 1 foi o desenvolvimento de uma revisão sistemática da literatura, visando identificar lacunas no tema pesquisado, e conhecer como outros pesquisadores abordam esta temática. A etapa 2 foi a aplicação de questionários online (survey). A etapa 3 se trata da realização de análises estatísticas dos resultados obtidos nos questionários.

A Figura 1 sintetiza as etapas e métodos desta pesquisa. 
Figura 1 - Etapas e métodos de pesquisa

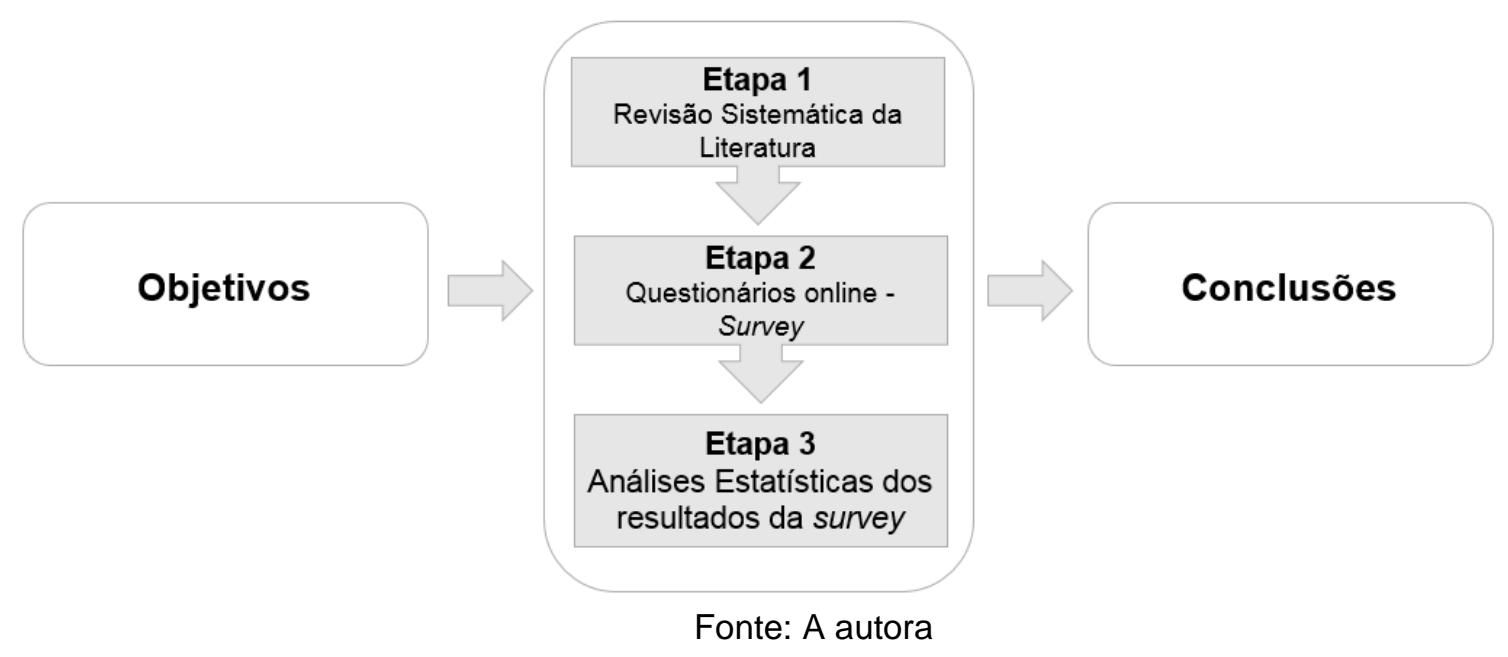

\subsection{Métodos de Pesquisa}

\subsubsection{Revisão Sistemática de Literatura}

A revisão sistemática sobre a literatura existente relacionada com responsabilidade social e projetos de construção civil teve por objetivo identificar lacunas e sintetizar como são desenvolvidas pesquisas sobre este tema em particular, através da aplicação procedimentos replicáveis para cada etapa do processo (HUSSAIN et al., 2011).

Há diferentes abordagens possíveis em uma revisão sistemática da literatura: bibliometria, meta análise e análise de conteúdo. Escolheu-se a primeira opção, uma vez que esta pode incluir uma análise de conteúdo, permitindo assim a identificação dos assuntos, abordagens e métodos mais importantes dentro desse tema (TATSIONI; IOANNIDIS, 2016).

\subsubsection{Obtenção da amostra e procedimentos}


Para a obtenção da amostra a ser estudada, inicialmente foi selecionado um banco de dados e efetuado uma busca sem restrições sobre disciplina, periódicos específicos ou datas de publicação. Para a busca foram utilizados três bancos de dados: ISI Web of Science, uma vez que este banco inclui artigos de outros bancos como (ProQuest e Wiley), buscou-se também nas bases Scopus e Science Direct. Para título de conferência de resultados a mesma busca foi realizada no periódico do International Journal of Project Management (IJPM), que pertence às duas bases de dados e é o principal jornal da área de Gestão de Projetos. Tanto o ISI quanto o Scopus possuem informações importantes para uma análise bibliométrica, que inclui: resumos, referências, número de citações, lista de autores, instituições envolvidas, países e o JCR - Journal Citation Report (CARVALHO; FLEURY; LOPES, 2013).

Os termos utilizados para a busca foram "Corporate Social Responsibility and Construction Projects". A busca inicial resultou em 124 artigos. Os resumos de todos os artigos identificados inicialmente foram lidos e então excluídos todos aqueles que não tinham aderência ao tema inicial proposto (Figura 2).

Após a exclusão dos artigos que não atendiam ao tema, a amostra resultou em 53 artigos, todavia um artigo foi excluído da consideração sobre metodologia e análise de conteúdo, uma vez que o texto integral não foi encontrado, totalizando então 52 artigos analisados.

Figura 2 -- Processo de obtenção de amostra de artigos

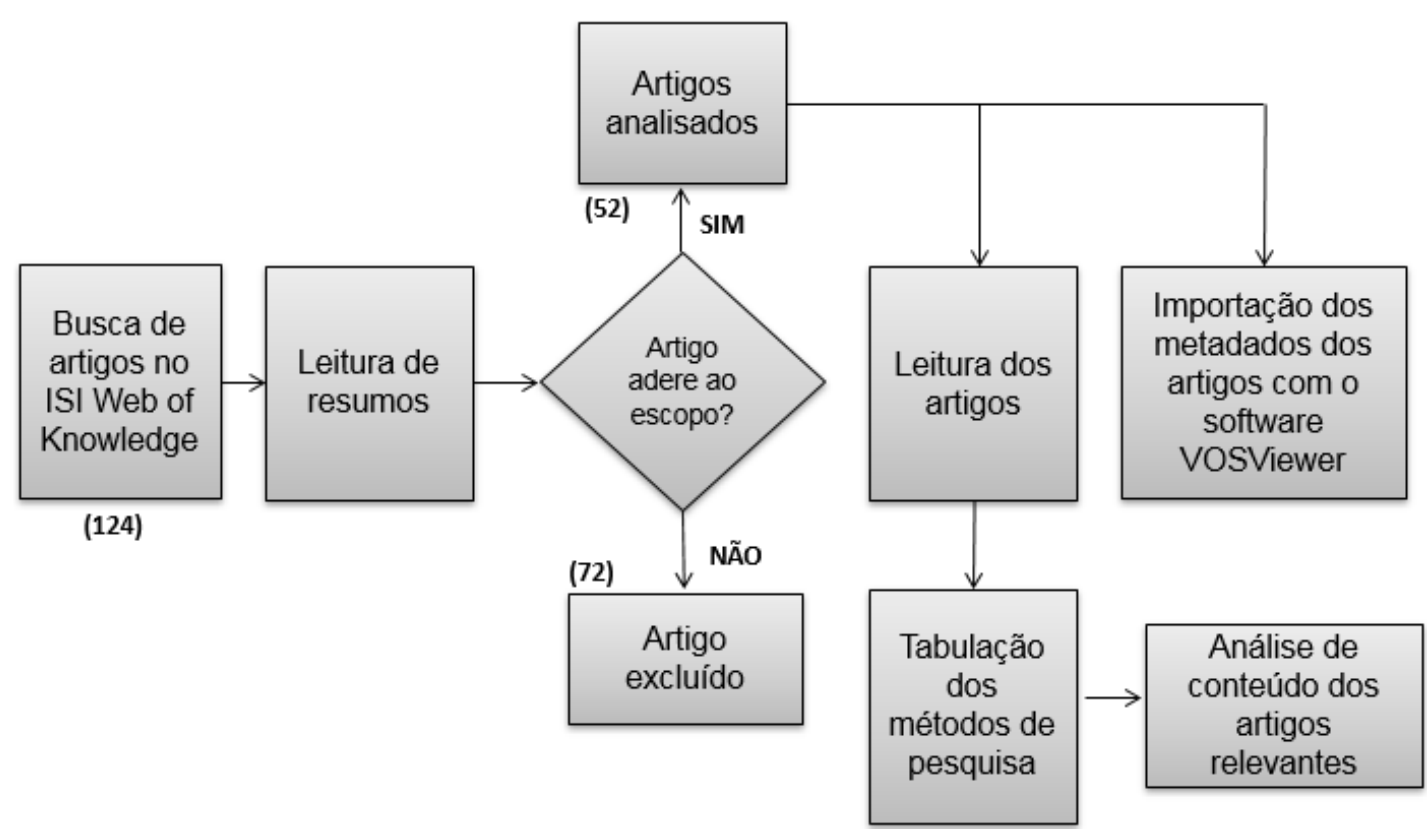

Fonte: A autora 
O primeiro indicador foi o número de publicações por periódico e por ano. Com essa análise, foi possível identificar as revistas que normalmente tratam sobre o tema e assim examinar a forma como as publicações evoluíram ao longo do tempo.

A lista de artigos mais frequentemente citados foi criada uma vez que estes são os artigos que possivelmente vieram a influenciar um grande número de autores. Estes foram analisados juntamente com suas referências para desenvolver duas redes de citações: palavras chaves e autores de referência. Essas análises foram conduzidas através do software VOSviewer, que consiste em um programa gratuito baseado em algoritmos, usado para construir e visualizar mapas bibliométricos (GAVIRIA-MARIN; MERIGÓ; BAIER-FUENTES, 2019; VAN ECK; WALTMAN, 2010).

Para análise dos dados foi utilizado também um índice de impacto desenvolvido por Carvalho, Fleury e Lopes (2013), sendo o índice de impacto (AIF) calculado com base no número de vezes que o artigo foi citado (ATC) e o fator de impacto do periódico, os quais foram obtidos do Jounal Citation Report (JCR $\left.\mathrm{I}_{\mathrm{IF}}\right)$ e Reaserchgate. O índice de impacto do artigo (AIF) foi calculado de acordo com a Equação 1:

$$
\mathrm{A}_{\mathrm{IF}}=\mathrm{A}_{\mathrm{TC}} *\left(\mathrm{JCR}_{\mathrm{IF}}+1\right) \quad \text { Equação } 1
$$

A primeira rede de citações desenvolvida neste estudo foi sobre as palavras chaves mais frequentemente citadas. A segunda rede foi a de citações de artigos de referência. Esta rede foi conectada aos artigos mais citados na amostra inicial com as referências mais citadas destes artigos (CARVALHO; FLEURY; LOPES, 2013).

Para a análise de conteúdo, foram selecionados os artigos com mais de 10 citações, os quais foram considerados outliers da amostra. Estes artigos foram lidos integralmente para a análise e discussão dos resultados da etapa 1 da pesquisa. Os achados desta etapa são abordados no Capítulo 3. 


\subsubsection{Questionários online - Survey}

Na segunda etapa desta pesquisa, foi realizada uma survey com indivíduos ligados a projetos e ao setor da construção civil. Foram utilizadas três estratégias de divulgação dos questionários: A primeira foi a publicação da pesquisa em redes sociais com orientação profissional como o Linkedin e convite para membros associados ao Project Management Institute (PMI). O link para acesso aos questionários da pesquisa foi lançado em grupos de discussão de engenharia civil de várias partes do mundo. No convite à participação da pesquisa, explanou-se que a pesquisa deveria ser respondida por profissionais que atuam com projetos relacionados à construção civil, em qualquer tipo de projeto e em qualquer nível da cadeia produtiva. A segunda estratégia foram envios de convites com o link da pesquisa por e-mail, direcionados à engenheiros, arquitetos e gerentes de projetos por meio de uma lista de contatos. A terceira estratégia consistiu na participação em eventos presenciais concernentes à área da engenharia civil e ao final destes o questionário era entregue em papel para colegas que aceitavam participar da pesquisa. Essa estratégia foi a menos efetiva, pois três questionários tiveram que ser descartados por haver respostas inconsistentes (devido a falta do bloqueio automático de questões com base em nas respostas dadas em perguntas anteriores).

O roteiro do questionário foi adaptado dos trabalhos desenvolvidos pelo Instituto FSB (2011) com base no trabalho de Souza (2011) e questões adaptadas da 14 Pesquisa Nacional sobre Responsabilidade Social e Práticas Sustentáveis nas empresas, realizada em 2013 pelo Instituto ADVB. O questionário da presente pesquisa foi focado no tema Responsabilidade Social, porém enfatizou-se o âmbito de projetos, não o nível empresarial, como as pesquisas predecessoras.

Além de estar disponível em português, o questionário foi traduzido para outros dois idiomas, inglês e espanhol, para aumentar seu alcance. O questionário final contou com 27 perguntas, sendo 19 efetivamente sobre as interações das ações de responsabilidade social em projetos de construção civil e 8 questões de caracterização do perfil da empresa e do respondente. As perguntas foram de múltipla escolha, exceto onde é solicitado que o respondente "descreva as ações de 
responsabilidade social realizadas nos PROJETOS desenvolvidos por sua empresa". Essa questão foi deixada propositalmente aberta, para dar voz e liberdade aos respondentes discorrerem livremente sobre o que fazem em relação ao tema, em nível de projetos. Os links dos questionários ficaram ativos durante o período de 31/10/2017 a 16/10/2018 na plataforma Google Forms.

De acordo com De Vaus (2012), as razões práticas para a utilização de um questionário são: anonimato, acessibilidade, velocidade e eficiência em se tratando de respondentes muito ocupados, ainda há o potencial de alcançar um maior número de entrevistados ao longo de uma grande área geográfica, possibilitando também a participação de pessoas que normalmente se deslocam com muita frequência, que seria difícil conseguir entrevistá-las pessoalmente. Os questionários online têm suas limitações conhecidas em comparação com as entrevistas face a face. Existe dificuldade em garantir que as pesquisas sejam respondidas apenas pela amostra alvo e que as perguntas sejam corretamente compreendidas (DE VAUS, 2012; SILLS; SONG, 2002). Outra potencial desvantagem é o viés associado a autosseleção dos respondentes que podem ter pontos de vistas extremos e querem que suas opiniões sejam ouvidas.

Nos APÊNDICES A; B e C são mostrados os questionários "Responsabilidade Social em Projetos de Construção Civil" em português, espanhol e inglês, respectivamente. No APÊNDICE D, encontra-se o link para download da planilha com os dados originais da pesquisa.

\subsubsection{Importação e análise dos dados da Survey}

A terceira etapa do trabalho se constituiu da importação, organização e tratamento dos dados obtidos através dos questionários (survey). Pelo fato de ter sido criado questionários em três diferentes idiomas, os dados estavam separados, cada um em seu respectivo link, além disso, houve questionários em papel que precisaram ser validados e transcritos manualmente para uma planilha de dados unificados. Este arquivo que foi usado como base para tratamento dos dados. 
Logo após esse procedimento os elementos foram explorados via análise estatística descritiva para facilitar a exibição e compreensão das informações, ou seja, foram confeccionados diversos gráficos e tabelas para apoiar a discussão dos resultados da survey, os quais são mostrados em detalhes no capítulo 3 . Adicionalmente, utilizou-se correlações de Pearson para se encontrar os padrões dentro das respostas múltiplas, em outras palavras, para as questões nas quais mais de uma resposta poderia ser marcada. Na aba III do APÊNDICE D, onde é mostrada a planilha com os dados originais, confeccionou-se uma matriz de correlações, atribuindo-se o valor 1 para um atributo selecionado pelo respondente, e 0 quando 0 item não era selecionado. A Figura 3 sintetiza o processo de importação e tratamento dos dados da survey.

A correlação de Pearson relaciona dois atributos (ou variáveis) para responder o quanto elas estão relacionadas. O número da correlação está entre - 1 e 1, onde 1 é a correlação direta mais forte e -1 a correlação inversa mais forte. Uma correlação de 0 significa que os atributos não se relacionam (WALK, MICHAEL; RUPP, 2010). De acordo com Mukaka (2012) a correlação de Pearson é calcula pela Equação 2, onde $\mathrm{x}_{1}, \mathrm{x}_{2}, \ldots \mathrm{x}_{\mathrm{n}}$ e $\mathrm{y}_{1}, \mathrm{y}_{2} \ldots, \mathrm{y}_{\mathrm{n}}$ são os valores medidos de ambas as variáveis, e $\bar{x} \quad$ e $\bar{y}$ são as médias aritméticas de ambas as variáveis (neste caso, atributo existente ou não existente, ou seja, numericamente, 1 ou 0 ).

$$
r=\frac{\sum_{i=1}^{n}\left(x_{i}-x\right)\left(y_{i}-y\right)}{\sqrt{\left[\sum_{i=1}^{n}\left(x_{i}-\bar{x}\right)^{2}\right]\left[\sum_{i=1}^{n}\left(y_{i}-\bar{y}\right)^{2}\right]}}
$$

Neste trabalho, ao se dizer que há uma correlação de 0,62 entre duas variáveis, por exemplo, as empresas que entendem por Responsabilidade Social as opções "Práticas Justas de Operação" e "Questões de Consumidores", pode-se dizer que com uma força de 0,62 (onde o mais forte seria 1), essas duas questões se relacionam, isto é, quando uma ocorre a outra também ocorre.

A análise completa dos coeficientes de Pearson, com relação a todos os dados da pesquisa se encontra a aba VI do APÊNDICE D. 
Figura 3 - Síntese do processo de importação e tratamento dos dados da Survey

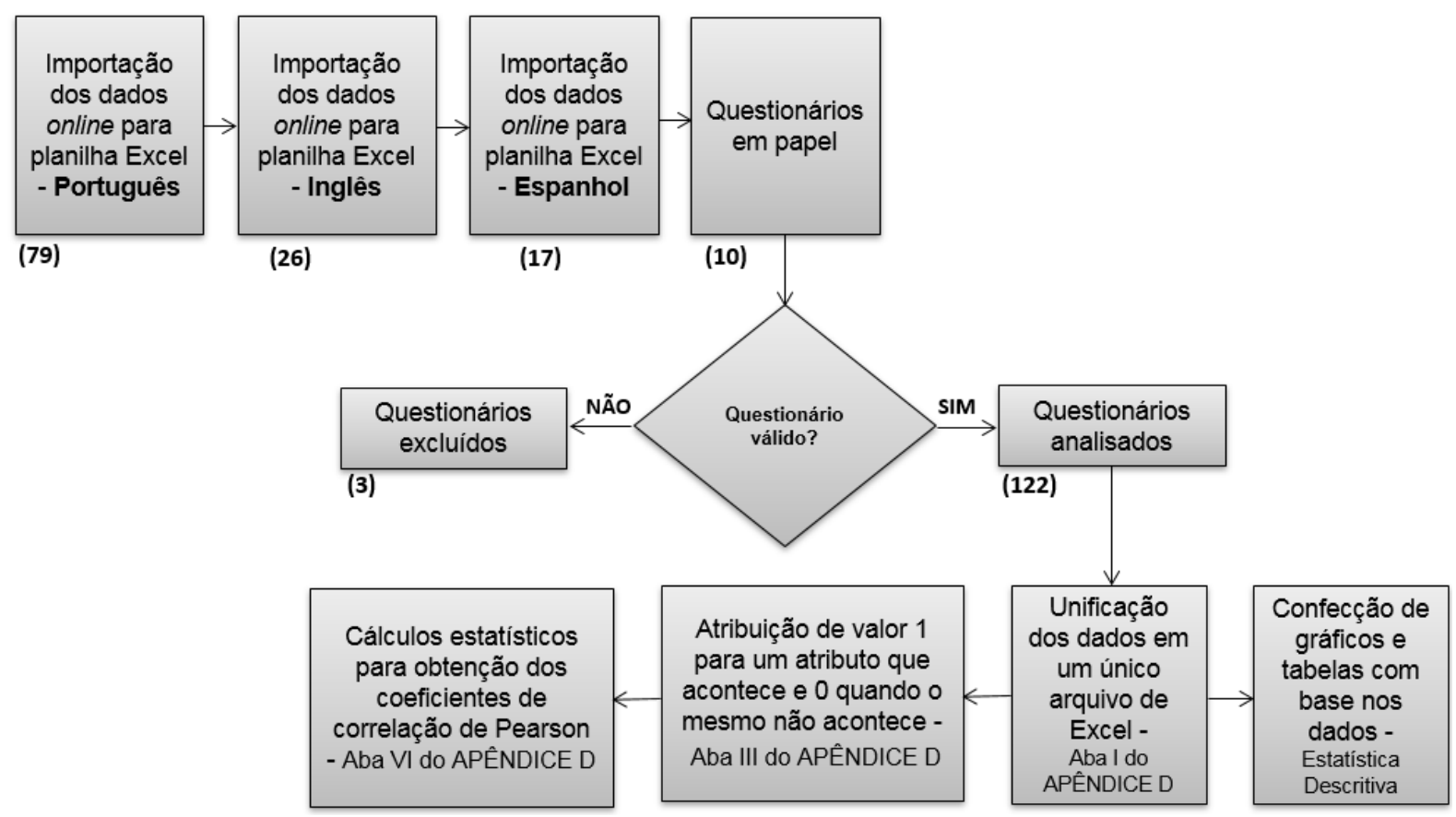

Fonte: A autora

\section{REVISÃO BIBLIOGRÁFICA}

\subsection{Responsabilidade Social - Definições}

Entre os autores que tratam do tema responsabilidade social, destaca-se o trabalho de Bewen (1953). O autor fornece a definição do termo como sendo as obrigações dos gerentes de buscar políticas, tomar decisões e ações que estejam de acordo com os objetivos e valores da sociedade. O termo original Corporate Social Responsibility, muitas vezes é traduzido como Responsabilidade Social Corporativa ou Responsabilidade Social Empresarial, e são tratados como sinônimos por vários autores. Neste trabalho será utilizado simplesmente o termo Responsabilidade Social (RS). Após o trabalho de Bewen (1953), várias outras definições foram produzidas por acadêmicos, governos e Organizações Não Governamentais (ONGs). Uma definição amplamente conhecida é a do Conselho Empresarial Mundial para o Desenvolvimento 
Sustentável (World Business Council for Sustainable Development) que define Responsabilidade Social como "o compromisso contínuo dos negócios de se comportar de forma ética e contribuir para a economia e desenvolvimento, melhorando a qualidade de vida da força de trabalho e suas famílias, bem como da comunidade local e da sociedade em geral" (HOLME, L \& WATTS, 1999). Pela norma brasileira NBR 16001: 2012 (ABNT, 2019), o termo é definido como a responsabilidade da organização com a sociedade e o meio ambiente, visando o desenvolvimento sustentável.

Ashley et al. (2002), por sua vez, conceituam responsabilidade social como:

"O compromisso que uma organização deve ter para com a sociedade, expresso por meio de atos e atitudes que a afetem positivamente de modo amplo e a alguma comunidade de modo específico, atingindo proativamente e coerentemente no que tange a seu papel específico na sociedade e a sua prestação de contas com ela".

Ghobadian, Money e Hillenbrand (2015) mostram a evolução do conceito de Responsabilidade Social, uma vez que foram incorporados numerosos conceitos relacionados entre si, tais como: responsabilidade corporativa (WADDOCK, 2004), sustentabilidade (ZADEK, 2004), cidadania corporativa (MATTEN; CRANE, 2005), cidadania empresarial global $(X U, 2008)$ e mais recentemente empreendedorismo social e nova governança pública (AREND, 2013; BARRAKET et al., 2016). No entanto, de acordo com os autores Visser (2005), (LOOSEMORE; LIM, 2017), o modelo mais conhecido e influente sobre Responsabilidade Social continua sendo a "pirâmide da responsabilidade social corporativa" de quatro níveis de Carroll (1991), a qual assevera que as empresas têm responsabilidades econômicas, legais, éticas e discricionárias para com a sociedade. As responsabilidades econômicas incluem a produção de bens e serviços de valor para a sociedade; as responsabilidades legais dizem respeito ao cumprimento das leis e regulamentos; as responsabilidades éticas representam a aderência aos princípios de justiça e equidade e finalmente as responsabilidades discricionárias dizem respeito ao voluntariado e esforços filantrópicos de uma empresa, que vão além do mínimo esperado pela sociedade. Em 
um trabalho mais recente de Carroll (2016), o autor aponta as tensões e as escolhas que devem ser feitas inevitavelmente à medida que as empresas procuram cumprir com todas essas responsabilidades. Assim, o modo como determinada empresa desenvolve estas ações, define sua orientação e reputação no tocante ao tema. Muito embora pesquisas sugiram que, na realidade, geralmente, há uma baixa conscientização sobre as iniciativas individuais de Responsabilidade Social de determinada companhia em sua comunidade, pois, normalmente, as pessoas tendem a fazer generalizações abrangentes sobre o tema com base em eventos notáveis que aparecem na mídia (DOLNICAR; POMERING, 2007). No setor da construção, Loosemore e Phua (2011) chegaram a uma conclusão semelhante baseada em estudos de caso de algumas das mais bem-conceituadas empresas de consultoria e construção do mundo. Nessa pesquisa, constatou-se que a maioria dos clientes se importa pouco com as estratégias detalhadas de responsabilidade social das empresas na cadeia de suprimentos da construção, ou seja, veem pouca ou nenhuma ligação com os resultados do projeto de construção. Os usuários dos edifícios estão ainda menos preocupados, geralmente, não têm ideia de qual empresa projetou ou construiu os edifícios que eles ocupam ou se tal companhia tem ações de responsabilidade social.

Ainda no trabalho de Loosemore e Phua (2011) os autores expuseram diversas barreiras às ações de Responsabilidade Social no setor da construção civil: culturas bem estabelecidas em relação à forma de se trabalhar; falta de entendimento do que significa o termo; ceticismo sobre o retorno do investimento em tais ações; resistência da cadeia de fornecedores e clientes desinteressados.

\subsection{Responsabilidade Social em Projetos de Construção Civil}

Projetos são organizações temporárias para atingir objetivos e metas únicos em um determinado período (PACKENDORFF, 1995; PMI, 2018). No domínio da arquitetura e engenharia civil, os projetos de construção são processos que consistem na concepção, edificação e/ou montagem de diferentes estruturas. A construção em larga escala é composta de muitas atividades. Normalmente, o trabalho é orientado 
por um gerente de projetos, supervisionado por um gerente de construção, engenheiro ou arquiteto (OTHMAN; IDRUS; NAPIAH, 2011).

O setor da construção civil integra um conjunto de atividades relevantes para o desenvolvimento econômico e social, influenciando diretamente a qualidade de vida da população e da infraestrutura econômica de um país. Ela tem forte relacionamento com outros setores industriais, uma vez que demanda vários insumos em seu processo produtivo, além de absorver uma significativa parcela da mão de obra com menor qualificação (MONTEIRO FILHA; COSTA; ROCHA, 2010).

Na construção civil, cada empreendimento que se inicia é tratado praticamente como um projeto novo, o qual muitas das vezes não há repetição de características entre obras similares. Outra peculiaridade é que o local onde se desenvolve as soluções técnicas do projeto é de modo geral distinto do local onde se realiza a obra, fator que gera muitas incertezas que podem comprometer a qualidade final do projeto. A etapa de construção acontece em contato com o meio externo, expondo os trabalhadores, os materiais, os equipamentos e a própria obra a intempéries que podem causar danos e, por conseguinte, atrasos na obra e desvios de custos. Os projetos de construção civil exigem intervenções constantes de várias pessoas de áreas distintas, originando conflitos, quebras de informação e dificuldades de comunicação (SILVA, 2009). Assim, o que já é complexo em projetos normais, ao se tratar de projetos de construção civil, torna-se ainda mais complicado, uma vez que há demandas contínuas por requisitos diferentes e às vezes contestatórios, incluindo velocidade, custo e controle de qualidade, saúde e segurança, sustentabilidade (SERTYESILISIK, 2017).

A responsabilidade social do projeto requer um sistema colaborativo de cogovernança envolvendo governos, empresas e o público (MA et al., 2017). Projetos de construção são complexos e dinâmicos, envolvendo múltiplas partes interessadas, incluindo governos, contratados, desenvolvedores, consultores, fornecedores, ONGs e instituições públicas (KARLSEN, 2002). Essas partes possuem interesses diferentes e mudam seu nível de poder de acordo com os objetivos do projeto, além de ter diferentes habilidades para levantar reivindicações e adquirir apoios necessários para atingir os objetivos desejados (AALTONEN; KUJALA, 2010). 
Para responder às demandas sociais contemporâneas, a responsabilidade social é uma abordagem quase que autorregulada, uma vez que amplia requisitos contratuais e legais para contribuir voluntariamente para uma sociedade e um ambiente melhores (DAVIS, 1967).

Nos tópicos a seguir serão abordadas as áreas de conhecimentos em projetos, com enfoque em projetos de construção civil que dizem respeito diretamente ao tema responsabilidade social. Serão tratados com mais detalhes as áreas de gestão de stakeholders, gestão de recursos humanos e gestão de riscos.

\subsubsection{Gestão de Stakeholders em Projetos de Construção Civil}

Os stakeholders, ou partes interessadas, são todos aqueles grupos com os quais uma organização tenha voluntariamente aceito benefícios, e para quem a organização tem obrigações decorrentes de equidade, incluindo-se grupos, tais como financiadores, funcionários, clientes, fornecedores e comunidades locais (PHILLIPS, 2004). Freeman (2015) vai um pouco além e inclui em sua lista de stakeholders qualquer grupo ou indivíduo que pode ajudar ou prejudicar a empresa, apontando além dos acima citados, os ambientalistas e o governo. Phillips (2004) destaca que os concorrentes podem certamente afetar uma organização e devem, portanto, ser considerados legítimos interessados, mas a organização e seus gestores não têm obrigação moral de comparecer ao seu bem-estar.

Um projeto de construção compreende uma série de atividades complexas. Diversas partes interessadas têm diferentes níveis, tipos de investimentos e interesses nos projetos em que estão envolvidas. De acordo com Eschenbach e Eschenbach (1996) é necessário engajar as partes interessadas antes do momento em que uma decisão é tomada, sendo essa atitude essencial quando se trata de projetos de construção. De acordo com Cleland e Ireland (2002) e Karlsen (2002), é essencial a gestão de múltiplos stakeholders para que ocorra a manutenção de um equilíbrio aceitável entre os interesses das partes e garantir assim o sucesso da entrega do projeto. Os pesquisadores Olander e Landin (2005) acreditam que uma atitude negativa das partes interessadas em relação a um projeto de construção pode 
atrapalhar seriamente sua implementação. Tais entraves levarão a excessos de tempo e custo e má qualidade devido a conflitos e controvérsias. Seu estudo revela que uma avaliação das demandas e influência das partes interessadas deve ser considerada como um passo necessário e importante no planejamento, implementação e conclusão de qualquer projeto de construção. É importante que o propósito do projeto seja entendido e feedbacks sejam solicitados às partes interessadas, de modo a alcançar o alinhamento entre elas e a equipe do projeto. Muitos problemas podem ser superados se aquelas partes estiverem ativamente engajadas no planejamento inicial e integradas à equipe. É fundamental que uma abordagem sistemática seja utilizada para identificar e gerenciar os interessados no processo de entrega do projeto (GEORGE et al., 2000).

De acordo com Jones (1996) para que realmente a responsabilidade social ocorra na perspectiva dos stakeholders, os gestores, os tomadores de decisão nas empresas, precisam desenvolver valores compatíveis e interesse em se responsabilizar pelos impactos causados. Além dessa dimensão individual, os níveis socioculturais e a racionalidade do setor empresarial e da própria empresa também precisariam avançar no sentido de dialogar com as partes envolvidas (JONES, 1996; TEOD, 2009). Dessa forma, os projetos passariam a ser concebidos e desenvolvidos em conjunto com as comunidades, inclusive partilhando ações, custos e soluções a serem implementadas. Nessa perspectiva, as comunidades e associações locais assumiriam status de parceiro privilegiado entre os stakeholders (TEOD, 2009).

Nos projetos, as partes interessadas precisam discutir as estratégias para cumprir suas responsabilidades sociais. A implementação da responsabilidade social se traduz em políticas, medidas, técnicas e atividades realizadas pelas partes interessadas. Em projetos de construção, tais práticas incluem projetos de construções verdes, iniciativas de relatórios sustentáveis, sistemas de gestão ambiental, participação pública e compras verdes (JAMALI, 2008). Como as partes interessadas têm recursos diferentes, elas devem ser engajadas de maneira diferente. No nível organizacional, é crucial descobrir como responder estrategicamente aos problemas complicados decorrentes do ciclo de vida de um projeto. 


\subsubsection{Gestão de Recursos Humanos em Projetos de Construção Civil}

A gestão de recursos humanos pode ser definida como: funções relacionadas principalmente a treinamento, desenvolvimento de carreira e desenvolvimento organizacional (SLOTTE; TYNJÄLÄ; HYTÖNEN, 2004). É a abordagem estratégica e coerente para gerir os ativos mais valiosos de uma organização - as pessoas que trabalham lá, que individual e coletivamente contribuem para a realização dos objetivos do negócio. Em outras palavras, significa empregar pessoas, desenvolvendo suas capacidades, utilizando, mantendo e compensando seus serviços em sintonia com o trabalho e exigência organizacional (MAVIN et al., 2007).

A gestão de recursos humanos em projetos de construção tem estudado a força de trabalho envolvida em edificações em várias partes do mundo. Revistas, teses, estudos de caso e livros foram produzidos sobre o tema. Muitos trabalhos tiveram como objetivo principal saber o impacto dessa gestão na construção. Ela tem sido amplamente definida como um campo de atividade organizacional e prática profissional, apesar de ter permanecido por algum tempo uma entidade complexa e pouco clara, interpretada de forma variada por profissionais e pesquisadores (MAVIN et al., 2007).

O departamento de Recursos Humanos $(\mathrm{RH})$ possui funções organizacionais que se destinam a promover a capacidade de aprendizagem em todos os níveis da organização, integrar a cultura de aprendizagem à sua estratégia geral de negócios e promover os esforços das organizações para alcançar desempenho de qualidade (SLOTTE; TYNJÄLÄ; HYTÖNEN, 2004). Um forte sistema de gestão de recursos humanos é o bem mais valioso do século XXI em empresas de construção, uma vez que a produtividade de uma empresa está intimamente ligadas às suas estratégias de gestão destes recursos (CHEN; LIAW; LEE, 2003). Com mudanças rápidas na tecnologia, as necessidades dos trabalhadores, o mercado, o ambiente competitivo, fizeram com que planejar os recursos se tornasse uma tarefa importante e desafiadora. O planejamento dos recursos humanos envolve planos para as necessidades futuras dos funcionários, suas habilidades necessárias, contratação de funcionários e desenvolvimento de pessoal. 
A gestão de recursos humanos realmente tem características específicas em uma empresa, que difere drasticamente das características específicas de empresas orientadas a projetos, uma vez que estas possuem a peculiaridade da natureza temporária dos processos e a natureza dinâmica do ambiente de trabalho. Sendo assim, existem desafios específicos para organizações e funcionários no quesito gestão de recursos humanos em empresas projetizadas. Desafios que não foram reconhecidos nem adequadamente conceitualizados nas literaturas de gestão de recursos humanos existentes (OTHMAN; IDRUS; NAPIAH, 2011).

Dentro da literatura típica de gestão de recursos humanos, há uma longa tradição de pesquisa argumentando que, para fazer uma contribuição ótima para o desempenho da empresa, as políticas e práticas de gestão de recursos humanos devem ser integradas à estratégia da firma - a chamada integração estratégica vertical - e uns com os outros - a chamada integração horizontal (WRIGHT; BOSWELL, 2002). A orientação da função de gestão de recursos humanos, seus objetivos e metas, precisa estar alinhada com a estratégia da organização.

É possível verificar que existe uma grande diferença entre a gestão típica de recursos humanos e a gestão baseada em empresas orientadas para projetos. A gestão de recursos humanos muda devido às próprias pessoas e ao ambiente de trabalho. A gerência deve aplicar sua política e estratégia de acordo com as necessidades e exigências de seus funcionários para garantir que eles possam responder positivamente e contribuir com a empresa (HUEMANN; KEEGAN; TURNER, 2007).

Há pesquisas que avaliaram se o nível de qualificação dos trabalhadores teria efeito significativo para o sucesso do projeto ou vice-versa. Um dos tópicos mais abordados nesse tipo de pesquisa é a formação dos trabalhadores nos projetos de construção civil. $O$ treinamento e o desenvolvimento são definidos como um processo de desenvolvimento de conhecimentos e habilidades relacionados ao trabalho, com o objetivo de melhorar o desempenho dos funcionários e dos projetos de forma sistemática (WRIGHT; MCMAHAN, 1992). Gerentes, executivos e supervisores podem ter um impacto construtivo significativo na transferência de conhecimento e habilidades para seus subordinados (DE JONG; LEENDERS; THIJSSEN, 1999). 
A construção é uma das indústrias que mais utiliza mão de obra em grande escala em comparação com outras indústrias. Ela envolve uma variedade de pessoas, que vão desde clientes, administradores, gerentes, designers, contratados, consultores, supervisores, mestres de obras, trabalhadores qualificados e trabalhadores não qualificados. Todas essas pessoas diferem em termos de educação, experiência e pontos de vista. A construção ainda é uma indústria muito dependente da mão de obra braçal, devido ao seu baixo nível de desenvolvimento tecnológico. Por esse motivo é fundamental que seja dada atenção às questões de gestão de recursos humanos (TABASSI; BAKAR, 2009). De acordo com os estudos feitos em vários projetos de construção em todo o mundo, as questões de gestão de recursos humanos e problemas em relação ao pessoal e mão de obra em construção influenciaram muito o sucesso e desempenho de um projeto (OTHMAN; IDRUS; NAPIAH, 2011).

Fica bastante evidenciada a relação entre a gestão de recursos humanos e a gestão da responsabilidade social, dado que a própria força de trabalho é impactada pela gestão dos projetos, sendo a mão de obra a primeira a sofrer os efeitos de uma má gestão. Adicionalmente, os projetos de construção afetam, pela sua extensão e impacto ambiental, populações situadas no entorno das obras.

\subsubsection{Gestão de Riscos em Projetos de Construção Civil}

A construção civil é bastante distinta das outras indústrias devido às suas particularidades já mencionadas anteriormente, sendo assim, é uma área muito exposta a diferentes riscos (FORTUNATO, 2013). Os projetos de construção são especialmente mais sujeitos a riscos e incertezas, pois os procedimentos para conduzi-lo, desde a avaliação do investimento inicial até a conclusão e uso, são bastante complexos, muitas vezes, ocorrendo, de modo particular, ou seja, sob medida, implicando em demora no desenvolvimento de soluções técnicas do projeto e do processo de produção. A participação de muitas pessoas com diferentes habilidades e interesses, que coordenam um conjunto de atividades desiguais, ainda que inter-relacionadas, traz uma inerente complexidade. Adiciona-se também o fato 
de este segmento ser fortemente afetado por diversos fatores externos incontroláveis (SZYMAŃSKI, 2017).

Segundo Ehsan et al. (2010), os riscos na construção civil são agravados pelos seus ambientes de projetos complexos e dinâmicos, que geram um clima de elevada incerteza. Estes são percebidos como uma combinação de atividades, que afetam negativamente os objetivos do projeto em relação ao prazo, custo, escopo e qualidade. A análise e a gestão dos riscos passaram a ser consideradas como partes importantes do processo de tomada de decisão no setor da construção (KARTAM; KARTAM, 2001).

Em um cenário como o da construção e seus projetos, a gestão de risco se apresenta como uma importante força estratégica, uma vez que ajuda a prevenir acidentes; perdas econômicas, devido à paralisação do projeto; danos à saúde e à integridade física dos colaboradores, bem como se antecipa aos problemas ambientais, ou seja, relaciona-se com todas as questões que poderiam comprometer a imagem da empresa e arruinar o projeto (CAIADO, 2015).

Considerando a imprevisibilidade e complexidade dos projetos, a crise econômico-financeiro a nível mundial - que tem afetado consideravelmente o setor da construção civil - além do rigor cada vez maior por parte dos clientes em relação ao planejamento dos custos e dos prazos, torna-se, portanto, essencial para o setor e seus projetos que adotem atitudes preventivas, através do estudo e da análise de riscos, assim como da criação de metodologias de gestão de risco para as obras (FORTUNATO, 2013).

Na literatura sobre riscos, nota-se que não existe uma única definição. Diversos guias e padrões fornecem seus conceitos de risco. No Quadro 1, são evidenciadas algumas definições relevantes. 
Quadro 1 - Definições de Risco

\begin{tabular}{|c|c|l|}
\hline Ano & Autor & \multicolumn{1}{c|}{ Definição } \\
\hline 2000 & BS6079: 3 & $\begin{array}{l}\text { Incerteza inerente em planos e a possibilidade de algo acontecer } \\
\text { (ou seja, uma contingência) que podem afetar as perspectivas } \\
\text { de alcançar os objetivos de negócio ou projeto. }\end{array}$ \\
\hline 2002 & Guia ISO/IEC 73 & $\begin{array}{l}\text { Combinação da probabilidade de um evento e suas } \\
\text { consequências. }\end{array}$ \\
\hline 2018 & Guia PMBOK & $\begin{array}{l}\text { Um evento ou condição incerta que, se ocorrer, tem um efeito } \\
\text { positivo ou negativo nos objetivos de um projeto. }\end{array}$ \\
\hline 2009 & $\begin{array}{l}\text { BS/ISO 31000 } \\
\text { que é esperado; incerteza é o estado de deficiência de } \\
\text { informações relacionadas com a compreensão ou o } \\
\text { conhecimento de um evento, sua consequência ou } \\
\text { probabilidade; objetivos podem ser aplicados em diferentes } \\
\text { níveis e aspectos. }\end{array}$ \\
\hline $\begin{array}{l}\text { Associação para a } \\
\text { Gestão de Projetos } \\
\text { (APM) }\end{array}$ & $\begin{array}{l}\text { Combinação da probabilidade ou frequência de ocorrência de } \\
\text { uma ameaça ou uma oportunidade definida e a magnitude das } \\
\text { consequências da ocorrência. }\end{array}$ \\
\hline
\end{tabular}

Fonte: Adaptado de Lowe (2013)

$\mathrm{Na}$ construção civil e seus projetos, de acordo com o trabalho de Patel et al. (2013), os riscos podem ser classificados em sete diferentes tipos: Técnicos, Riscos de Construção, Riscos Físicos, Organizacionais, Financeiros, Sócio-políticos e Ambientais. O Quadro 2 detalha os riscos associados de acordo com cada tipologia. 
Quadro 2 - Riscos associados a Indústria da Construção

\begin{tabular}{|c|c|c|c|c|c|c|}
\hline \multicolumn{7}{|c|}{ Tipos de Riscos } \\
\hline $\begin{array}{l}\text { Projeto } \\
\text { incompleto }\end{array}$ & $\begin{array}{l}\text { Produtividade do } \\
\text { trabalho }\end{array}$ & $\begin{array}{l}\text { Danos às } \\
\text { estruturas }\end{array}$ & $\begin{array}{l}\text { Relações } \\
\text { contratuais }\end{array}$ & $\begin{array}{l}\text { Aumento de } \\
\text { custos dos } \\
\text { materiais }\end{array}$ & $\begin{array}{l}\text { Mudanças nas } \\
\text { leis e } \\
\text { regulamentos }\end{array}$ & $\begin{array}{l}\text { Desastres } \\
\text { naturais }\end{array}$ \\
\hline $\begin{array}{l}\text { Especificações } \\
\text { inadequadas }\end{array}$ & $\begin{array}{l}\text { Conflitos } \\
\text { trabalhistas }\end{array}$ & $\begin{array}{c}\text { Danos ao } \\
\text { equipamento }\end{array}$ & $\begin{array}{l}\text { Experiência do } \\
\text { empreiteiro }\end{array}$ & $\begin{array}{c}\text { Baixa } \\
\text { demanda de } \\
\text { mercado }\end{array}$ & $\begin{array}{c}\text { Diferentes regras } \\
\text { de poluição e } \\
\text { segurança }\end{array}$ & $\begin{array}{l}\text { Implicações } \\
\text { Meteorológicas }\end{array}$ \\
\hline $\begin{array}{c}\text { Investigações } \\
\text { inadequadas dos } \\
\text { locais }\end{array}$ & Condições locais & $\begin{array}{l}\text { Lesões de } \\
\text { trabalho }\end{array}$ & $\begin{array}{l}\text { Atitude dos } \\
\text { participantes }\end{array}$ & $\begin{array}{l}\text { Flutuações } \\
\text { das taxas de } \\
\text { câmbio }\end{array}$ & $\begin{array}{l}\text { Suborno / } \\
\text { Corrupção }\end{array}$ & \\
\hline $\begin{array}{l}\text { Mudanças nos } \\
\text { escopos }\end{array}$ & $\begin{array}{l}\text { Falhas nos } \\
\text { equipamentos }\end{array}$ & $\begin{array}{c}\text { Roubo de } \\
\text { Equipamentos e } \\
\text { materiais }\end{array}$ & $\begin{array}{l}\text { Força de trabalho } \\
\text { inexperiente }\end{array}$ & $\begin{array}{c}\text { Estimativa } \\
\text { inadequada } \\
\text { de atrasos de } \\
\text { pagamentos }\end{array}$ & $\begin{array}{c}\text { Barreira } \\
\text { cultural/de } \\
\text { linguagem }\end{array}$ & \\
\hline \multirow[t]{2}{*}{$\begin{array}{l}\text { Disponibilidade } \\
\text { insuficiente de } \\
\text { recursos }\end{array}$} & $\begin{array}{l}\text { Padrões muito } \\
\text { altos de } \\
\text { qualidade }\end{array}$ & & & & $\begin{array}{l}\text { Requerimentos } \\
\text { de autorizações e } \\
\text { aprovações }\end{array}$ & \\
\hline & $\begin{array}{l}\text { Implementação } \\
\text { de novas } \\
\text { tecnologias }\end{array}$ & & & & & \\
\hline
\end{tabular}

Fonte: Patel et al. (2013) 


\subsection{Teoria e estratégia em Responsabilidade Social na Construção Civil}

Tanto academicamente quanto no mercado, responsabilidade social tornou-se um termo amplamente utilizado para descrever uma grande variedade de questões, para uma grande variedade de partes interessadas, em relação ao desejo de repensar as formas tradicionais de fazer negócios. As empresas e os pesquisadores se afastaram de uma orientação explicitamente ética para uma abordagem voltada para o desempenho, que se concentra nos benefícios da responsabilidade social através de mecanismos relacionais, voltados para a reputação e a produtividade; mecanismos comportamentais; mecanismos psicológicos; e mecanismos de grupo e identidade (GHOBADIAN; MONEY; HILLENBRAND, 2015). A indústria da construção parece estar seguindo um caminho similar ao adotar uma abordagem que reconhece a reciprocidade dos interesses entre empresas e sociedade (LOOSEMORE; LIM, 2017).

Ainda que não exista um consenso no desenvolvimento da teoria, houve um grande empenho em categorizar os tipos de atividades de responsabilidade social que as empresas utilizam para construir suas estratégias nessa área. No entanto, todas essas tentativas foram desenvolvidas fora do setor da construção civil. Um exemplo foi a International Organization for Standardization (ISO) que gerou, sem dúvida, a categorização mais amplamente utilizada e reconhecida das atividades de responsabilidade social em sua norma internacional de cunho voluntário, a ISO 26000. A importância desta norma reside no fato de ela ter sido desenvolvida por vários grupos de partes interessadas: empresas privadas, organizações públicas, ONGs e pesquisadores de universidades. Com base nas opiniões desses diferentes grupos, foram criadas sete categorias principais de responsabilidade social, as quais fazem parte das mais recentes definições voltadas para esse tema. No manual sobre implementação da ISO 26000 (ECOLOGIA, 2011) são descritos os tipos de atividades normalmente incluídas nessas categorias. Uma síntese sobre as categorias e as atividades desenvolvidas é mostrada no Quadro 3. 
Quadro 3 - Resumo das categorias da ISO 26000

\begin{tabular}{|c|c|}
\hline Categoria & Atividades envolvidas \\
\hline Governança Organizacional & $\begin{array}{l}\text { Envolve atividades como: responsabilização e } \\
\text { transparência na tomada de decisões; } \\
\text { respeitando as leis; uso responsável de recursos } \\
\text { financeiros, naturais e humanos, considerando } \\
\text { todos os principais interessados na tomada de } \\
\text { decisões, incluindo grupos minoritários; } \\
\text { monitoramento e divulgação de atividades de } \\
\text { negócios, tanto positivas quanto negativas. }\end{array}$ \\
\hline Direitos Humanos & $\begin{array}{l}\text { Estabelecer mecanismos justos para promover } \\
\text { os direitos humanos; políticas de equidade e } \\
\text { diversidade; gerenciamento responsável de } \\
\text { recursos e cadeia de suprimentos, respeitando } \\
\text { os direitos dos indivíduos à liberdade de } \\
\text { associação, opinião e expressão; e também os } \\
\text { direitos econômicos, sociais e culturais. }\end{array}$ \\
\hline Práticas de Trabalho & $\begin{array}{l}\text { Envolve qualquer atividade que: ofereça um } \\
\text { ambiente de trabalho justo, seguro e saudável } \\
\text { para os funcionários envolvendo: bons salários e } \\
\text { condições de trabalho, como pensões, direito a } \\
\text { feriados, licença por doença e seguro social; } \\
\text { apoiar o diálogo entre empregadores e } \\
\text { funcionários; e proporcionar oportunidades para } \\
\text { o desenvolvimento de recursos humanos. }\end{array}$ \\
\hline Meio Ambiente & $\begin{array}{l}\text { Inclui atividades como prevenção da poluição; } \\
\text { redução de emissões; uso de recursos } \\
\text { renováveis sustentáveis; gerenciamento do ciclo } \\
\text { de vida dos materiais, usando tecnologias e } \\
\text { práticas ambientalmente saudáveis; e compras } \\
\text { sustentáveis. }\end{array}$ \\
\hline Práticas Legais de Operação & $\begin{array}{l}\text { Inclui o respeito das diferentes leis, praticando } \\
\text { responsabilidade e justiça nas relações } \\
\text { comerciais; compras sociais; fonte responsável } \\
\text { (fornecedores qualificados). }\end{array}$ \\
\hline Questões relativas ao Consumo & $\begin{array}{l}\text { Fornecer produtos saudáveis e seguros; fornecer } \\
\text { informações precisas e promover o consumo } \\
\text { sustentável; projetar produtos que possam ser } \\
\text { reutilizados, reparados ou reciclados, reduzindo } \\
\text { o desperdício de embalagens; e proteger a } \\
\text { privacidade do consumidor ao tratar com dados } \\
\text { pessoais. }\end{array}$ \\
\hline $\begin{array}{l}\text { Envolvimento e Desenvolvimento da } \\
\text { Comunidade }\end{array}$ & $\begin{array}{l}\text { Envolve atividades como o envolvimento da } \\
\text { comunidade; apoiar instituições locais de } \\
\text { caridade e causas, sendo um bom vizinho e } \\
\text { proporcionando oportunidades para os membros } \\
\text { da comunidade através de compras locais e } \\
\text { emprego. }\end{array}$ \\
\hline
\end{tabular}

Fonte: Adaptado ABNT NBR ISO 26000 (2010) 
Hoje não são tão claras as categorias de ações relacionadas com responsabilidade social no setor da construção civil, uma vez que os quadros de categorização acima foram desenvolvidos para um ambiente de negócios permanente, e o setor da construção civil atua principalmente através de projetos temporários. Os pesquisadores Watts, Dainty e Fernie (2015), em seu trabalho, indicaram diferenças importantes na compreensão sobre responsabilidade social entre participantes de projetos de construção civil e concluíram que o que conta como ação deste tipo em uma localidade para um determinado cliente, pode não contar para outro em uma localização diferente.

\subsection{Referências normativas e Indicadores da responsabilidade social}

Esse item apresenta os principais documentos normativos vigentes e alguns indicadores referentes ao tema responsabilidade social que são mais importantes e utilizados por administradores na análise, implementação, acompanhamento e avaliação das práticas que uma organização deseja adotar, para que estas ações não se transformem em atos filantrópicos isolados ou com objetivos puramente mercadológicos. O termo "organização" é aplicável a instituições, empresas, assim como a projetos, que nada mais são do que organizações temporárias.

Os indicadores de responsabilidade social são ferramentas que gestores podem utilizar para direcionar e avaliar o retorno das suas estratégias, como também para avaliar a eficácia das metas e iniciativas planejadas para as parcerias e transformações do seu entorno. Assim como é necessário acompanhar e avaliar as estratégias e práticas empresariais, para que estes sejam competitivos e lucrativos, também é indispensável conhecer e utilizar indicadores para identificar necessidades e apontar deficiências das iniciativas de responsabilidade social nos projetos de construção civil. 


\subsubsection{SA 8000 - Social Accountability 8000}

O padrão SA 8000 foi concebido pela primeira vez em 1997 pela Social Accountability International (SAI) e tornou-se operacional no ano seguinte. A SAI é uma associação de diferentes tipos de organizações: sindicatos, organizações de defesa dos direitos humanos e dos direitos das crianças, academias, indústrias, etc. O objetivo da SA 8000 é preservar os direitos dos trabalhadores, sendo um padrão baseado em convenções internacionais em relação aos direitos humanos, trabalho infantil, trabalho forçado, saúde e segurança, liberdade de associação, discriminação, práticas disciplinares, jornada de trabalho, remuneração e práticas de gestão (JORGENSEN, 2008).

A SA 8000 foi a primeira norma auditável em nível mundial que certifica organizações com Sistema de Gestão de Responsabilidade Social (SGRS) implementados. Todavia, essa norma é um código de conduta global voluntário, que tem como objetivo implementar, manter e melhorar a qualidade social das práticas no local de trabalho. É considerada um ótimo instrumento de gestão disponível para a implementação e monitorização da Responsabilidade Social (SETHI; ROVENPOR (2016).

Ainda a SA 8000 foi uma resolução importante no mundo corporativo quando se trata da institucionalização da ética empresarial via normas de prestação de contas, sendo de modo geral a norma de responsabilidade social mais representativa, uma vez que oferece um sistema de verificação aceito e respeitado internacionalmente para o desempenho ético e uma descrição abrangente para criar as condições de trabalho decente nas empresas (SETHI; ROVENPOR, 2016).

Assim, a SA 8000 é a primeira norma de responsabilidade social para organizações, com o objetivo de zelar por condições dignas de trabalho ao longo da cadeia de abastecimento em uma base global. Na norma são definidos requisitos mínimos para condições de trabalho que devem ser atendidos pelas empresas e seus fornecedores. Além disto, essa norma é aplicável a uma ampla gama de setores da indústria e a organizações de qualquer tamanho (GÖBBELS; JONKER, 2003). Em sua conformação, se utiliza de procedimentos de gestão da qualidade ISO 9000 e gestão ambiental ISO 14000 como referências (JIANG; BANSAL, 2003). 
Para que uma empresa se torne membro do SA 8000, com o aval do SAI, é necessário preencher um módulo de auto avaliação e passar por alguns procedimentos, como formular seu próprio programa para implementar a política de responsabilidade social. Além disso, deve notificar seus fornecedores e colaboradores sobre seu propósito de implementar as medidas propostas pelo programa SA 8000. Desse modo, deve também incentivar seus fornecedores a adotarem padrões internacionalmente reconhecidos para locais de trabalho e informar que cancelará relações comerciais com empresas fornecedoras que estejam abaixo dos padrões recomendados. A partir do momento em que o programa passa a ser operacionalizado, a empresa solicitará uma pré-avaliação da auditoria. Quando não houver conformidade e ações corretivas forem necessárias, a organização contará com um tempo adequado para ajustar e aprimorar as políticas de recursos humanos, segurança e manutenção dos padrões da SA 8000 . O Certificado do SA 8000 , obtido após todos os procedimentos de auditoria, terá validade por três anos, havendo, durante esse período e a cada seis meses, uma avaliação de aderência aos princípios e às normas editados pelo programa SA 8000 (KARKOTLI, 2004).

É interessante notar que, anualmente, as organizações que são membros do SA8000 divulgam ao público um relatório comunicando seus objetivos em relação às questões propostas pelo programa SA 8000 e as ações que estão realizando para alcançá-las.

\subsubsection{AA 1000 - Institute of Social and Ethical Accountability - ISEA}

A Norma AA 1000 foi lançada em 1999 no Reino Unido pelo ISEA (Institute of Social and Ethical Accountability), hoje AccountAbility; trata-se de uma organização não-governamental sediada em Londres, que tem como missão promover e dar suporte às organizações nas atividades de implementação de sistemas de gestão éticos e socialmente responsáveis. Tem também o objetivo de orientar o aprendizado, desempenho e avanço das organizações, auxiliando-as em relação a como construir sua responsabilidade social e posteriormente a prestação de contas, indicando a 
necessidade da integração das partes interessadas nas atividades diárias da empresa e orientando quanto o estabelecimento de um processo bem estruturado de engajamento das partes interessadas para geração de indicadores (ACCOUNTABILITY, 2018).

Essa norma é um modo de estimular a gestão baseada em princípios de qualidade e ética, garantindo confiabilidade e transparência aos stakeholders através de demonstrações e relatórios divulgados pela organização. Desse modo, a AA 1000 define as melhores práticas para prestação de contas, a fim de assegurar a qualidade da contabilidade, auditoria e relato social ético. Foi pensada para auxiliar empresas, acionistas, auditores, consultores e organizações certificadoras, podendo ser usada isoladamente ou em conjunto com outros padrões de prestação de contas, como a Global Report Initiative (GRI), e normas padrões como as da International Organization for Standardization (ISO) e Social Accountability - SA 8000 (KARKOTLI, 2004).

A Norma AA 1000 apresenta os principais tópicos ligados à responsabilidade social, também pontos de divergência e de convergência com os demais padrões. A estrutura da AA 1000 contém processos e princípios para relatórios, prestação de contas e auditoria. Os padrões de processo do referencial AA 1000 passam pelos seguintes estágios: planejamento, contabilidade, auditoria e relatório, implementação e engajamento das partes interessadas (KARKOTLI, 2004; BECKETT; JONKER, 2002)

Assim, a AA 1000 se configura como uma ferramenta que promove transparência e governança corporativa, garantindo a qualidade das informações apresentadas em relatórios, fornecendo mecanismos de avaliação e verificação de dados, principalmente para as informações não financeiras.

Uma vez que uma organização decide orientar-se pelo AccountAbility AA1000, esta é enriquecida com o gerenciamento de sua responsabilidade social e ética, além de obter vantagens como: avaliação por meio de indicadores chaves do desempenho social; melhoria na gestão da qualidade nos relacionamentos com os stakeholders; fomento do relacionamento com trabalhadores; melhoria nos níveis de confiança das partes interessadas externas; fomento de boas relações de parcerias; conseguem suporte para gestão da organização; obtêm melhoria dos relacionamentos com 
instituições e organizações públicas; são promotoras de treinamento e identificação de fornecedores de serviços qualificados (KARKOTLI, 2004; ACCOUNTABILITY, 2018).

Portanto, as contribuições da AA 1000 são os processos e definições que dão suporte à prática da responsabilidade social empresarial. Estabelecendo passos para a adoção de um processo de melhoria contínua no gerenciamento ético e socialmente responsável de uma organização, tendo como pilar a comunicação e o interrelacionamento entre as partes interessadas (KARKOTLI, 2004; GOMES, 2012).

\subsubsection{Responsabilidade Social - NBR 16001}

A NBR 16001 é uma norma brasileira criada pela Associação Brasileira de Normas Técnicas (ABNT) em conjunto com outras partes. Teve sua primeira versão lançada em dezembro de 2004 e, após, revisada em 2012. Essa norma estabelece requisitos para a implementação de um Sistema de Gestão de Responsabilidade Social (ABNT, 2012). É uma norma certificável, com objetivos e metas de acordo com o tema responsabilidade social. Ela determina requisitos mínimos relativos a um sistema da gestão da responsabilidade social. Permite à organização formular e implementar políticas com objetivos que levem em consideração exigências legais, compromissos éticos, atenção com a promoção da cidadania e do desenvolvimento sustentável, além da transparência das suas atividades (ABNT, 2019).

Por meio de requisitos genéricos, estes podem ser aplicados a qualquer tipo de organização. Sua aplicação dependerá de fatores como: política de responsabilidade social da organização; natureza das atividades desenvolvidas; dos produtos e serviços prestados; da localidade e das condições de operação.

De acordo com Silva Jr. (2008), a norma brasileira NBR 16001 foi baseada em outras normas de especificações e diretrizes de responsabilidade social, de outros países como Austrália, Áustria, França, Inglaterra, Israel e México - em forma de minuta ou em aplicação. Esta é fundamentada em três dimensões da sustentabilidade - econômica, ambiental e social, ou seja, no conceito de Triple Bottom Line (TBL). De acordo com Kerr, Rouse e De Villiers (2015) o TBL estimula as 
pessoas a pensar sobre as três dimensões da vida social, econômica e ambiental. E também segue a metodologia PDCA (plan, do, check, act) com foco na melhoria contínua (PINHEIRO, 2008).

Ainda de acordo com Silva Jr. (2008), os objetivos e metas devem ser compatíveis com a política de responsabilidade social e devem contemplar os seguintes aspectos:

- Boas práticas de governança;

- Combate à pirataria, sonegação e corrupção;

- Práticas leais de concorrência;

- Direitos da criança e do adolescente, incluindo o combate ao trabalho infantil;

- Direitos dos trabalhadores, incluindo o de livre associação, de negociação, a remuneração justa e benefícios básicos, assim como o combate ao trabalho forçado;

- Promoção da diversidade e combate a todo tipo de discriminação (cultural, de gênero, de raça/etnia, idade, deficiências físicas);

- Compromisso com o desenvolvimento profissional;

- Fomento das condições de saúde e segurança;

- Promoção de padrões sustentáveis de desenvolvimento, produção, distribuição e consumo, contemplando fornecedores, prestadores de serviço, entre outros envolvidos nas atividades da organização;

- Proteção ao meio ambiente e dos direitos das gerações futuras;

- Desenvolvimento de ações sociais de interesse público.

Em estudos realizados sobre o tema, foram observados obstáculos relacionados à certificação e à avaliação da conformidade da NBR 16001, uma vez que algumas empresas consideram seus requisitos subjetivos e difíceis de serem quantificados. Todavia, o trabalho de Ferreira e Gerolamo (2016), comprovou que a NBR 16001 é a norma que mais apresenta elementos de sustentabilidade em seu escopo, quando comparadas com as normas ISO 9001, ISO 14001 e OHSAS 18001. Sendo assim, empresas que objetivam introduzir a sustentabilidade no ambiente corporativo devem se concentrar na implementação da NBR 16001. 


\subsubsection{Gestão Ambiental - ISO 14001}

A ISO 14000 é uma série de normas e diretrizes formuladas em 1996 pela ISO, com a finalidade de padronizar os programas de gestão ambiental nas indústrias em todo o mundo. É interessante notar que a certificação ISO 14001 não é necessariamente estabelecida de forma independente de outros sistemas de gestão existentes, uma vez que em alguns casos, é possível cumprir os requisitos da norma ISO 14001, adaptando os elementos do sistema de gestão existentes (GHISELLINI; THURSTON, 2005).

A série ISO 14000 é composta por cinco aspectos: Sistema de Gestão Ambiental (SGA), auditoria ambiental, rotulagem ambiental, avaliação de desempenho ambiental, e avaliação do ciclo de vida. Os padrões são classificados em dois tipos: notas e especificações de orientação. A série da ISO 14000 tem uma abordagem sistemática e fornece uma ferramenta para permitir que as organizações controlem o impacto de suas atividades, produtos e serviços sobre o meio ambiente contribuindo assim para práticas de responsabilidade social (ORECCHINI, 2000).

É importante lembrar que a implantação da gestão ambiental exige a preparação e adoção de um Sistema de Gestão Ambiental (SGA), sendo que este é precedido de normas e procedimentos que auxiliarão a empresa a manter suas atividades e processos organizacionais de acordo com a legislação ambiental. O SGA é a forma pela qual as empresas se motivam interna e externamente na busca pela qualidade ambiental desejada. Pode ainda constituir uma estratégia para que a empresa em processo contínuo identifique oportunidades de melhorias que reduzam os impactos das atividades de sua empresa sobre o meio ambiente, de forma integrada à situação de conquista de mercado e da lucratividade (NADAE, 2016).

\subsubsection{Segurança e Saúde ocupacional - OHSAS 18001}

A OHSAS 18001 foi formulada por entidades certificadoras internacionais com base em normas internacionais com vistas ao tema relacionado à saúde e segurança ocupacional. A norma foi publicada pela primeira vez em 1999, após estudos de um 
grupo de organismos certificadores e de entidades de normalização da Irlanda, Austrália, África do Sul, Espanha e Malásia. Essa norma passou por uma revisão em 2007 e pode ser descrita como um padrão e base para a certificação de sistemas de gestão da segurança e saúde ocupacional.

A certificação OHSAS 18001 foi pensada para ser compatível com a norma ISO 9001 e ISO 14001, de modo a facilitar a integração da qualidade, meio ambiente, bem como sistemas de gestão de segurança e saúde ocupacional, quando as organizações optam por fazê-lo (JORGENSEN, 2008).

A OHSAS 18001 visa criar e manter um ambiente de trabalho seguro, além de proteger e manter a boa saúde dos colaboradores. Ela não estabelece requisitos absolutos para o desempenho da SST, todavia requer que a empresa atenda integralmente à legislação e regulamentos aplicáveis e que esteja comprometida com o aperfeiçoamento contínuo dos processos (ETHOS, 2017).

A OHSAS 18001 não estabelece critérios específicos de desempenho de Saúde e Segurança no Trabalho (SST), nem fornece especificações detalhadas para o projeto de um sistema de gestão, por este motivo, é aplicável para qualquer organização. De acordo com Zeng et al. (2007), pelo fato de não estabelecer padrões rígidos, duas organizações que desenvolvam atividades similares, mas que apresentem níveis diferentes de desempenho da SST podem igualmente atender aos requisitos da norma. Ainda de acordo com os autores, de forma resumida, as empresas devem desenvolver os seguintes critérios, de modo a atender a esta certificação:

- Estabelecer um sistema de gestão de SST de modo a diminuir os riscos para os colaboradores e outras partes interessadas;

- Implementar, manter e melhorar continuamente um sistema de gestão de SST;

- Assegurar a conformidade da organização com sua política de SST definida;

- Demonstrar a conformidade a terceiros;

- Buscar certificação e/ou registro do seu sistema de gestão da SST por uma organização externa;

- Fazer uma autodeterminação e declaração de conformidade com as especificações da norma. 
Organizações atentas às necessidades dos trabalhadores e capazes de antecipar e prever possíveis riscos investem em Sistema de Segurança e Saúde Ocupacional (SSSO) e em certificação com a OHSAS 18001, buscando: minimizar custos, devido ao baixo absenteísmo; diminuir os riscos de acidentes; aumentar a satisfação e saúde dos trabalhadores; obter melhores resultados operacionais; diminuir o número de doenças ocupacionais e melhorar a imagem da empresa perante a sociedade e aos funcionários (NADAE, 2016), atuando assim com práticas de responsabilidade social.

\subsubsection{Responsabilidade Social - Diretrizes - ISO 26000}

O Conselho da ISO depois anos de discussões, aprovou a elaboração da Norma Internacional de Responsabilidade Social, após a Conferência Internacional, em Estocolmo - Suécia, em junho de 2004, formando um grupo de Trabalho de Responsabilidade Social, responsável pela elaboração dessa norma. Foi o primeiro grupo da ISO a ser coordenado em conjunto por uma entidade normatizadora de um país industrializado, a Suécia, através do Swedish Standards Institute (SIS) em conjunto com uma associação de um país em desenvolvimento, o Brasil, através da Associação Brasileira de Normas Técnicas (ABNT). Assim, a partir de 15 de setembro de 2004, Brasil e Suécia passaram a presidir e secretariar de maneira compartilhada, O Grupo de Trabalho sobre Responsabilidade Social da ISO (conhecido como Strategic Advisory Group - SAG). Inaugurou-se, com isso, o processo de elaboração da chamada "terceira geração de normas de sistemas de gestão", após as séries da qualidade (ISO 9000) e do meio ambiente (ISO 14000). A ISO 26000 foi finalmente lançada em $1^{\circ}$ de novembro de 2010, na Suíça. No Brasil, no dia 8 de dezembro de 2010, a versão em português da norma, a ABNT NBR ISO 26000, foi lançada em evento na Fiesp, em São Paulo (ABNT, 2019). Após anos de discussões, é a norma mais controversa da série, sendo exclusiva para dar diretrizes, ou seja, não tem propósito de certificação (UTTING; REED; MUKHERJEE-REED, 2012).

A norma ISO 26000 fornece instruções para todos os tipos de organizações, independentemente do porte ou localização, a respeito de conceitos, termos e 
definições referentes à responsabilidade social; histórico, tendências e características da responsabilidade social; princípios e práticas relativas à responsabilidade social; os temas centrais e as questões referentes à responsabilidade social; integração, implementação e promoção de comportamento socialmente responsável em toda a organização e por meio de suas políticas e práticas dentro de sua esfera de influência; identificação e engajamento de partes interessadas; comunicação de compromissos, desempenho e outras informações referentes a responsabilidade social (ABNT, 2019).

Autores como Hahn (2013) tem questionado a abrangência e o generalismo da norma. De acordo com o pesquisador, diferentes situações requerem diferentes tipos de orientações. Ele considera que para empresas que não têm os recursos, a experiência ou a vontade de se envolver com ações de responsabilidade social podem não ver os benefícios na ISO 26000. Em sua análise sobre como a ISO 26000 é útil para os processos de gerenciamento estratégico de uma empresa, o autor avalia que a norma é mais adequada para análises internas e externas de questões de sustentabilidade emergentes, e tem o problema de não informar aos gerentes como integrar a Responsabilidade Social na visão e missão da empresa, nem fornece informações claras sobre como estabelecer objetivos para diferentes problemas e também não oferece uma orientação robusta sobre como gerar estratégias sobre o tema.

\subsection{Estratégias para mensuração do Desempenho Social}

Medir o desempenho em sustentabilidade e gestão, significa mensurar a gestão da interação entre as empresas, a sociedade e o meio ambiente. Os problemas e perspectivas da avaliação de desempenho em sustentabilidade e gestão podem ser analisados em três níveis: o nível de indicadores de desempenho de sustentabilidade individuais, o nível de todo o sistema de medição de desempenho e o nível da relação desse sistema global com o ambiente externo (KEEBLE; TOPIOL; BERKELEY, 2003).

A melhoria do desempenho ambiental pode, por vezes, afetar negativamente 0 
desempenho social ou econômico, ou vice-versa, mostrando que a progressão nas três dimensões pode não ocorrer no mesmo ritmo, direção ou tempo.

Dada a complexidade da avaliação do desempenho organizacional na perspectiva do TBL, muitas empresas adotam os indicadores consolidados e internacionalmente conhecidos como o Global Reporting Initiative (GRI) e o Global Compact. No Brasil, algumas empresas adotam os Indicadores Ethos de Responsabilidade Social como forma de analisar seu desempenho relacionado à sustentabilidade e apresentar um relatório sobre o desempenho da empresa para os stakeholders. Esses indicadores serão abordados nos tópicos a seguir.

\subsubsection{Global Reporting Initiative (GRI)}

A Global Reporting Initiative, GRI, é uma organização não-governamental composta por uma rede multistakehoulders, líder no campo da sustentabilidade, promove elaboração de relatórios que pode ser adotada por qualquer tipo de organização. Ela possui representantes regionais, conhecidos como Pontos Focais (Focal Points) nos países: Austrália, Brasil, China, Índia e Estados Unidos, contanto com uma rede mundial de cerca de 30.000 pessoas (GRI, 2018).

A GRI promove o uso de relatórios de sustentabilidade como uma maneira de as organizações se tornarem mais sustentáveis e contribuírem para o desenvolvimento sustentável (GRI, 2018). Sua missão é fazer com que os relatórios de sustentabilidade, se tornem uma prática padrão para todas as organizações, de modo a embasar decisões que criem benefícios sociais, ambientais e econômicos para todos (GRI, 2018).

De acordo com Brower e Mahajan (2013) os relatórios de sustentabilidade preparados de acordo com as diretrizes da GRI, uma vez que seguem um padrão pré-estabelecido, tornam-se então uma ferramenta poderosa para fins de comparação, benchmarking e classificação, atuando como um artifício para uma empresa se mostrar aos seus stakeholders como sendo uma empresa socialmente responsável e transparente. 
O GRI é considerado um dos instrumentos de comunicação sobre as práticas sustentáveis mais completos e difundidos mundialmente. Este visa o desenvolvimento econômico sustentável (LOZANO; HUISINGH, 2011). O GRI concede diretrizes sobre quais informações devem ser fornecidas para os stakeholders e como elas devem ser fornecidas além de proporcionar diretrizes específicas nos âmbitos econômico, ambiental e social da Responsabilidade Social. Através da análise desses relatórios, é possível articular e compreender as contribuições das empresas para o desenvolvimento sustentável (GIANNARAKIS; LITINAS; SARIANNIDIS, 2011).

Os Relatórios de Sustentabilidade da GRI consistem em um conjunto de materiais de orientação para o relato, ou seja, a estrutura compreende as Diretrizes, os Conteúdos Setoriais, os Limites do Relatório e os Protocolos Técnicos. Esse modelo pode ser aplicado por organizações de qualquer tamanho, tipo, setor e região. A estrutura é usada por milhares de organizações no mundo inteiro como referência na elaboração de seus relatórios de sustentabilidade (GRI, 2018).

$\mathrm{Na}$ categoria Social, encontram-se os indicadores sociais, que são divididos em quatro subcategorias: práticas trabalhistas e trabalho decente; direitos humanos; sociedade; e responsabilidade pelo produto. A categoria Ambiental abrange impactos relacionados a insumos (por exemplo: energia e água) e saídas (por exemplo: emissões, efluentes e resíduos); impactos relacionados à biodiversidade, aos transportes e a produtos e serviços, bem como a conformidade com leis e regulamentos ambientais e gastos e investimentos na área ambiental (GRI, 2018).

\subsubsection{Global Compact}

O Pacto Global (Global Compact) foi uma iniciativa criada pelo ex-secretáriogeral da ONU, Kofi Annan, em janeiro de 1999, com o intuito de mobilizar a comunidade empresarial internacional para a adoção, em suas práticas de negócios, de valores fundamentais e internacionalmente aceitos nas áreas de direitos humanos, relações de trabalho, meio ambiente e combate à corrupção refletidos em 10 princípios. A iniciativa tem a participação de agências das Nações Unidas, empresas, 
sindicatos, organizações não-governamentais e outros parceiros necessários para a construção de um mercado global mais igualitário (GLOBAL COMPACT, 2018).

As empresas participantes do Pacto Global são diversificadas e representam diferentes setores da economia, regiões geográficas e buscam gerenciar seu crescimento de uma maneira responsável, que contemple os interesses e preocupações de suas partes interessadas - incluindo funcionários, investidores, consumidores, organizações militantes, associações empresariais e comunidade. Em 2017 havia 9727 organizações signatárias articuladas em 162 países que, juntos, disponibilizam 49.861 relatórios públicos (GLOBAL COMPACT, 2018).

O Pacto Global não se trata de um instrumento regulatório, nem um código de conduta obrigatório ou um fórum para fiscalizar as políticas e práticas gerenciais. É simplesmente uma iniciativa voluntária que tenta fornecer diretrizes para a promoção do crescimento sustentável e da cidadania, por meio de lideranças corporativas comprometidas e inovadoras. O Pacto Global dá complementaridade às práticas de responsabilidade social empresarial sendo um compromisso mundial. Essa foi uma iniciativa importante e base para a criação da ISO 26000 (GLOBAL COMPACT, 2018).

O Pacto Global defende dez princípios universais, provenientes da Declaração Universal de Direitos Humanos, da Declaração da Organização Internacional do Trabalho sobre Princípios e Direitos Fundamentais no Trabalho, da Declaração do Rio +20 sobre Meio Ambiente e Desenvolvimento e da Convenção das Nações Unidas Contra a Corrupção. A Conferência das Nações Unidas sobre Desenvolvimento Sustentável, realizada no Rio de Janeiro, entre os dias 20 a 22 de junho de 2012, onde líderes de todos os países se reuniram para discutir um caminho mais sustentável para o mundo, ficou conhecida como Rio+20.

Finalmente, o objetivo do Pacto Global é encorajar o alinhamento das políticas e práticas empresariais com os valores e os objetivos aplicáveis internacionalmente e universalmente acordados. Os dez princípios universais são divididos em quatro áreas: direitos humanos, direitos do trabalho, proteção ao meio ambiente e combate à corrupção. Abaixo os dez princípios são explicitados, de acordo com as informações disponibilizadas na página web do Pacto Global (www.unglobalcompact.org): 


\section{- Direitos Humanos}

1. As empresas devem apoiar e respeitar a proteção de direitos humanos reconhecidos internacionalmente; e

2. Assegurar-se de sua não participação em violações destes direitos.

- Trabalho

3. As empresas devem apoiar a liberdade de associação e o reconhecimento efetivo do direito à negociação coletiva;

4. A eliminação de todas as formas de trabalho forçado ou compulsório;

5. A abolição efetiva do trabalho infantil; e

6. Eliminar a discriminação no emprego.

- Meio Ambiente

7. As empresas devem apoiar uma abordagem preventiva aos desafios ambientais;

8. Desenvolver iniciativas para promover maior responsabilidade ambiental; e

9. Incentivar o desenvolvimento e difusão de tecnologias ambientalmente amigáveis.

\section{- Contra a Corrupção}

10. As empresas devem combater a corrupção em todas as suas formas, inclusive extorsão e propina.

Para aderir ao Pacto Global, a organização deve:

- Preencher uma carta modelo de acordo com seu perfil da empresa;

- Repassar a carta preenchida ao principal executivo da organização, que deverá assiná-la.

- Preencher um formulário de adesão de acordo com o perfil do interessado (com ou sem atividade empresarial) e anexar a carta de adesão ao Pacto Global.

Assim que realizados os trâmites de adesão, a empresa pode emitir uma clara declaração de apoio ao Pacto Global e seus dez princípios, e assim publicamente advogar o Pacto Global. Isso significa que a companhia estará informando aos seus funcionários, acionistas, consumidores e fornecedores da sua adesão ao Pacto Global; em seguida a empresa deve incorporar os princípios do Pacto Global na declaração de sua missão; deverá também incluir o compromisso com o Pacto Global no Relatório Anual e em outros documentos publicados pela empresa; e emitir 
comunicados para a imprensa (press-releases) para tornar o compromisso público (GLOBAL COMPACT, 2018).

\subsubsection{Indicadores Ethos de Responsabilidade Social}

O Instituto Ethos de Empresas e Responsabilidade Social é uma Oscip (Organização da Sociedade Civil de Interesse Público), fundada em 1998 por um grupo de empresários e executivos da iniciativa privada. Sua missão é "mobilizar, sensibilizar e ajudar as empresas a gerir seus negócios de forma socialmente responsável, tornando-as parceiras na construção de uma sociedade justa e sustentável" (ETHOS, 2018).

O Instituto Ethos é um polo de organização de conhecimento, troca de experiências e desenvolvimento de ferramentas para auxiliar as empresas a analisar suas práticas de gestão e aprofundar seu compromisso com a responsabilidade social e o desenvolvimento sustentável. Ele tem como associados centenas de empresas em operação no Brasil, de diferentes portes e setores de atividade (ETHOS, 2018).

A geração dos Indicadores Ethos é continuamente aprimorada, apresentando novas abordagens para a gestão das empresas que querem integrar os princípios e comportamentos da responsabilidade social com os objetivos de sustentabilidade, baseando-se num conceito de negócios sustentáveis e responsáveis. Hoje, os indicadores Ethos têm maior integração com as diretrizes de relatórios de sustentabilidade da Global Reporting Initiative (GRI), com a Norma de Responsabilidade Social ABNT NBR ISO 26000, CDP (Carbon Disclosure Program) e outras iniciativas. Os Indicadores Ethos para Negócios Sustentáveis e Responsáveis têm como cerne avaliar quanto a sustentabilidade e a responsabilidade social têm sido incorporadas aos negócios, ajudando a definir estratégias, políticas e processos. Ainda que tenha medidas de desempenho em sustentabilidade e responsabilidade social, essa ferramenta não se propõe a medir o desempenho das empresas nem reconhecer empresas como sustentáveis ou responsáveis (ETHOS, 2018). 
A estrutura do questionário que gera os indicadores Ethos é feita através do agrupamento de 4 dimensões que seguem o conceito ESG (Environmental, Social and Governance) e são complementados pela dimensão Visão e Estratégia. Estas são desdobradas em temas inspirados na Norma ISO 26000, os quais, por sua vez, estendem-se em subtemas e, finalmente, nos indicadores (ETHOS, 2018).

Atualmente os indicadores são gerados através de um sistema online. Todavia o conteúdo dos Indicadores Ethos preserva a estrutura que os consolidou no passado como ferramenta de aprendizado, ou seja, há questões de profundidade, questões binárias e questões quantitativas. Cada indicador é composto por esses três tipos de questões, sendo as de profundidade e as binárias obrigatórias para a elaboração do relatório de diagnóstico. As questões quantitativas são opcionais e recomenda-se que sejam preenchidas na etapa de planejamento (ETHOS, 2018). 


\section{RESULTADOS E DISCUSSSÃO}

\subsection{Revisão Sistemática da Literatura}

\subsubsection{Evolução das Pesquisas}

Os resultados desta seção consideram a evolução do número de publicações com o passar dos anos. Nota-se que há uma tendência de evolução no número de publicações. O primeiro artigo encontrado que relaciona responsabilidade social com projetos de construção civil foi publicado em 2001, porém o número de pesquisas nessa área começou a crescer a partir de 2008 (Tabela 1). Os 53 artigos estão distribuídos em 26 periódicos, sendo que a maioria dos artigos selecionados na amostra inicial foram publicados no Journal of Cleaner Production, representando aproximadamente $28,3 \%$ dos artigos (15 de 53 ).

Tabela 1- Número de publicações por periódico e por ano

\begin{tabular}{|c|c|c|c|c|c|c|c|c|c|c|c|c|c|c|c|c|c|c|}
\hline \multirow{3}{*}{ Journal } & \multirow{3}{*}{ JCR } & \multirow{2}{*}{\multicolumn{17}{|c|}{ Ano }} \\
\hline & & & & & & & & & & & & & & & & & & \\
\hline & & চ্ণু & 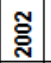 & ֻั & ్ㅗ․ & 오ํ & ๕్ & స్. & 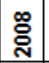 & ఃे & 울 & స్ & ัㅜㄹ & 를 & $\stackrel{\sim}{\vec{N}}$ & సొ & $\stackrel{\circ}{\stackrel{2}{2}}$ & 퐁 \\
\hline Renewable and Sustainable Energy Reviews & 6,798 & & & & & & & & & & & & 1 & 1 & 1 & & & 3 \\
\hline Journal of Cleaner Production & 4,959 & & & & & & & & & & 1 & & 2 & 2 & & 3 & 7 & 15 \\
\hline Building and Environment & 3,394 & & & & & & & & & & & & & & 1 & & & 1 \\
\hline Resources, Conservation and Recycling & 3,28 & & & & & & & & & & & & & & & 1 & & 1 \\
\hline Ecological Indicators & 3,190 & & & & & & & & & & & & & & & & 1 & 1 \\
\hline Journal of Environmental Management & 3,131 & & & & & & & & & & 1 & 1 & & & & & & 2 \\
\hline International Journal of Project Management & 2,885 & & & & & & & & & & & & & & & 2 & 2 & 4 \\
\hline European Journal of Operational Research & 2,679 & & & & & & & & & & & & & & 1 & & & 1 \\
\hline Journal of Purchasing and Supply Management & 2,562 & & & & & & & & & & & & & & & 1 & & 1 \\
\hline Resources Policy & 2,489 & & & & & & & & & & & & & & & 1 & & 1 \\
\hline Journal of Civil Engineering and Management & 2,290 & & & & & & & & & 1 & & & & & & & & 1 \\
\hline Habitat International & 2,029 & & & & & & & & & & & 1 & & 1 & 1 & 1 & 1 & 5 \\
\hline Journal of International Management & 1,982 & & & & & & & & 1 & & & & & & & & & 1 \\
\hline Journal of Safety Research & 1,504 & & & & 1 & & & & & & & & & & & & & 1 \\
\hline European Management Journal & 1,437 & & & & & & 1 & & & & & & & & & & & 1 \\
\hline Building Research and Information & 1,433 & & & & & & & & 1 & & & & & & & & & 1 \\
\hline Construction Management and Economics & 1,210 & & & & & & & & & & & & & & 1 & & & 1 \\
\hline Procedia Computer Science & 1,080 & & & & & & & & & & & & & & & & 1 & 1 \\
\hline Sustainable Cities and Society & 1,044 & & & & & & & & & & & & 1 & & & & & 1 \\
\hline Procedia Engineering & 0,730 & & & & & & & & & & & & & & 1 & & 3 & 4 \\
\hline Procedia CIRP & 0,572 & & & & & & & & & & & & & & & 1 & & 1 \\
\hline Corporate Environmental Strategy & 0,520 & 1 & & & & & & & & & & & & & & & & 1 \\
\hline International Journal of Construction Management & 0,510 & & & & & & & & & & & 1 & & & & & & 1 \\
\hline Procedia Economics and Finance & 0,400 & & & & & & & & & & & & & & & 1 & & 1 \\
\hline Journal of Engineering, Design and Technology & 0,173 & & & & & & & & & & & & & & & & 1 & 1 \\
\hline Malaysian Construction Research Journal & 0,104 & & & & & & & & & & & & 1 & & & & & 1 \\
\hline Total & & 1 & 0 & 0 & 1 & 0 & 1 & 0 & 2 & 1 & 2 & 3 & 5 & 4 & 6 & 11 & 16 & 53 \\
\hline
\end{tabular}


O segundo periódico que mais publicou dentro dessa temática foi o Habitat International, com cerca de $9,4 \%$ das publicações (5 de 53) e em terceiro lugar, com $7,5 \%$ (4 de 53), estão os trabalhos publicados no periódico International Journal of Project Management e Procedia Engineering.

A partir de 2008 houve um aumento contínuo no número de publicações dentro dessa temática, indicando que este é um assunto de interesse crescente para os pesquisadores. É interessante notar que 94,33\% das publicações estão entre 2007 a 2016, sendo que apenas em 2016 foram encontradas 16 publicações aderentes ao tema, ou seja, $30,1 \%$ das publicações aconteceram recentemente.

\subsubsection{Principais Estudos}

A Tabela 2 evidencia os 18 artigos mais citados. Os pesquisadores Zuo e Zhao (2014) tiveram o maior número de citações em seu artigo de revisão de literatura sobre Construções Verdes, obtendo no total 82 citações. Considerando o cálculo do índice de impacto, a Tabela 2 evidencia também os artigos mais relevantes dentro da temática proposta, uma vez que este índice considera não só o número de citações, mas também o fator de impacto da revista na qual o artigo foi publicado. Sendo assim, mesmo alguns artigos obtendo numericamente maior quantidade de citações, podem ser considerados menos relevantes, caso tenha sido publicado em uma revista com um fator de impacto baixo. 
Tabela 2 - Lista de artigos mais relevantes de acordo com o índice de impacto e número de citações

\begin{tabular}{lcc}
\hline Artigo & $\mathbf{A}_{\text {if }}$ & N $^{\circ}$ Citações \\
\hline Zuo e Zhao (2014) & 639,44 & 82 \\
Shen et al. (2010) & 375,42 & 63 \\
Zhao et al. (2012) & 268,16 & 45 \\
Egri e Ralston (2008) & 235,58 & 79 \\
Lam et al. (2010) & 181,76 & 44 \\
Yang et al. (2009) & 180,95 & 55 \\
Liu et al. (2013) & 148,16 & 19 \\
Tan, Shen e Yao (2011) & 145,39 & 48 \\
Sarkis, Meade e Presley (2012) & 143,02 & 24 \\
Kolk e Pinkse (2006) & 134,04 & 55 \\
Zuo et al. (2012) & 132,57 & 17 \\
Tsai e Chang (2012) & 131,10 & 22 \\
Lam et al. (2011) & 107,41 & 26 \\
Barandica et al. (2013) & 89,39 & 15 \\
Rechenthin (2004) & 80,13 & 32 \\
Tsai et al. (2014) & 51,51 & 14 \\
Zeng et al. (2015) & 27,20 & 7 \\
Hartmann, Reymen e Van Osterom (2008) & 26,76 & 11 \\
\hline
\end{tabular}

Fonte: A autora

Para sintetizar a ideia, a Tabela 3 mostra a lista dos artigos que receberam acima de 10 citações. Esta tabela contém o número de citações, a porcentagem de citações relativa a cada artigo, o fator de impacto do periódico responsável pela publicação e os respectivos índices de impactos. A título de exemplificação, o artigo de Shen et al. (2010) foi o terceiro da lista dos artigos mais citados; todavia, este artigo é considerado o segundo mais relevante, devido ao fato de ter sido publicado em uma revista com fator de impacto maior que a do segundo colocado em número de citações. 
Tabela 3 - Artigos que receberam mais de 10 citações

\begin{tabular}{|c|c|c|c|c|c|c|}
\hline Artigo & Periódico & $\begin{array}{c}\mathbf{N}^{\circ} \\
\text { Citações } \\
\end{array}$ & \% Citações & JCR & $A_{\text {if }}$ & País de Origem \\
\hline Zuo e Zhao (2014) & Renewable and Sustainable Energy Reviews & 82 & 11,4 & 6,798 & 639,44 & Austrália \\
\hline Egri e Ralston (2008) & Journal of International Management & 79 & 11,0 & 1,982 & 235,58 & Canada \\
\hline Shen et al. (2010) & Journal of Cleaner Production & 63 & 8,7 & 4,959 & 375,42 & Hong Kong \\
\hline Yang et al. (2009) & Journal of Civil Engineering and Management & 55 & 7,6 & 2,290 & 180,95 & Hong Kong \\
\hline Kolk e Pinkse (2006) & European Management Journal & 55 & 7,6 & 1,437 & 134,04 & Holanda \\
\hline Tan, Shen e Yao (2011) & Habitat International & 48 & 6,7 & 2,029 & 145,39 & Hong Kong \\
\hline Zhao et al. (2012) & Journal of Cleaner Production & 45 & 6,2 & 4,959 & 268,16 & China \\
\hline Lam et al. (2010) & Journal of Environmental Management & 44 & 6,1 & 3,131 & 181,76 & Hong Kong \\
\hline Rechenthin (2004) & Journal of Safety Research & 32 & 4,4 & 1,504 & 80,13 & Estados Unidos \\
\hline Lam et al. (2011) & Journal of Environmental Management & 26 & 3,6 & 3,131 & 107,41 & Hong Kong \\
\hline Sarkis, Meade e Presley (2012) & Journal of Cleaner Production & 24 & 3,3 & 4,959 & 143,02 & Estados Unidos \\
\hline Tsai e Chang (2012) & Journal of Cleaner Production & 22 & 3,1 & 4,959 & 131,10 & Taiwan \\
\hline Liu et al. (2013) & Renewable and Sustainable Energy Reviews & 19 & 2,6 & 6,798 & 148,16 & China \\
\hline Zuo et al. (2012) & Renewable and Sustainable Energy Reviews & 17 & 2,4 & 6,798 & 132,57 & Austrália \\
\hline Barandica et al. (2014) & Journal of Cleaner Production & 15 & 2,1 & 4,959 & 89,39 & Espanha \\
\hline $\begin{array}{l}\text { Tsai et al. (2014) } \\
\text { Hartmann, Reymen e Van Osterom }\end{array}$ & European Journal of Operational Research & 14 & 1,9 & 2,679 & 51,51 & Taiwan \\
\hline (2008) & Building Research and Information & 11 & 1,5 & 1,433 & 26,76 & Holanda \\
\hline
\end{tabular}


Foi feita uma análise dos países de origem dos trabalhos aderentes à temática responsabilidade social e projetos de construção civil, verificando-se que Hong Kong tem maior número de artigos publicados dentro da temática deste estudo, com 11 publicações, seguido por China com 9, Austrália e Estados Unidos com 5. Um pequeno país como a Malásia, contribui com 4 trabalhos e o Brasil possui uma modesta contribuição com 3 artigos. Espanha, Holanda, Reino Unido, Singapura e Taiwan cooperam com a temática, publicando 2 artigos cada um. E ainda se verificou a participação da Arábia Saudita, Canadá, Finlândia, Japão, Letônia e Suécia com 1 artigo cada país. Nota-se, portanto, uma grande preocupação dos asiáticos com o tema e de grandes potências econômicas como Estados Unidos e Austrália. O tema tem recebido atenção também de países com populações menores, como Malásia e Singapura.

Analisou-se também a rede de principais autores citados, conforme a Figura 4. Foi possível observar uma distribuição centralizada, com força de atração alta, sustentando a formação de vários clusters, gerados pelo software VOSviewer.

Figura 4 - Cluster de autores citados
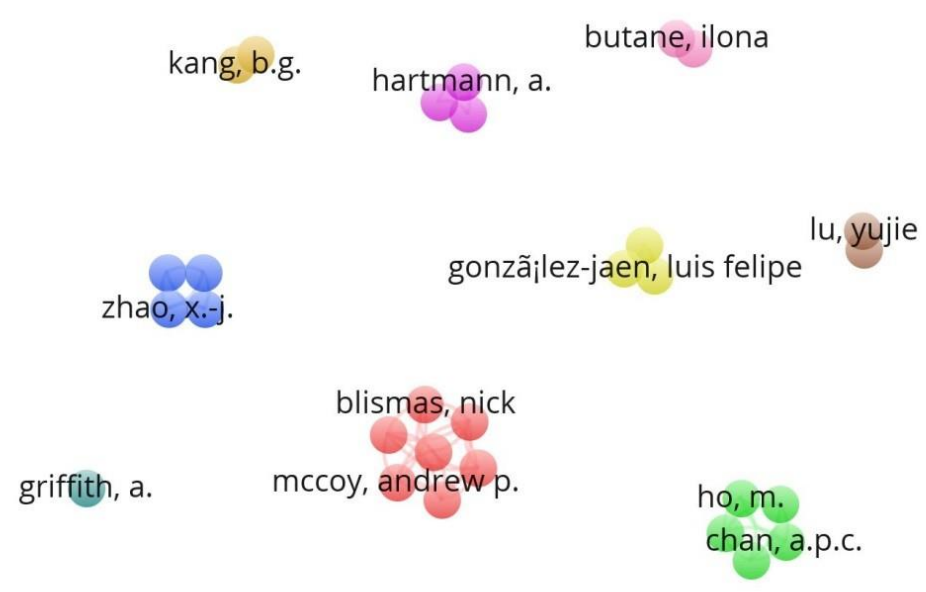

jiang, weiyan

VOSviewer

chang, andrew s. close, r.

Fonte: A autora

Através da compilação dos dados da amostra de 53 artigos, com o auxílio do Microsoft Excel, foram encontradas grupos de 231 palavras chaves, sendo que as 
palavras que apareceram com mais frequência foram aquelas que remetem à temática de sustentabilidade. As palavras em inglês encontradas foram: Sustainability/ Sustainable development/ Sustainable transformation (aparecendo 29 vezes), Corporate Social Responsibiliy/ Social responsibility (12 vezes), Construction/ Construction Projects (10 vezes).

Através do software VOSviewer, uma rede das palavras chaves principais foi criada (ver Figura 5). E em seguida comparada com as palavras contidas no banco de dados criados no Microsoft Excel. O tamanho do círculo gerado no software como por exemplo "projects e social responsibility" foram palavras que mais se destacaram na rede, estando fortemente ligadas entre si. A rede feita através do VOSviewer ainda consegue mostrar através da coloração das linhas os anos nos quais as ligações entre as palavras foram mais fortes. Nota-se que em 2011 estas duas palavras se relacionaram mais fortemente. Já as palavras "China" e "organization" aparecem como palavras mais recentes a partir de 2015. O mapa resultante faz sentido, uma vez que trabalhos encontrados nesta temática vieram em sua maioria da Ásia.

As palavras "quality" e "safety" aparecem a partir de 2013, indicando alguns dos objetivos finais dos projetos de construção (RECHENTHIN, 2004).

Figura 5 - Rede de palavras chaves

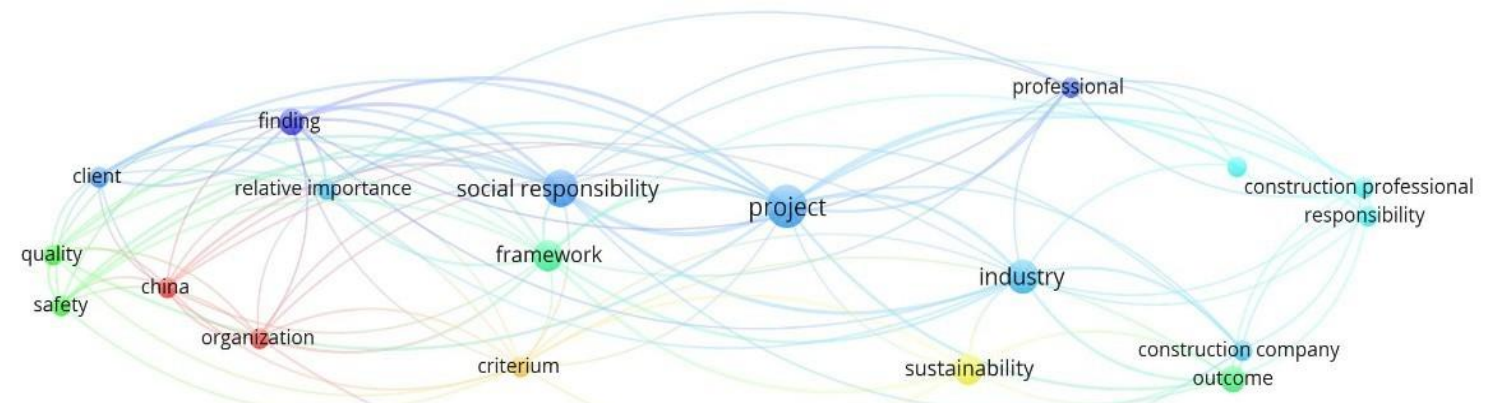


Os artigos foram analisados em relação às metodologias utilizadas para a condução das pesquisas dentro da temática de responsabilidade social e projetos de construção civil. A contabilização dos resultados foi evidenciada na Tabela 4.

Tabela 4 - Principais abordagens metodológicas

\begin{tabular}{|c|c|c|}
\hline Metodologia da Pesquisa & $\begin{array}{c}\text { Quantidade de } \\
\text { artigos }\end{array}$ & Referência \\
\hline Revisão de literatura & 12 & $\begin{array}{l}\text { Zuo e Zhao (2014) } \\
\text { Egri e Ralston (2008) } \\
\text { Yanget al.(2009) } \\
\text { Zuo et al.(2012) } \\
\text { Ng, Skitmore e Cheung (2013) } \\
\text { Vanags e Butane (2013) } \\
\text { Tan et al. (2015) } \\
\text { Chang et al.(2016) } \\
\text { Abdel-Raheem e Ramsbottom (2016) } \\
\text { Pocock, Steckler e Hanzalova (2016) } \\
\text { Jiang e Wong (2016) } \\
\text { Jamil e Fathi (2016) }\end{array}$ \\
\hline Estudos de Caso & 12 & $\begin{array}{l}\text { Shen et al.(2010) } \\
\text { Kolk e Pinkse (2006) } \\
\text { (Liu et al.(2013) } \\
\text { Hartmann, Reymen e Van Osterom } \\
\text { (2008) } \\
\text { Shi et al.(2015) } \\
\text { Lu e Zhang (2016) } \\
\text { Pan e Ning (2015) } \\
\text { Andelin, Karhu e Junnila (2015) } \\
\text { Morioka e Carvalho (2014) } \\
\text { Wenblad (2001) } \\
\text { González, Gonçalves e Vasconcelos } \\
\text { (2017) } \\
\text { Saunders et al. (2015) }\end{array}$ \\
\hline Survey & 10 & $\begin{array}{l}\text { Lam et al.(2010) } \\
\text { Lam et al.(2011) } \\
\text { Papargyropoulou et al. (2012) } \\
\text { Wong e Abe (2014) } \\
\text { Close e Loosemore (2014) } \\
\text { Yusof et al. (2016) } \\
\text { Mousa (2015) } \\
\text { Kang e Shahary (2012) }\end{array}$ \\
\hline
\end{tabular}




\begin{tabular}{|c|c|c|}
\hline & & $\begin{array}{l}\text { Martens e Carvalho (2016) } \\
\text { Wu et al. (2015) }\end{array}$ \\
\hline Framework Conceitual & 7 & $\begin{array}{l}\text { Zhao et al.(2012) } \\
\text { Rechenthin (2004) } \\
\text { Sarkis, Meade e Presley (2012) } \\
\text { Zeng et al. (2015) } \\
\text { Marcelino-Sádaba, González-Jaen e } \\
\text { Pérez-Ezcurdia (2015) } \\
\text { Tan, Shen e Yao (2011) } \\
\text { Zhao et al. (2016) }\end{array}$ \\
\hline $\begin{array}{c}\text { Entrevistas e Estudos de } \\
\text { Caso }\end{array}$ & 4 & $\begin{array}{l}\text { Tsai e Chang (2012) } \\
\text { Zhang, Wu e Shen (2015) } \\
\text { Zhang (2014) } \\
\text { Wong, Chan e Wadu (2016) }\end{array}$ \\
\hline Entrevistas & 3 & $\begin{array}{l}\text { Loosemore, (2016) } \\
\text { Liao, Tseguun e Liang (2016) } \\
\text { Kibwami e Tutesigensi (2016) }\end{array}$ \\
\hline Modelos Matemáticos & 2 & $\begin{array}{l}\text { Chen, Lin e Tseng (2015) } \\
\text { Wang et al. (2016) }\end{array}$ \\
\hline $\begin{array}{l}\text { Experimento/ Modelo } \\
\text { experimental }\end{array}$ & 2 & $\begin{array}{l}\text { Barandica et al. (2013) } \\
\text { Tsai et al.(2014) }\end{array}$ \\
\hline
\end{tabular}

Fonte - A autora

Observa-se que a revisão de literatura é a abordagem metodológica ainda mais utilizada dentro desta temática, devido ao amplo acesso a informações e pesquisas ao redor do mundo (ROWLEY; SLACK, 2004). O estudo de caso é a segunda maior metodologia utilizada. Isso deve-se à própria natureza de projetos de construção civil, os quais permitem a obtenção de grande número de informações durante a execução do projeto. Percebe-se que algumas metodologias ainda são pouco exploradas, como é o caso do desenvolvimento de modelos matemáticos e experimentais.

\subsubsection{Análise de conteúdo}

O objetivo da análise de conteúdo dos 17 artigos outliers da amostra, foi verificar as essências dos trabalhos de autores que receberam mais de 10 citações, ou seja, conhecer o tema e a forma de abordagem do tema destes trabalhos. 
O artigo com maior número de citações na amostra foi o trabalho de Zuo e Zhao (2014), estes autores fazem uma revisão da literatura, porém de forma não sistemática, sobre construções verdes. Eles acreditam que a maioria dos trabalhos dentro dessa temática focam muito mais fortemente no aspecto ambiental da sustentabilidade, como por exemplo em aspectos como consumo de energia, bom uso da água e emissões de gases de efeito estufa. Afirmam que estudos de aspectos sociais e econômicos dentro de sustentabilidade são ainda poucos explorados, se comparados com aqueles de enfoque ambiental. Todavia os autores salientam que $o$ desempenho social de construções verdes são garantias de sucesso de futuras investigações.

O trabalho de Lam et al. (2010) enfoca especificações verdes como constituintes de um dos elementos mais importantes na construção verde, uma vez que novos elementos de sustentabilidade e mudança de prioridades no gerenciamento da construção tem estimulado a ascensão desse tipo de especificação em velocidade mais acelerada. Nesse trabalho, uma série de entrevistas foram conduzidas em Hong Kong em 2010 para identificar os principais fatores que levam ao sucesso na preparação de especificações verdes. Baseando-se na literatura sobre gerenciamento da construção, cinco fatores independentes para especificações bem-sucedidas foram categorizados nessa análise, são estas: tecnologias e técnicas verdes; confiabilidade e qualidade da especificação, liderança e responsabilidade, envolvimento do stakeholder e ainda guias e sistemas de benchmarking. Sabendo as diferentes ênfases dadas aos stakeholders em relação a projetos com especificações verdes, as considerações dessa pesquisa apontam para uma direção na busca de um adequado framework para se fazer especificações que mitiguem problemas associados a responsabilidade social.

Em um trabalho posterior, Lam et al. (2011) afirmam que a implementação de um sistema de gerenciamento ambiental é uma das mais importantes ferramentas para a realização de uma construção sustentável. No entanto, muitas preocupações sobre desenvolvimento sustentável não foram devidamente abordadas, existindo então a necessidade da introdução de especificações verdes para que se possa avançar no desempenho das construções, através do gerenciamento de contratos com tais especificações. Esse artigo define especificações verdes, identificando as razões para adotá-las e coloca em evidência as questões ambientais que foram 
abordadas somente pela adoção do sistema de gerenciamento ambiental. O trabalho apresenta os resultados de uma survey com profissionais da área, consultando a opinião destes sobre a adoção de especificações verdes. Através do resultado da pesquisa, os autores desenvolveram um framework para realização desse tipo de especificações, o qual os autores acreditam ser de grande valia para cidades em busca de sustentabilidade.

No trabalho de Tsai et al. (2014) um modelo de decisão para avaliação do custo durante o ciclo de vida de projetos de construções verdes é proposto. A maior contribuição desse estudo é a ajuda que fornece aos gerentes, para que estes entendam como determinar de modo mais preciso os custos de recursos e economia de energia de cada atividade de um projeto de construção. Também funciona como ferramenta para gerenciamento de tomada de decisão de pré-construção, ou seja, na fase de planejamento de uma proposta eco-friendly.

A pesquisa de Egri e Ralston (2008) enfoca o tema responsabilidade social identificando 321 artigos de interesse no tema salientando o gerenciamento internacional. $\mathrm{O}$ assunto foi categorizado em quatro grandes temas: responsabilidade social corporativa, responsabilidade ambiental, ética e governança. Os autores fizeram então a separação de acordo com a orientação da pesquisa: teórica ou empírica. Junto ao estudo empírico realizou-se ainda outra categorização de acordo com a metodologia e nível de internacionalização dos trabalhos. O trabalho conclui que temas sobre ética e governança são mais enfatizados que responsabilidade social corporativa e que a abordagem empírica é a predominantemente utilizada, sendo que essas foram realizadas grande parte em nações com maior poder aquisitivo no ocidente, sendo assim um tema pouco explorado em nações pobres da América Latina, África e Ásia.

O artigo de Shen et al. (2010) analisa os maiores desafios de se conduzir um estudo de viabilidade para construções sustentáveis. Os autores avaliaram oitenta e sete estudos de viabilidade de diferentes tipos de projetos de construção civil: projetos residenciais, projetos públicos e nos setores industriais e comerciais. Os estudos indicaram que os fatores econômicos são mais valorizados que os sociais e ambientais quanto se trata de estudo de viabilidade. Apesar de ter uma conclusão simples, o trabalho aproveita para propor uma nova abordagem para estudos de 
viabilidade de projetos de construção, devendo estes incluir 18 atributos econômicos, pelo menos 9 sociais e 8 ambientais.

O trabalho de Kolk e Pinkse (2006) tem por objetivo ser uma luz sobre contextos, mecanismos organizacionais e estratégias subjacentes à má gestão de stakeholders. Foram estudados dois casos que aconteceram na Holanda: Ahold e a empresa Dutch, uma grande companhia no setor da construção civil. Os dois casos abordados foram grandes exemplos em que a responsabilidade social em empresas que atuam com projetos, deixou a desejar em diversos pontos e afetou negativamente a imagem do país. Verificou-se, em ambos os casos, a existência de contabilidade paralela, sistema de acordos de preços ilegais, faturas falsas, venda de produtos no mercado negro, subornos de funcionários, evasão de divisas, entre outras aberrações do ponto de vista da responsabilidade social. Note-se que a má gestão de mecanismos organizacionais têm consequências desastrosas em projetos que queiram estar alinhados com práticas de responsabilidade social.

No artigo de Zhao et al. (2012) é proposto um sistema de indicadores de responsabilidade social baseado na teoria dos stakeholders, os quais servem de base para a construção de um framework conceitual que oferece uma tipologia para organizar os atributos de responsabilidade social que servem para evitar problemas desta natureza.

Ainda sobre gerenciamento de stakeholders em projetos de construção, o trabalho de Yang et al. (2009) visa identificar os fatores críticos de sucesso, associados ao gerenciamento de stakeholders em projetos de construção civil. Sendo que quinze fatores foram identificados na revisão de literatura e consolidados através de entrevistas e estudos pilotos com profissionais da construção civil. Os três principais fatores que foram apontados são: gerenciamento de stakeholders com responsabilidade social, avaliação das necessidades destes e a identificação das limitações do projeto, além de comunicação adequada e frequente com as partes interessadas. Em sua abordagem metodológica, os 15 fatores foram agrupados em 5 dimensões: pré-condição, fator, estimação de stakeholders, informação sobre inputs, tomada de decisão e apoio sustentável. Por ser uma pesquisa conduzida em Hong Kong, os pesquisadores sugerem que as técnicas (questionários) sejam aplicadas em outras localidades para verificação das eventuais diferenças de resultados, identificando assim mais uma oportunidade de pesquisa. 
O trabalho de Rechenthin (2004) diz que em indústrias de alto risco como é o caso da construção civil, uma força de trabalho segura pode ser uma vantagem competitiva. Os registros sobre segurança podem impactar a moral, a lucratividade, a rotatividade e produtividade. Ainda que seja difícil quantificar, um programa bemsucedido de segurança é uma vantagem competitiva com desvantagens limitadas.

No trabalho de Tan, Shen e Yao (2011) é enfatizado que a implementação de práticas de construção sustentável pode contribuir para o desempenho e melhora da sustentabilidade de empreiteiros. Sendo assim esses pesquisadores conduziram uma revisão de estudos sobre a relação entre desempenho em sustentabilidade e competitividade do negócio. Eles finalmente encontraram que não existe uma única relação entre as duas variáveis. Se usada uma visão de longo prazo, o desempenho em sustentabilidade terá uma grande contribuição na competitividade do negócio no futuro. Foi então desenvolvido um framework conceitual para ajudar as empreiteiras a melhorar seu desempenho e competitividade no negócio. Os autores consideram que esse modelo será útil para ser usado como um guia aos empreiteiros.

No trabalho de Sarkis, Meade e Presley (2012) é apresentado um modelo de decisão e seleção de subempreiteiros e formação de equipes em construção, baseado em fatores econômicos, sociais e ambientais, ou seja, baseado nos aspectos do Triple Bottom Line. Esse modelo ajuda justamente na tomada de decisão sobre a formação de uma equipe que melhor beneficiará o objetivo de sustentabilidade do projeto. O modelo usa Analytic Hierachy Process (AHP) e Analytic Network Process (ANP) como bases. A robustez da solução é demonstrada usando análise sensitiva, permitindo ao responsável pela tomada de decisões apreciar as complexidades do ambiente de decisão. Esse trabalho constrói também um modelo matemático e aplicações para sustentabilidade no contexto da construção civil.

Para Tsai e Chang (2012) questões de sustentabilidade vêm sendo amplamente discutidas na indústria da construção civil nos últimos anos. A fase do planejamento é uma etapa chave no ciclo de vida para integrar a sustentabilidade em projetos de construção. Assim métodos práticos e ferramentas são necessárias para facilitar a sustentabilidade no trabalho nessa fase. Sendo assim, os autores desenvolveram um framework através da revisão de requerimentos do LEED (Leadership in Energy and Environmental Design) e no GRI, além de se basear em estudos relevantes na área, projetos sustentáveis de rodovias e entrevistas com profissionais do ramo. $\mathrm{O}$ artigo 
propõe um modelo para desenvolvimento de itens sustentáveis no planejamento especificamente de rodovias. Esses itens foram selecionados a partir de uma revisão de literatura e um checklist contendo uma lista de sessenta técnicas e materiais sustentáveis. O checklist foi testado em quatro projetos de rodovias para verificar a aplicabilidade do framework. Os resultados mostraram que mais de $52 \%$ dos itens foram considerados e $50 \%$ incorporados ao design. A grande contribuição desse trabalho foi para os desenvolvedores de projetos. Estes podem usar o checklist como uma ferramenta, logo esse framework diminuiu a lacuna entre requerimentos teóricos e práticos atuais da fase de planejamento em projetos de construção civil, levando-os rumo à sustentabilidade.

O trabalho de Liu et al. (2013) assevera que projetos hidrelétricos têm impactos significativos na sociedade e nas comunidades economicamente, ambientalmente e socialmente. Esses impactos podem ir muito além do nível regional. $O$ desenvolvimento dessa pesquisa se deu através do estudo de caso da hidrelétrica de Três Gargantas na China. A corporação responsável se comprometeu a gerenciar questões ambientais, econômicas e de responsabilidade social durante os vários estágios do projeto: concepção, planejamento, construção e operação. A prática de sustentabilidade adotada no projeto seguiu, de modo geral, o protocolo da Associação Internacional de Hidrelétricas. No entanto, mesmo seguindo protocolos internacionais, não foi um projeto isento de problemas. Questões de assentamento de pessoas e problemas ambientais causados são os mais citados pelos críticos. Todavia, os autores afirmam que não se pode negar que o governo chinês e a empresa Three Gorges Corportation fizeram grandes esforços para mitigar os impactos negativos, através da incorporação de práticas de responsabilidade social.

Para Zuo et al. (2012) a sustentabilidade é uma questão preocupante em vários setores industriais. A indústria da construção não é uma exceção. Esse trabalho tem uma abordagem crítica qualitativa para investigar as políticas práticas sobre sustentabilidade nesse setor. Essa abordagem inclui a declaração de princípios, relatório de sustentabilidade atrelado a um relatório financeiro e um sistema autônomo de relatório de sustentabilidade. Para a pesquisa foram examinadas as mais importantes empreiteiras listadas na revista Engineering News Records. Os resultados mostraram que os desenvolvimentos das políticas de sustentabilidade variam de caso para caso nessas empresas, todavia, esse tipo de política vem como uma tendência 
emergente comum em empresas empreiteiras. Outro resultado mostra uma tendência crescente no nível de divulgação dos comprometimentos da empresa e realizações na área de sustentabilidade. De modo análogo, a eficiência energética, a redução da emissão de gases de efeito estufa e a integração de fontes renováveis de energia em projetos, são temas comuns das divulgações de política de sustentabilidade pelas empresas de construção civil. Foi interessante notar o emprego do método de análise de conteúdo para a investigação da prática de sustentabilidade adotada pelas cinquenta empresas mais importantes do setor da construção civil. Ao concluir a pesquisa, os autores afirmam que o número de empresas que fazem este tipo de relatório está crescendo; e que as empresas mais bem ranqueadas tendem a divulgar relatórios mais detalhados e ver com bons olhos o fato de terem suas agendas sobre sustentabilidade vasculhadas para serem listadas na lista GRI e Índice Dow Jones de Sustentabilidade; além de notarem que essas empresas considerem os temas: conservação de energia, eficiência energética, redução de gases de efeito estufa e integração fontes de energias renováveis, todos, como parte integrantes de suas políticas de sustentabilidade.

O trabalho de Barandica et al. (2014) realizou a avaliação de gases de efeito estufa em projetos de construção de uma rodovia através da análise do ciclo de vida desta. Os pesquisadores identificaram os elementos que tiveram maiores contribuições para as emissões e estratégias para controle e redução destes níveis. Para esse propósito, um sistema de gerenciamento de informação foi construído e suportado por um banco de dados obtidos através de uma bibliografia especializada. Foram testados quatro projetos de rodovias na Espanha. Assim, o total de emissões obtidas em um ciclo de vida ficou na faixa de 8.880 a $50.300 \mathrm{t} \mathrm{CO}_{2} / \mathrm{km}$, a maior parte dele relacionado a atividades de construção de rodovias. Constatou-se que 60 a $85 \%$ das emissões são realizadas no período de construção da rodovia, ou seja, estão estritamente relacionadas ao uso de maquinários, em outras palavras, ações antropogênicas. Nota-se que esse tipo de pesquisa, com enfoque mais científicoexperimental é também de grande valia para ações relacionadas com responsabilidade social, pois saber medir para controlar e reduzir problemas é parte da política de responsabilidade social.

No trabalho de Hartmann, Reymen e Van Oosterom (2008) os autores abordam a temática de como clientes têm uma posição proeminente na construção e como, por 
consequência, afetam o potencial de implementação de inovação em projetos de construção civil. Nesse artigo foram estudados três casos que envolveram a adoção de inovação tecnológica. Notou-se que existem fatores que contribuem para que estes clientes aceitem ou até atuem em prol da mudança, sendo os fatores: cumprimento de requerimentos sociais, conhecimento do projeto de modo geral e ciência sobre os riscos e incertezas do projeto.

A análise de conteúdo dos artigos obtidos através da técnica de revisão sistemática de literatura levou ao conhecimento de várias abordagens acadêmicas sobre o tema sustentabilidade e responsabilidade social na construção civil. No Quadro 4 buscou-se relacionar as categorias contempladas na ISO 26000 com os trabalhos analisados neste tópico. Pelo fato de apenas 17 artigos terem sido selecionados para a análise conteúdo, algumas categorias como "Práticas Leais de Operação", Questões relativas ao consumidor e Envolvimento e Desenvolvimento da Comunidade" não tiveram artigos representantes. Os trabalhos que foram categorizados como "Geral" são os que englobam mais de uma categoria.

Quadro 4 - Relação da Análise de Conteúdo com as Categorias de Responsabilidade Social

\begin{tabular}{|c|c|}
\hline Categoria & Autores \\
\hline Governança Organizacional & $\begin{array}{l}\text { Egri e Ralston (2008) } \\
\text { Kolk e Pinkse (2006) }\end{array}$ \\
\hline Direitos Humanos & Rechenthin (2004) \\
\hline Práticas de Trabalho & Sarkis, Meade e Presley (2012) \\
\hline Meio Ambiente & $\begin{array}{l}\text { Zuo e Zhao (2014) } \\
\text { Lam et al. (2010) } \\
\text { Lam et al. (2011) } \\
\text { Barandica et al. (2014) }\end{array}$ \\
\hline Práticas Leais de Operação & - \\
\hline Questões relativas ao consumidor & - \\
\hline $\begin{array}{c}\text { Envolvimento e Desenvolvimento da } \\
\text { Comunidade }\end{array}$ & e \\
\hline Geral & $\begin{array}{l}\text { Shen et al. (2010) } \\
\text { Zhao et al. (2012) } \\
\text { Yang et al. (2009) } \\
\text { Tan, Shen e Yao (2011) } \\
\text { Tsai e Chang (2012) } \\
\text { Liu et al. (2013) } \\
\text { Zuo et al. (2012) } \\
\text { Hartmann, Reymen e Van Oosterom (2008) }\end{array}$ \\
\hline
\end{tabular}

Fonte: A autora 


\subsection{Resultados dos Questionários online - Survey}

A pesquisa foi realizada durante os meses de outubro de 2017 a outubro de 2018, tendo obtido 122 respostas com participantes de 26 países: África do Sul, Austrália, Brasil, Canadá, Chile, Colômbia, Costa Rica, Espanha, Estados Unidos, Gana, Índia, Indonésia, Malásia, México, Nicarágua, Portugal, Omã, Paquistão, Panamá, Peru, Rússia, Arábia Saudita, Serra Leoa, Turquia, Emirados Árabes Unidos e Reino Unido. A Figura 6 mostra a distribuição dos respondentes destacados no mapa-múndi.

Figura 6 - Países participantes na survey

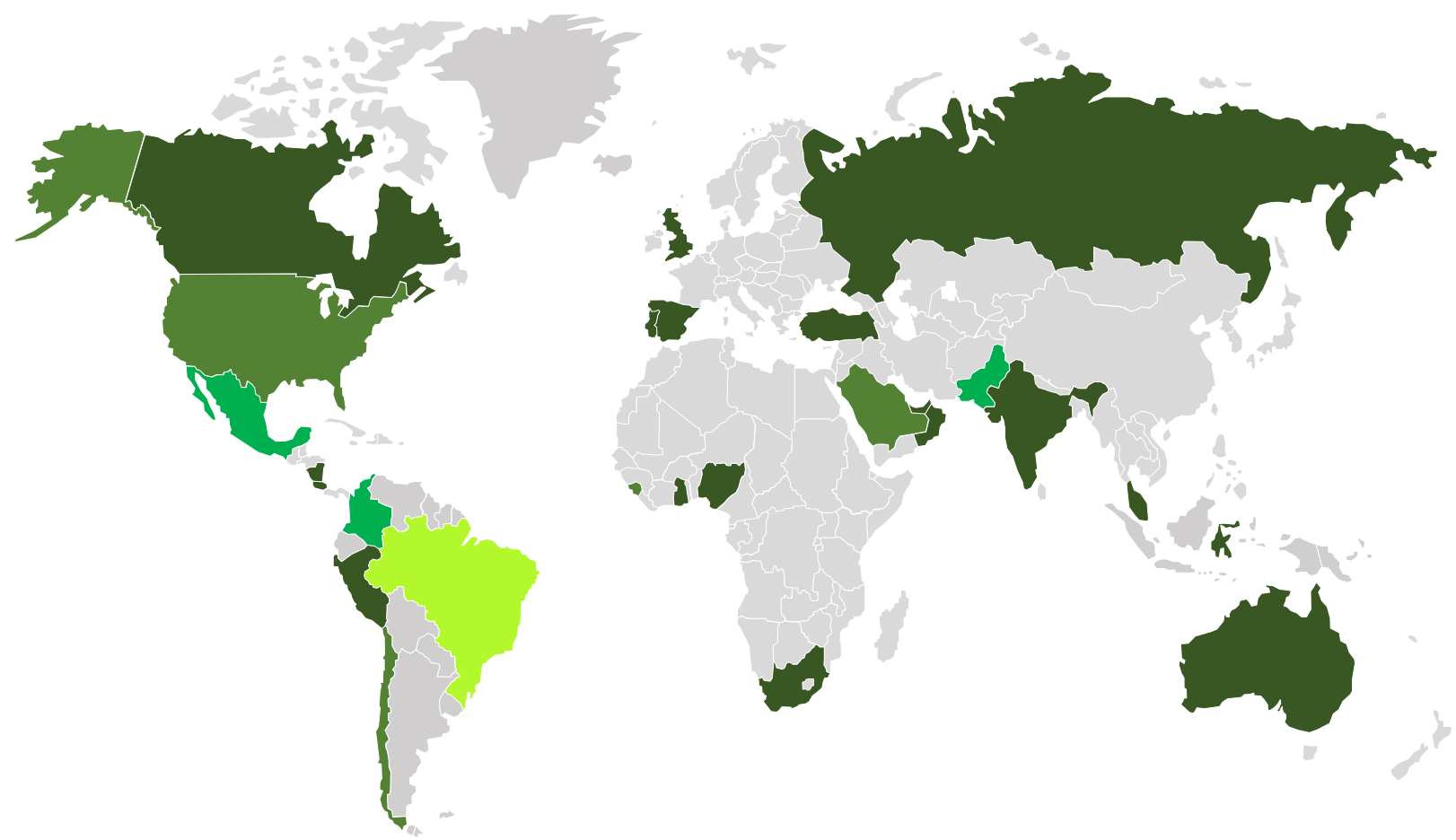

Fonte: A autora

$\mathrm{Na}$ Tabela 5 são mostrados os países que contaram com mais de um respondente. 
Tabela 5 - Países com mais de um respondente

\begin{tabular}{|lc|}
\hline Brasil & 80 \\
México & 5 \\
Paquistão & 4 \\
Colômbia & 4 \\
Estados & \\
Unidos & 3 \\
Chile & 3 \\
Arábia Saudita & 2 \\
Serra Leoa & 2 \\
\hline \multicolumn{2}{|c|}{ Fonte: A autora } \\
\hline
\end{tabular}

O Brasil foi o país com maior quantidade de respondentes, com um total de 80 participantes. A Figura 7 mostra a distribuição geográfica dos respondentes e a Tabela 6 evidencia o número de participantes por estado.

São Paulo teve o maior número de respondentes, possivelmente porque o universo de contatos utilizados para a pesquisa contém principalmente profissionais e empresas desde estado. No entanto, pela sua relevância econômica e influência sobre o restante do território nacional, acredita-se que as respostas tenham representatividade.

Figura 7 - Distribuição geográfica dos participantes da survey no Brasil

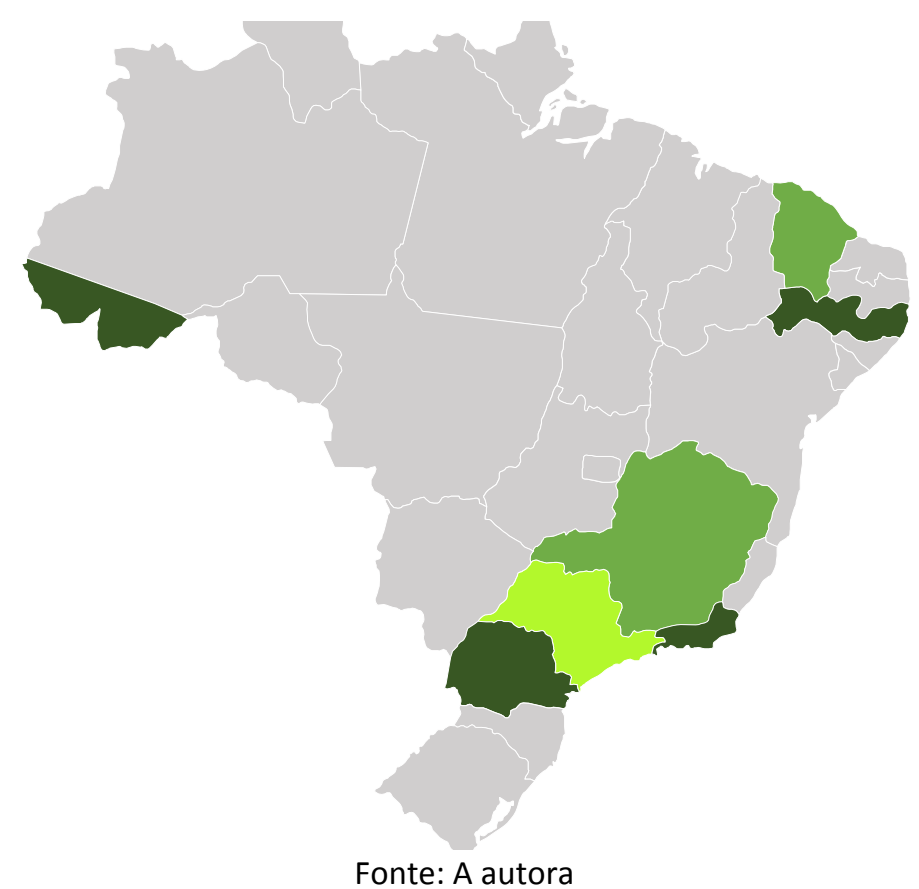

Tabela 6 - Número de participantes por Estado

\begin{tabular}{|ll|}
\hline SP & 69 \\
MG & 3 \\
CE & 2 \\
Outros & 6 \\
\hline \multicolumn{2}{r|}{ Fonte: A autora }
\end{tabular}


Em relação ao setor representado pelos respondentes, verificou-se que a grande maioria atua com Projetos Residenciais e Comerciais, totalizando 51\% dos participantes da survey. Em segundo lugar aparecem os respondentes de Projetos Estruturais, com 16\% e em terceiro lugar os de Projetos Elétricos, representando 9\% dos respondentes. A Figura 8 mostra a distribuição completa dos respondentes por tipo de projeto de atuação.

Figura 8 - Distribuição dos respondentes por tipo de projeto de atuação

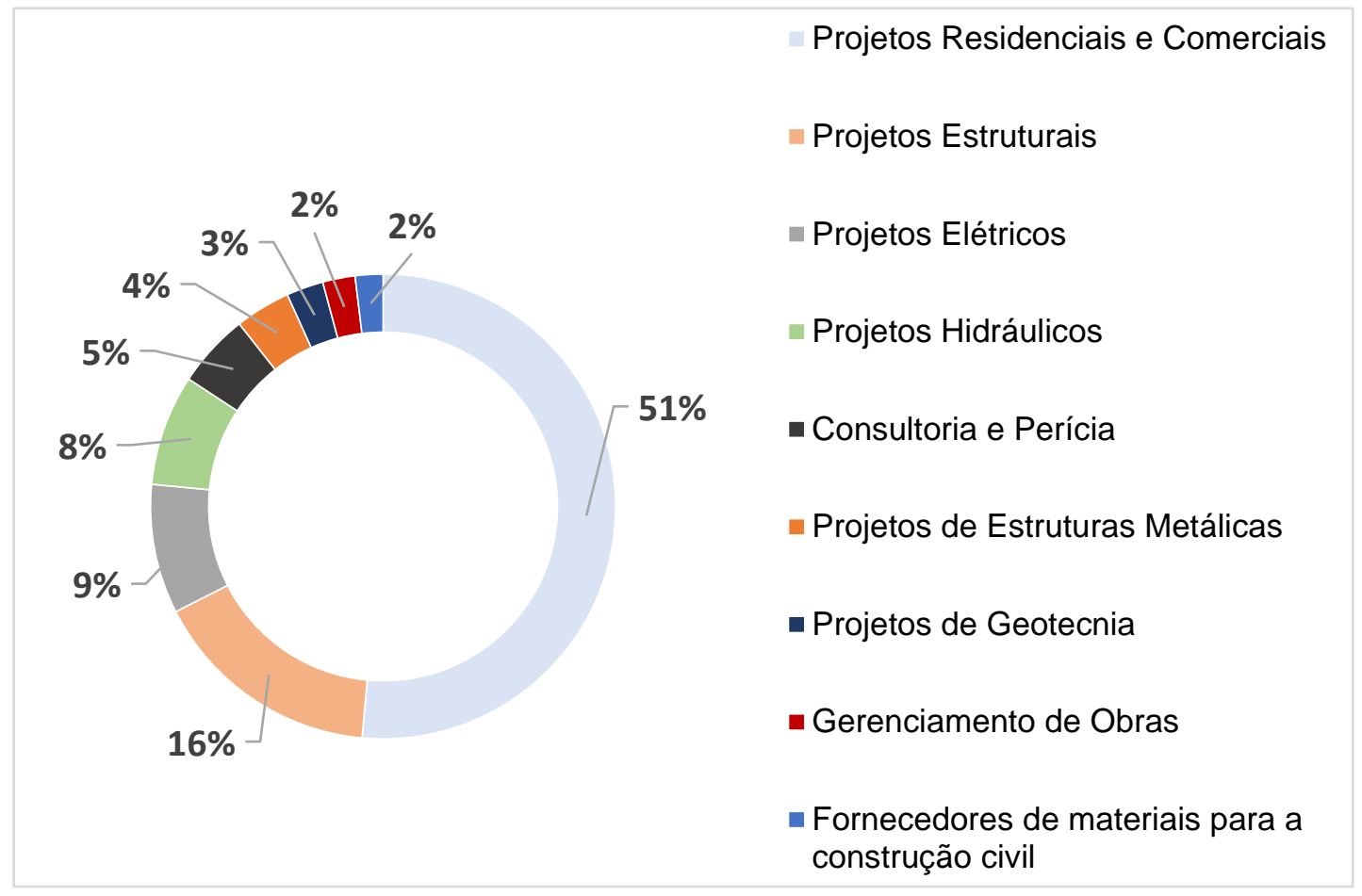

Fonte: A autora

Através da survey, verificou-se que a grande maioria dos respondentes já haviam ouvido falar sobre o termo "responsabilidade social empresarial" (84\% dos respondentes, Figura 9), no entanto percebe-se que é limitado o entendimento do significado do termo, estando muitas vezes restrito a um sentido comunitário e ambiental, como é evidenciado pelos dados mostrados na Figura 10. O gráfico expõe as categorias que os respondentes julgaram estar relacionadas à questão da "Responsabilidade Social". 
Figura 9 - Nível de conhecimento do termo "Responsabilidade Social"

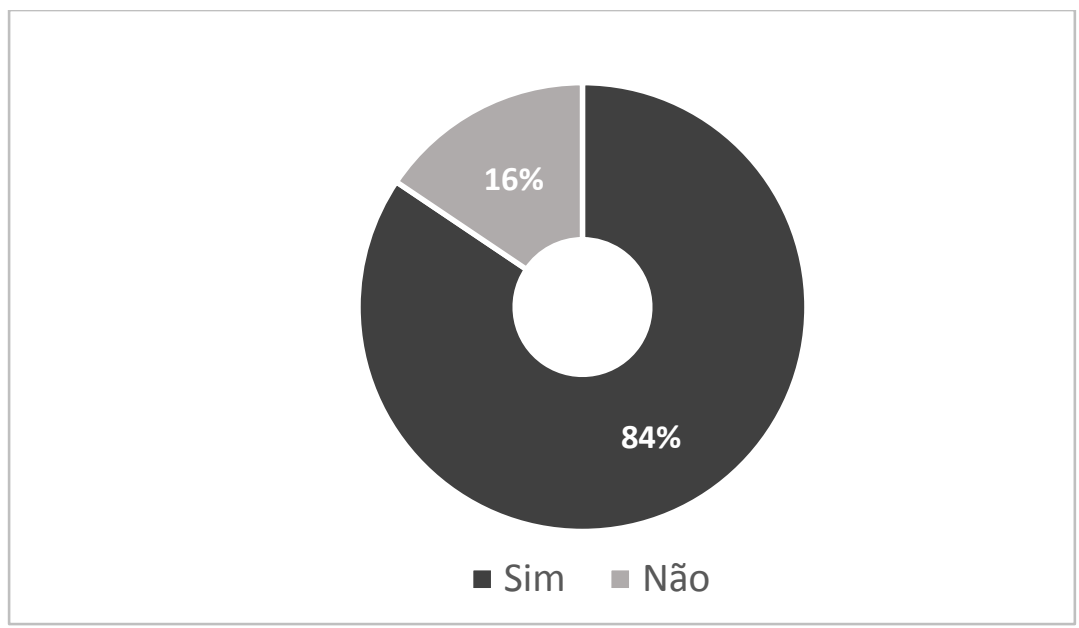

Fonte: A autora

Figura 10 - Categorias consideradas Responsabilidade Social

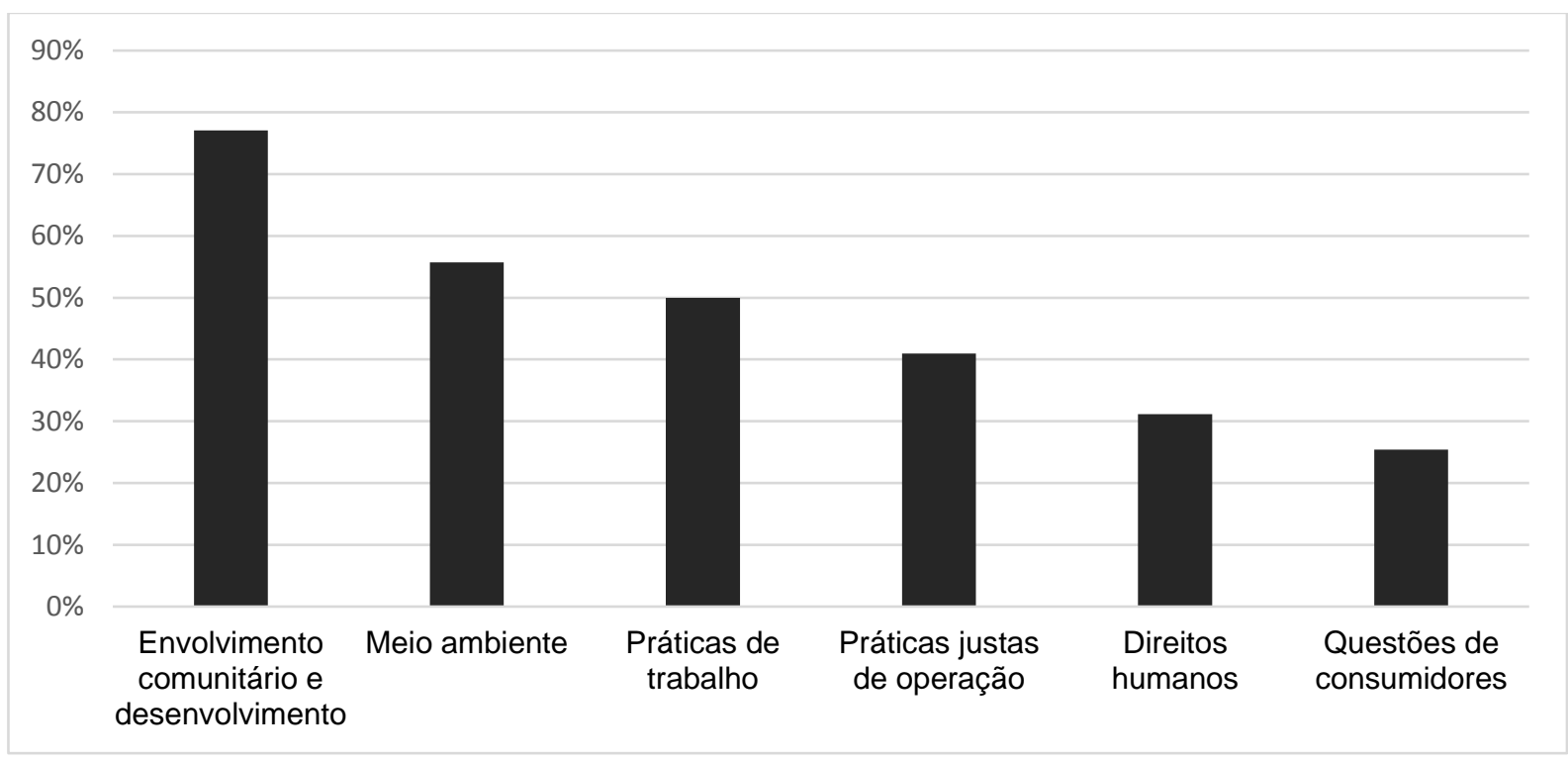

Fonte: A autora

Através da análise do coeficiente de Pearson $(0,62)$, verificou-se que há uma forte correlação entre empresas que mencionam "prática justas de operação" e "questões de consumidores", sugerindo que esses pontos são relevantes na obtenção de uma política adequada ao tema. Estas categorias possuem definições diferentes, porém tem objetivos concernentes. Lembrando que por práticas justas de operação se subentendem o respeito das diferentes leis; a prática de responsabilidade e justiça nas relações comerciais; compras sociais; e fonte responsável (fornecedores qualificados). As questões de consumo visam fornecer produtos saudáveis e seguros, 
informações precisas e promover o consumo sustentável; projetar produtos que possam ser reutilizados, reparados ou reciclados, reduzindo o desperdício e protegendo a privacidade do consumidor ao se lidar com dados pessoais.

Através da Figura 11 observa-se que há relativamente pouco incentivo interno, apenas $39 \%$, para a prática de trabalhos voluntários nas empresas voltadas a projetos de construção civil, no entanto, naquelas em que a responsabilidade social integra a visão estratégica do negócio, o incentivo é muito maior (63\%), Figura 12.

Figura 11 - Nível de estímulo a trabalhos voluntários

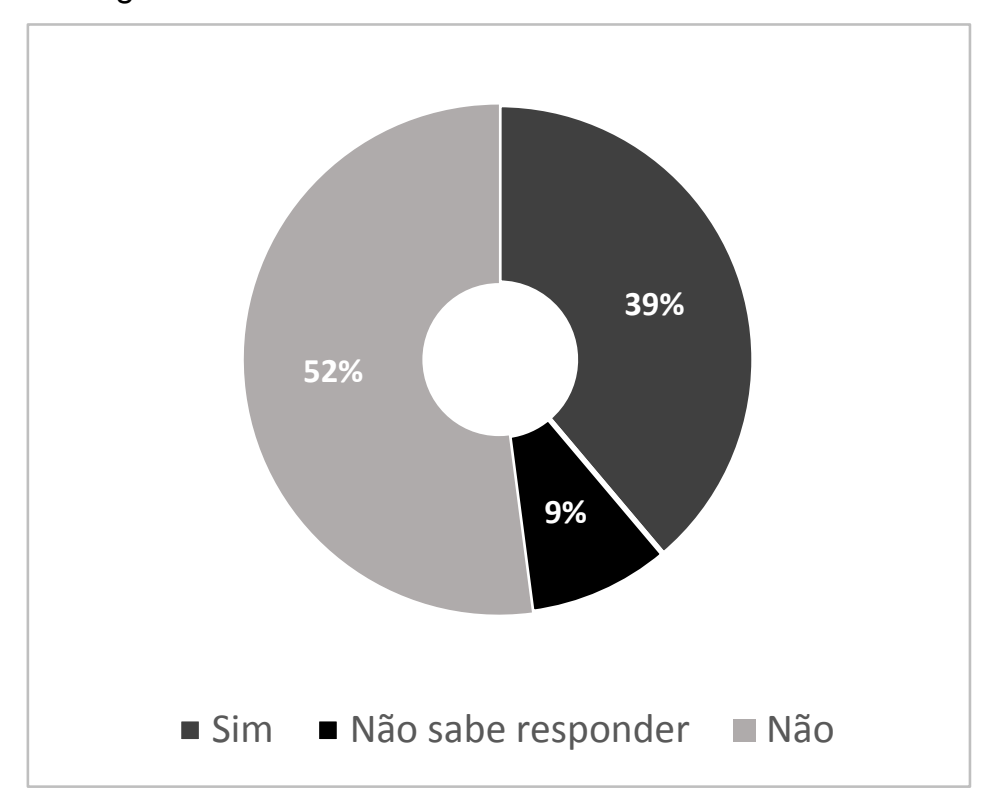

Fonte: A autora

Figura 12 - Nível de estímulo a trabalhos voluntários quando a Responsabilidade Social integra a Visão Estratégica

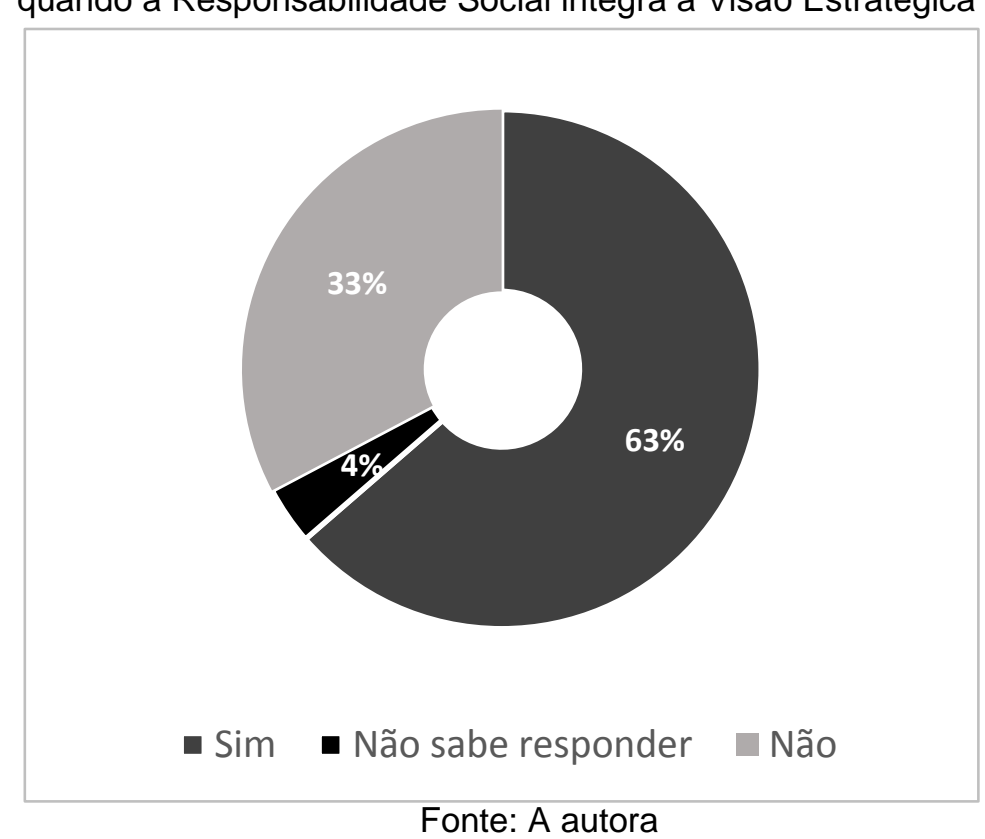


Em $81 \%$ das empresas de pequeno porte (até nove funcionários) as ações de responsabilidade social são contempladas nos planejamentos orçamentários dos projetos e $79 \%$ das empresas de grande porte (mais de 500 funcionários) o fazem, como exposto na Figura 13. Todavia, é gritante a diferença entre o volume de recursos financeiros gastos. Em $80 \%$ das pequenas empresas, o volume de investimentos no ano de 2017 foi de até 20 mil reais com ações de responsabilidade social nos projetos, enquanto apenas cerca de $5 \%$ das empresas de maior porte investiram esse valor. $O$ restante das empresas de grande porte dispendeu quantias maiores com esses tipos de ações. Sendo que $20 \%$ delas, alegaram ter gasto mais de cinco milhões de reais com ações de responsabilidade social em seus projetos no ano de 2017 (Figura 14).

Figura 13 - Percentual de empresas que contemplam ações de Responsabilidade Social no planejamento e orçamento de seus projetos versus tamanho da empresa

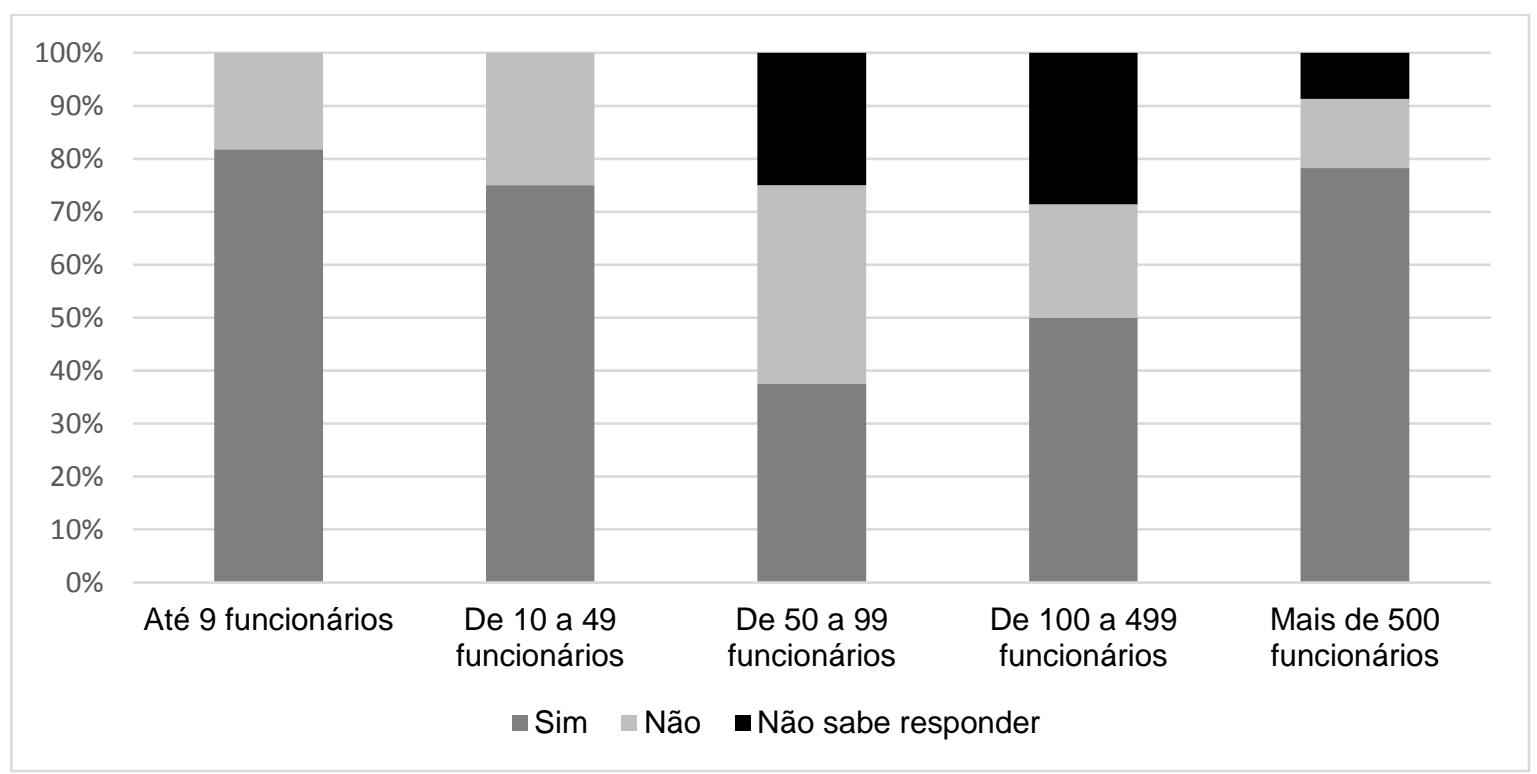

Fonte: A autora 
Figura 6 - Volume de investimento em ações de Responsabilidade Social nos projetos versus tamanho da empresa

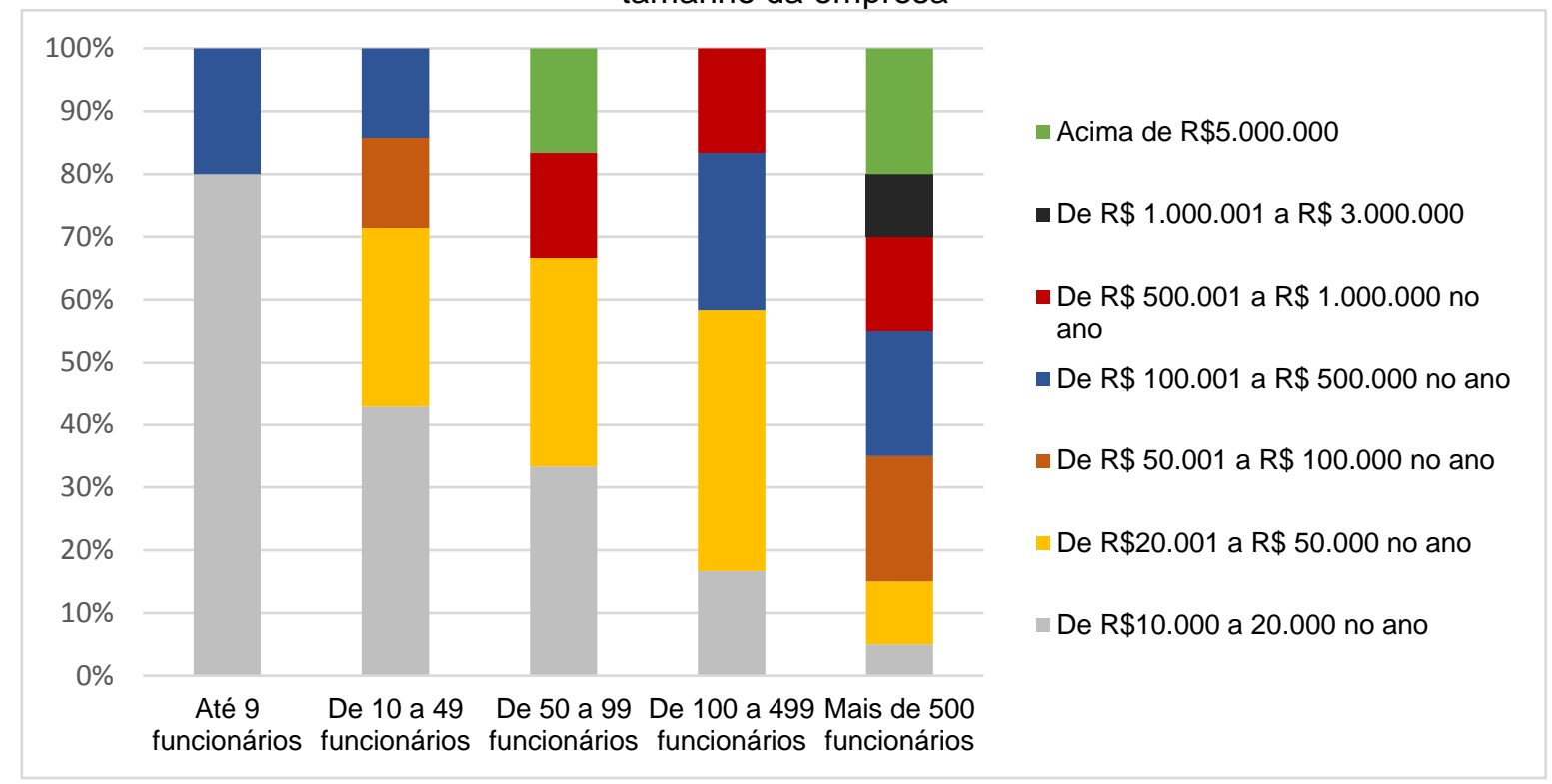

Fonte: A autora

As informações sobre as ações de responsabilidade social dos projetos são mais divulgadas nas empresas com mais de 50 funcionários, conforme exposto na Figura 15. De acordo com $27 \%$ dos respondentes, a principal forma de divulgação se dá através da página de internet da empresa. É interessante notar que apenas 14\% das empresas ligadas a projetos elaboram relatórios anuais sobre as ações de responsabilidade social em seus projetos (Figura 16).

Figura 15 - Nível de divulgação das ações de Responsabilidade Social nos projetos versus tamanho da empresa

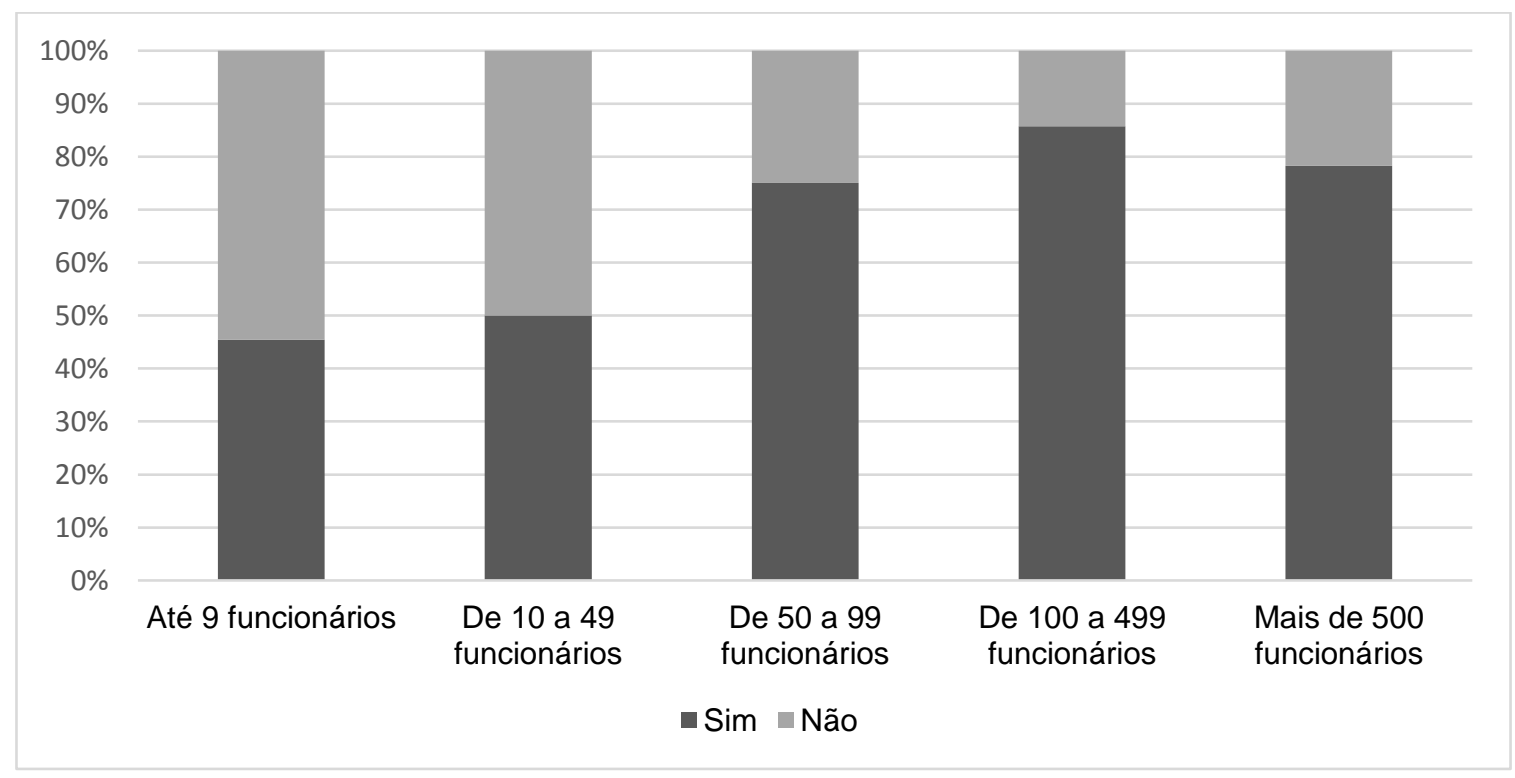

Fonte: A autora 
Figura 16 - Métodos de divulgação das ações de Responsabilidade Social dos projetos

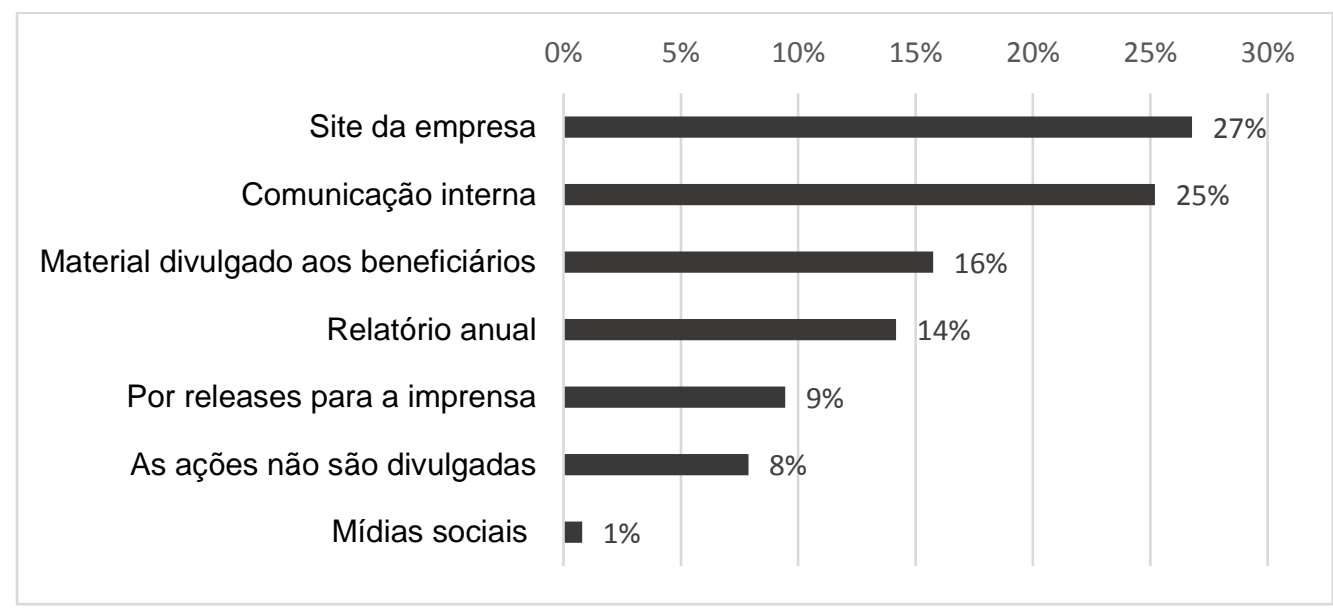

Fonte: A autora

Hahn e Kühnen (2013) afirmaram que, ao divulgar informações sobre os procedimentos de responsabilidade social, as empresas são capazes de demonstrar sua competitividade, motivar os funcionários e, subsequentemente, aumentar o valor da marca. O coeficiente de Pearson de 0,56 corrobora com esse fato, uma vez que confirma que as empresas que realizam relatórios anuais sobre o tema são mais preocupadas em manter uma boa imagem institucional. As práticas de divulgação incluem relatos sobre as responsabilidades das empresas por seus impactos na sociedade, tais como obrigações morais ou atividades éticas nas quais as empresas se engajaram para minimizar danos à comunidade, ao ambiente, aos funcionários e consumidores (GRAY et al., 2001; HAHN; KÜHNEN, 2013; LEE; CASSELL, 2008; SAID; ZAINUDDIN; HARON, 2009).

Em uma visão geral, observando-se todos os respondentes desta survey, notase que é bastante dividido o cenário entre as empresas que atuam com responsabilidade social em seus projetos e as que não o fazem (Figura 17). No Brasil, essa segmentação é ainda mais evidente, porém ao contrário do que acontece no cenário mundial, nacionalmente, a maior parte das empresas não contemplam ações de responsabilidade social em seus projetos (Figura 18). Verifica-se adicionalmente diferenças entre o nível de atuação entre os diferentes setores: empresas de projetos elétricos e hidráulicos atuam mais do que empresas de projetos estruturais e residenciais (Figura 19). 
Figura 17 - Percentual de empresas que possuem ações de Responsabilidade Social em seus projetos

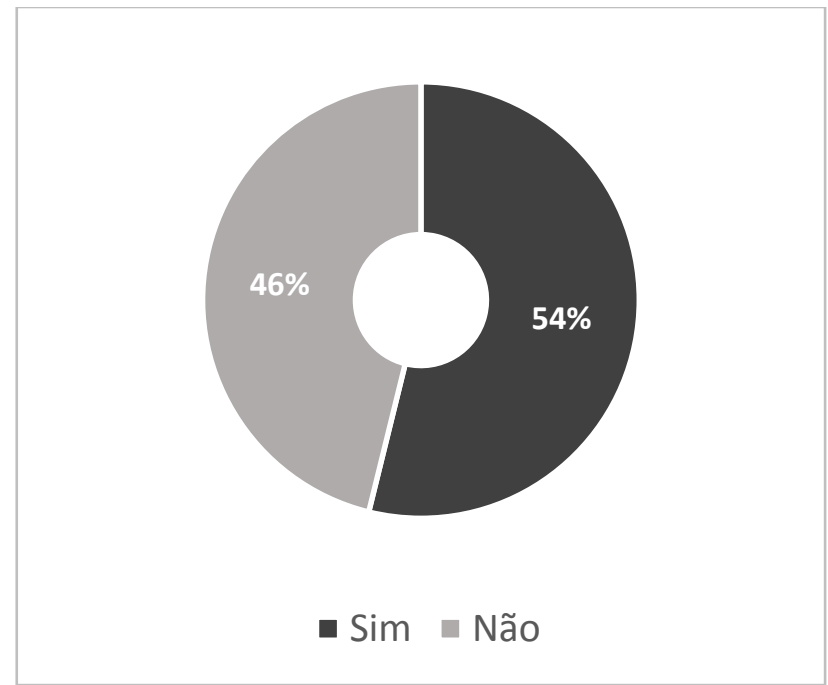

Fonte: A autora

Figura 18 - Percentual de empresas que possuem ações de Responsabilidade Social em seus projetos - Comparação Brasil versus Exterior
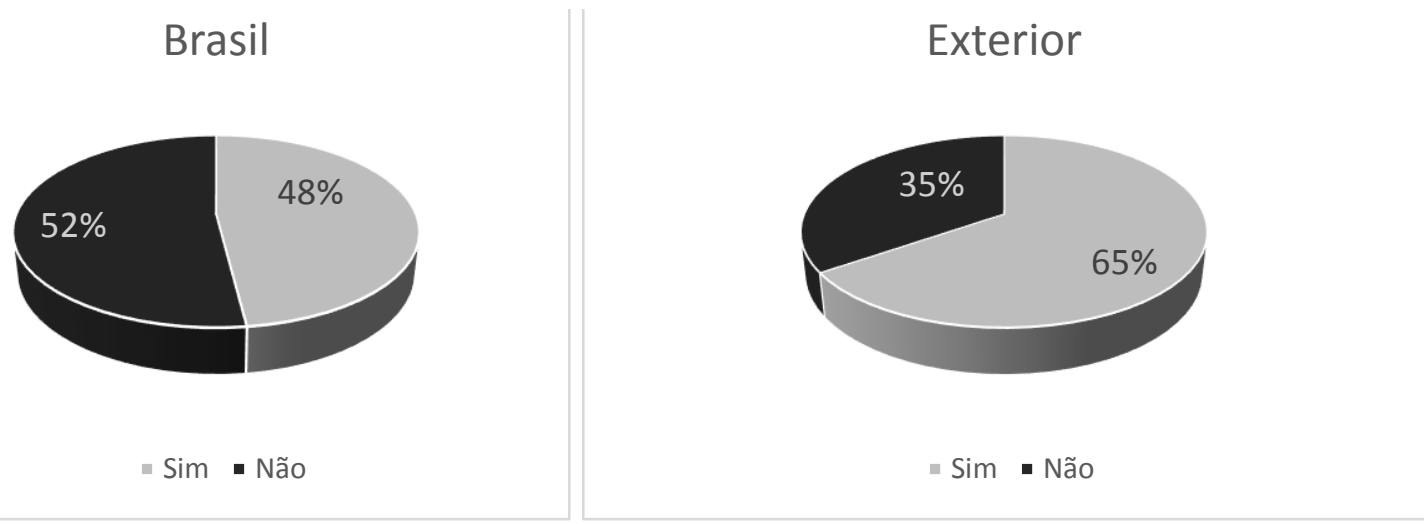

Fonte: A autora

Figura 19 - Percentual de empresas que possuem ações de responsabilidade social em seus projetos: Comparação por segmento de atuação

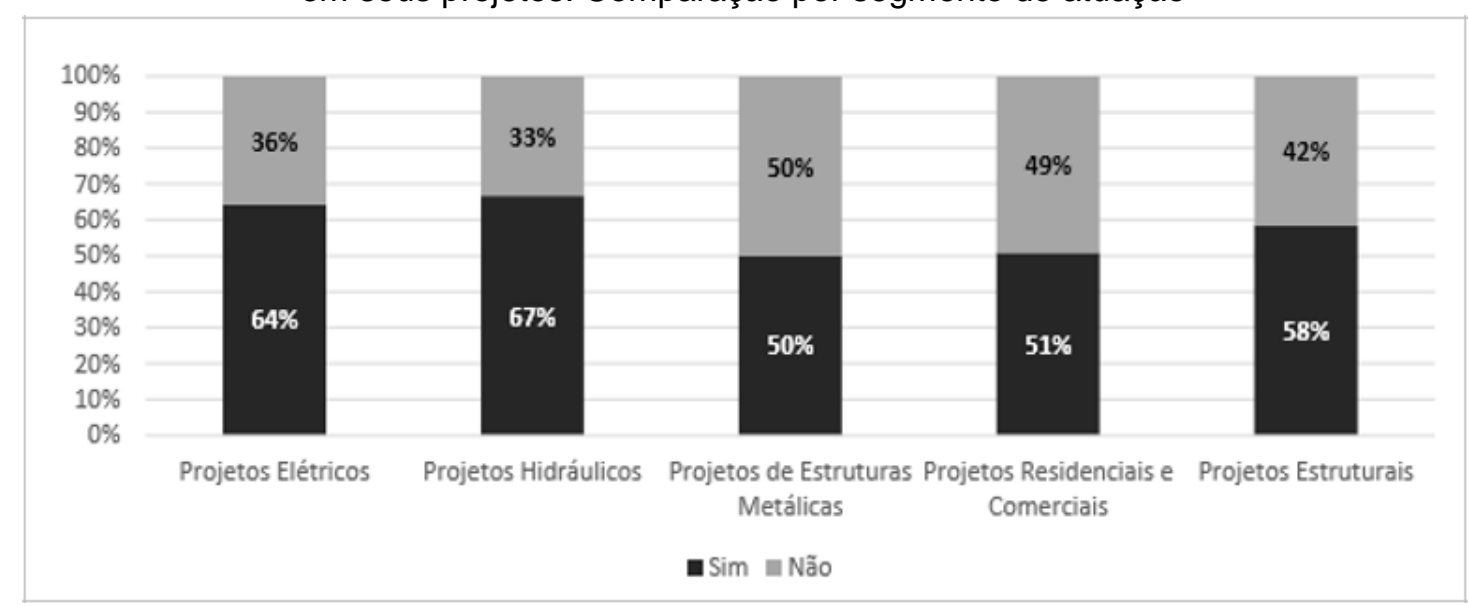

Fonte: A autora 
Sobre as atividades de responsabilidade social desenvolvidas nos projetos de construção civil, deixou-se propositalmente uma questão aberta para dar voz e liberdade de expressão aos participantes da survey. Insights interessantes foram apresentados. As respostas mais representativas são mostradas a seguir, com tradução livre para o português das respostas dadas originalmente em inglês ou espanhol. As transcrições nos idiomas originais foram deixadas como notas de rodapé para consulta.

"Parte do nosso faturamento é destinado à ajuda social de um lar de idosos em Fortaleza. Outra parte do faturamento é destinada ao auxílio de uma instituição ligada à Igreja Católica que abriga crianças em situação de risco, muitas delas vítimas de abusos sexuais e órfãos. As doações variam de $1 \%$ a $2 \%$ do faturamento. Isso corresponde a um montante anual de $R \$ 20.000,00$.

Talvez este montante não seja tão expressivo, mas é representativo para a nossa empresa, que é uma empresa de pequeno porte e o valor é extraído do faturamento bruto. Promovemos campanhas arrecadadoras de fraldas, leites e lençóis duas vezes ao ano em parceria com a Grande Loja Maçônica do Estado do Ceará".

Respondente do Ceará, atuação em Projetos, Orçamentos, Avaliações, Perícias, Assistência Técnica e Consultoria de Engenharia. Sem investimentos no ano de 2017.

"Doamos nosso trabalho para a cruz vermelha de um projeto "vila dos idosos", trabalhamos com valor de custo para quem não pode pagar, entre outras ações. Num projeto de uma faculdade, conseguimos convencer o proprietário a abrir o campus para uso da comunidade local para uso da quadra, creche, auditório, promovendo assim uma interação".

Respondente do estado de São Paulo, atuação em Projetos Residenciais e Comerciais. Sem investimentos no ano de 2017.

"Apoio a projetos voluntários (ex.: um teto para meu país), apoio a ONGs ou instituições que auxiliam comunidades carentes (ex.: Fono Kids \& Cia, Creche Algo Tão Doce), apoio funcionários (ex.: cadeira de rodas para funcionário)".

Respondente do estado de São Paulo, atuação em Projetos Comerciais, Infraestrutura e Industriais. Investiu de R\$50.000 a R\$ 100.000 em ações de responsabilidade social no ano de 2017.

“- Alfabetização para colaboradores (às vezes até analfabetos);

- Ações de Páscoa, dia das crianças e Natal em alguma entidade de extrema pobreza;

- Dentista móvel para atuação por determinado tempo no canteiro de obras;

- Campanha de vacinas;

- Reforma em sedes sociais de ONG's."

Respondente do estado do Paraná, atuação em Incorporação e Construção. Investiu de $\mathbf{R} \mathbf{2 0 . 0 0 0}$ a $\mathbf{R} \mathbf{\$} \mathbf{5 0 . 0 0 0}$ em ações de responsabilidade social no ano de 2017. 
"Foram incorporadas soluções prediais visando redução do consumo e reaproveitamento de água, automatizações para redução do consumo de energia e aproveitamento de energia solar. Entendo tais soluções como de utilidade para a comunidade em geral, tendo em vista uma redução/ melhor aproveitamento no uso dos recursos naturais. Anualmente a empresa realiza algumas atividades de voluntariado em escolas do ensino médio, com palestras de funcionários sobre a área de atuação. Um projeto bastante interessante foi realizado com a equipe de obras, visando alfabetização da equipe e familiares que tivessem interesse, cursos de informática básica também foram realizados com a mesma intenção".

Respondente do estado de São Paulo, atuação em Projetos Residenciais e Comerciais. Investiu de $\mathbf{R} \$ \mathbf{2 0 . 0 0 0}$ a $\mathbf{R} \boldsymbol{\$} \mathbf{5 0 . 0 0 0}$ em ações de responsabilidade social no ano de 2017.

"Promoção da educação, concessão de bolsas de estudo para estudantes talentosos, fornecimento de serviços de saúde, promoção e desenvolvimento de esportes, ética nos negócios e medidas anticorrupção ${ }^{1 "}$.

Respondente do Paquistão, atuação em Projetos Estruturais. Investiu de $\mathbf{1 0 . 0 0 0}$ a 20.000 dólares em ações de responsabilidade social no ano de 2017.

"Foco na sociedade antes de aceitar um projeto criando um produto que não seja apenas benéfico para os clientes, mas também para o meio ambiente2".

Respondente do Paquistão, atuação em Projetos Estruturais. Investiu de 20.000 a $\mathbf{5 0 . 0 0 0 ~ d o ́ l a r e s ~ e m ~ a c ̧ o ̃ e s ~ d e ~ r e s p o n s a b i l i d a d e ~ s o c i a l ~ n o ~ a n o ~ d e ~} 2017$.

"Certos projetos são designados como intensos em mão de obra; nenhuma máquina deve ser usada como força humana. Através disso, o emprego é fornecido à comunidade".

Respondente da África do Sul, atuação em Projetos Sanitários. Investiu de 500.000 a 1.000 .000 dólares em ações de responsabilidade social no ano de 2017.

"São realizadas avaliações de impactos sociais para determinar os efeitos das obras nas diferentes comunidades. Além disso, promove-se uma cultura de transparência e comunicação das atividades da Instituição. Nestes momentos uma certificação interna é desenvolvida em assuntos relacionados à integridade que será de aprovação obrigatória para qualquer trabalhador 4".

Respondente do México, atuação em Projetos Elétricos e Hidráulicos. Investiu mais de 5.000.000 dólares em ações de responsabilidade social no ano de 2017.

\footnotetext{
1 "Promotion of education, scholarships for talented students, provision of health facilities, Sports promotion and development, Business Ethics and Anti corruption measures".

2 "Focus on society before accepting a project by creating a product that is not only beneficial to its customers, but also to the environment."

3 "Certain project are designated labour intensive there no machine should be used be human power. Through this, employment is provided to community."

4 "Se realizan Evaluación de impactos sociales para determinar las afectaciones de las obras en las distintas comunidades afectadas. Adicionalmente se promueve una cultura de transparencia y comunicación de las actividades de la Institución. En estos momentos se desarrolla una certificación interna en temas relacionados con la integridad que será de aprobación obligada para cualquier trabajador."
} 
"Contratar pessoal da localidade afetada pelo projeto;

Desenvolver algum(as) atividade(s) de interesse(s) social(is), com recursos próprios da empresa;

Escutar e manter informadas as comunidades afetadas, sobre o desenvolvimento do projeto;

Realizar jornada de ajuda às comunidades;

Assegurar que os padrões de segurança da empresa sejam cumpridos por todos os trabalhadores da empresa, uma vez que constituem o capital mais importante desta e é de suma importância que retornem sãos e salvos aos seus lares;

Construir obras de qualidade para ser útil e criar oportunidades para melhorar a qualidade de vida das comunidades e da sociedade que aproveitam os produtos ou obras que geram tais projetos ${ }^{5}$.

Respondente da Costa Rica, atuação em Obras Marítimas. Investiu entre 100.000 a 500.000 USD em ações de responsabilidade social no ano de 2017.

Todas as 122 respostas obtidas através dos questionários online foram categorizadas de acordo com a Tabela 6.

Tabela 7 - Categoria das ações de Responsabilidade Social realizadas nos projetos

\begin{tabular}{|l|c|}
\hline \multicolumn{1}{|c|}{ CATEGORIA } & $\%$ \\
\hline $\begin{array}{l}\text { Oferecimento de cursos de } \\
\text { capacitação }\end{array}$ & $\mathbf{2 8 \%}$ \\
\hline Direitos Humanos & $\mathbf{2 7 \%}$ \\
\hline $\begin{array}{l}\text { Ações relacionadas ao meio } \\
\text { ambiente }\end{array}$ & $\mathbf{2 4 \%}$ \\
\hline $\begin{array}{l}\text { Colaboração com entidades não } \\
\text { governamentais }\end{array}$ & $\mathbf{1 9 \%}$ \\
\hline Práticas justas de operação & $\mathbf{3 \%}$ \\
\hline \multicolumn{2}{|c|}{ Fonte: A autora } \\
\hline
\end{tabular}

\footnotetext{
${ }^{5}$ Contratar personal de la localidad afectada por el proyecto;

Desarrollar alguna (s) obra de interés social, con recursos propios de la empresa;

Escuchar y mantener al tanto del desarrollo del proyecto a las comunidades afectadas;

Realizar jornadas de ayuda a las comunidades;

Velar por que las normas de seguridad de la empresa sean cumplidas por todos los trabajadores de la empresa ya que conforman el capital más importante de esta y es de suma importancia que regresen a sus casas sanos;

Construir obras de calidad para que sean de provecha y creación de oportunidades de mejora de la calidad de vida de las comunidades y sociedad que se aprovechan de los productos u obras que generan dichos proyectos."
} 
Por meio desta categorização e das análises individuais das respostas, observase que ações nos projetos seguem de modo geral a tendência do setor da construção civil, ou seja, é confirmado o que dizem os pesquisadores Loosemore e Lim (2017), os quais afirmam que as iniciativas no setor da construção são isoladas, muito focadas em atividades ambientais, imaturas e baseadas em fazer o que é obrigatório e operacional, e de modo geral não são ações estratégicas. Isso pode ser de fato observado, quando, por exemplo, respondentes mencionam destinar parte de seu faturamento à para ajudar lar de idosos, igrejas e órfãos. Ainda que estas ações são de modo geral benéficas para a sociedade, estas são ações sem relação direta com os projetos. Uma determinada ação fora do escopo do projeto e sem ligação com seus stakeholders é consequentemente menos focada no impacto da atividade. Existem diversos casos na história da construção civil de empresas que praticam algum tipo de "filantropia", ações sociais, mas que negligenciaram áreas importantes da gestão de projetos e suas relações com ações de responsabilidade social. Um exemplo disso foi a poluição do Rio das Pérolas, na província de Guangdong, na China onde fábricas e a construção de uma estação de energia ao longo do rio, causaram sua poluição. De acordo com um relatório do Greenpeace (2009), a taxa de potabilidade da água do rio era de apenas $67,8 \%$. O governo, desenvolvedores e contratadas não tomaram medidas de controle efetivo a tempo porque não pensaram que eles fossem os responsáveis pela poluição. Não houve uma devida gestão de stakeholders nesse caso. Um outro exemplo de falta de responsabilidade social e ambiental, combinada com a falta de uma efetiva gestão de riscos, foi o caso do rompimento de uma das barragens de uma mineradora, que deixou um rastro de destruição na cidade de Brumadinho, em Minas Gerais: casas, pousadas e sítios foram soterrados. A lama atingiu o rio Paraopeba, um dos afluentes do rio São Francisco; e além de ocasionar inúmeras mortes, o desastre causou uma catástrofe ambiental cujos danos são difíceis de mensurar.

Uma outra observação importante com base nas respostas dos participantes desta survey, foi a preocupação bastante evidente em relação a questão educacional e capacitação da mão de obra. Essa inquietude apareceu mais pronunciada entre os respondentes de países em desenvolvimento. Muitos dizem realizar ações que visam dar cursos e palestras para funcionários e comunidade local, visando tocar em 
questões ambientais e ensinar temas relacionados com saúde e segurança. Nota-se que, ainda que essas ações não parecem ser de caráter estratégico, elas podem fazer a diferença na segurança e qualidade durante o desenvolvimento de um projeto de construção civil. Sabe-se que este setor é um dos que mais emprega mão de obra com baixa qualificação, de acordo com a OIT (Organização Internacional do Trabalho), em 2001 mais de 33\% dos trabalhadores registrados na construção civil eram analfabetos funcionais. Todavia essa realidade parece estar melhorando nos últimos. Segundo dados do CBIC com base em informações da RAIS 2017 (Relação Anual de Informações Sociais) elaborada pelo MTE (Ministério do Trabalho e Emprego), em 2017, 45\% do estoque de trabalhadores na construção civil tem o ensino médio completo (Ver tabela 7). Com base nessas informações, percebe-se que as ações voltadas para a educação têm surtido algum efeito. Nesse aspecto, as empresas ligadas a projetos de construção civil, que realizam ações voltadas a educação têm tentado contribuir em elevar o nível de seus colaboradores, pois sabem que isso refletirá em melhora de produtividade e qualidade dos produtos gerados.

Tabela 8 - Estoque de trabalhadores na Construção Civil Segundo o grau de instrução - Brasil 2017*6

\begin{tabular}{|c|c|c|c|c|c|c|c|c|c|c|}
\hline Localidade & Analfabeto & $\begin{array}{c}\text { Até o } 5^{\circ} \text { ano } \\
\text { Incompleto do Ensino } \\
\text { Fundamental }\end{array}$ & $\begin{array}{c}5^{2} \text { ano Completo } \\
\text { do Ensino } \\
\text { Fundamental } \\
\end{array}$ & \begin{tabular}{|c|} 
Do $6^{\circ}$ ao $9^{\circ}$ ano \\
Incompleto do Ensino \\
Fundamental \\
\end{tabular} & $\begin{array}{c}\text { Ensino } \\
\text { Fundamental } \\
\text { Completo } \\
\end{array}$ & \begin{tabular}{|c|} 
Ensino \\
Médio \\
Incompleto \\
\end{tabular} & $\begin{array}{c}\text { Ensino } \\
\text { Médio } \\
\text { Completo } \\
\end{array}$ & $\begin{array}{c}\text { Educação } \\
\text { Superior } \\
\text { Incompleta } \\
\end{array}$ & $\begin{array}{c}\text { Educaçäo } \\
\text { Superior } \\
\text { Completa } \\
\end{array}$ & TOTAL $^{1}$ \\
\hline Rondônia & 60 & 592 & 370 & 1.107 & 1.079 & 1.047 & 6.409 & 183 & 400 & 11.249 \\
\hline Acre & 53 & 338 & 218 & 186 & 514 & 292 & 3.590 & 140 & 374 & 5.708 \\
\hline Amazonas & 73 & 878 & 548 & 1.498 & 2.043 & 1.727 & 11.176 & 490 & 1.201 & 19.661 \\
\hline Roraima & 58 & 176 & 200 & 347 & 819 & 331 & 2.196 & 74 & 177 & 4.379 \\
\hline Pará & 296 & 2.713 & 1.741 & 6.242 & 10.884 & 4.745 & 29.772 & 776 & 2.340 & 59.704 \\
\hline Amapá & 35 & 249 & 193 & 334 & 506 & 531 & 2.316 & 69 & 130 & 4.365 \\
\hline Tocantins & 92 & 1.119 & 477 & 1.287 & 1.448 & 1.234 & 6.046 & 221 & 559 & 12.489 \\
\hline Maranhäo & 342 & 2.083 & 1.475 & 4.692 & 6.541 & 2.301 & 18.193 & 427 & 1.340 & 37.405 \\
\hline Piaú & 396 & 2.383 & 1.762 & 3.003 & 3.554 & 1.764 & 6.333 & 282 & 811 & 20.375 \\
\hline Ceará & 975 & 5.797 & 3.253 & 7.147 & 11.115 & 3.822 & 24.845 & 1.318 & 3.112 & 61.437 \\
\hline Rio Grande do Norte & 405 & 2.544 & 1.773 & 2.392 & 3.428 & 2.102 & 11.638 & 393 & 1.196 & 25.878 \\
\hline Paraiba & 849 & 4.226 & 1.969 & 3.602 & 4.511 & 2.235 & 11.272 & 569 & 1.143 & 30.406 \\
\hline Pernambuco & 691 & 6.332 & 3.942 & 7.762 & 9.572 & 4.940 & 29.399 & 1.456 & 3.801 & 67.932 \\
\hline Alagoas & 302 & 3.285 & 1.030 & 2.173 & 2.148 & 1.097 & 8.403 & 366 & 769 & 19.578 \\
\hline Sergipe & 164 & 1.798 & 1.240 & 2.476 & 2.613 & 1.597 & 6.937 & 535 & 1.050 & 18.421 \\
\hline Bahia & 663 & 7.080 & 4.110 & 10.295 & 11.516 & 9.110 & 59.933 & 1.619 & 5.701 & 110.683 \\
\hline Minas Gerais & 1.431 & 18.604 & 14.049 & 26.357 & 35.008 & 21.035 & 96.796 & 4.932 & 13.410 & 231.728 \\
\hline Espirito Santo & 247 & 2.083 & 1.687 & 4.075 & 6.140 & 3.831 & 18.078 & 705 & 1.925 & 38.790 \\
\hline Rio de Janeiro & 839 & 8.210 & 7.504 & 14.336 & 25.254 & 12.145 & 79.568 & 3.795 & 10.719 & 162.528 \\
\hline Sao Paulo & 2.628 & 31.083 & 24.230 & 45.921 & 92.312 & 42.590 & 232.666 & 13.381 & 44.242 & 529.786 \\
\hline Paraná & 610 & 6.158 & 6.041 & 11.715 & 19.801 & 11.411 & 56.840 & 2.255 & 6.498 & 121.402 \\
\hline Santa Catarina & 654 & 3.902 & 4.078 & 7.963 & 17.147 & 6.441 & 42.959 & 2.178 & 4.759 & 90.112 \\
\hline Rio Grande do Sul & 505 & 5.423 & 5.369 & 16.359 & 20.102 & 10.563 & 47.712 & 3.265 & 5.125 & 114.460 \\
\hline Mato Grosso do Sul & 132 & 1.240 & 1.103 & 3.116 & 3.797 & 2.129 & 9.862 & 513 & 1.253 & 23.150 \\
\hline Mato Grosso & 271 & 2.110 & 1.231 & 3.117 & 4.143 & 3.354 & 15.353 & 681 & 1.761 & 32.035 \\
\hline Goiás & 548 & 4.390 & 3.585 & 7.325 & 9.404 & 6.124 & 26.724 & 1.449 & 3.851 & 63.426 \\
\hline Distrito Federal & 237 & 3.293 & 1.669 & 3.785 & 6.181 & 3.798 & 20.477 & 1.029 & 4.137 & 44.704 \\
\hline TOTAL BRASIL & 13.556 & 128.089 & 94.847 & 198.612 & 311.580 & 162.296 & 885.493 & 43.101 & 121.784 & 1.961 .791 \\
\hline
\end{tabular}

Fonte: Bando de Dados - CBIC (2017)

${ }^{6} \mathrm{O}$ total de trabalhadores contabilizam mestres e doutores.

Dados de acordo com a nova Classificação Nacional de Atividades Econômicas - CNAE2.0/IBGE de novembro/2006. 
As Tabelas 8 e 9 mostram a porcentagem de respondentes engajados em cada tipo de ação, separados por tipo de projeto de construção civil. Na Tabela 8 é mostrada a visão geral, enquanto a Tabela mostra a realidade do Brasil. Globalmente, a maior parte dos respondentes representantes das empresas que atuam com projetos residenciais e comerciais atuam mais em atividades relacionadas a envolvimento comunitário (30\%). No Brasil essa relação também é verdadeira (31\% dos respondentes desse segmento de projeto). Nos envolvidos com projetos Estruturais, globalmente, as atividades mais encabeçadas são relacionadas a envolvimento comunitário/ desenvolvimento e meio ambiente (ambas as categorias com $24 \%$ dos respondentes). No Brasil, predomina ainda o envolvimento comunitário nesses tipos de projetos (24\%). Nos projetos Hidráulicos, predomina o envolvimento comunitário a nível global (22\%) e meio ambiente no Brasil (24\%). Nos projetos elétricos tanto no âmbito global quanto no Brasil predominam o envolvimento comunitário e o desenvolvimento, com $24 \%$ e $31 \%$ respectivamente. No segmento de consultoria e perícia de projetos de engenharia, a nível global ficam igualados os níveis de atuação em envolvimento comunitário, práticas de trabalho e práticas justas de operação (todos com $20 \%$ ), enquanto no Brasil há equilíbrio de valores em relação ao envolvimento comunitário e práticas de trabalho $(21 \%)$. Nos atuantes em projetos de Estruturas Metálicas, a maioria dos respondentes no âmbito global realizam ações relacionadas ao meio ambiente (26\%), enquanto no Brasil as ações relacionadas a envolvimento comunitário e desenvolvimento, meio ambiente, direitos humanos e questões de consumidores se igualam em $20 \%$. 
Tabela 9 - Categorias de ações de Responsabilidade Social versus tipo de projetos - Todos os respondentes

\begin{tabular}{|c|c|c|c|c|c|c|}
\hline GERAL & $\begin{array}{c}\text { Envolvimento } \\
\text { comunitário e } \\
\text { desenvolvimento }\end{array}$ & Meio ambiente & $\begin{array}{l}\text { Práticas de } \\
\text { trabalho }\end{array}$ & Direitos humanos & $\begin{array}{c}\text { Práticas justas de } \\
\text { operação }\end{array}$ & $\begin{array}{l}\text { Questões de } \\
\text { consumidores }\end{array}$ \\
\hline $\begin{array}{l}\text { Projetos Residenciais e } \\
\text { Comerciais }\end{array}$ & $30 \%$ & $22 \%$ & $16 \%$ & $11 \%$ & $13 \%$ & $9 \%$ \\
\hline Projetos Estruturais & $24 \%$ & $24 \%$ & $16 \%$ & $9 \%$ & $13 \%$ & $13 \%$ \\
\hline Construção Civil & $28 \%$ & $18 \%$ & $21 \%$ & $9 \%$ & $15 \%$ & $9 \%$ \\
\hline Projetos Hidráulicos & $22 \%$ & $20 \%$ & $13 \%$ & $15 \%$ & $17 \%$ & $13 \%$ \\
\hline Projetos Elétricos & $24 \%$ & $22 \%$ & $13 \%$ & $9 \%$ & $20 \%$ & $11 \%$ \\
\hline Consultoria e Perícia & $20 \%$ & $17 \%$ & $20 \%$ & $10 \%$ & $20 \%$ & $13 \%$ \\
\hline $\begin{array}{l}\text { Projetos de Estruturas } \\
\text { Metálicas }\end{array}$ & $22 \%$ & $26 \%$ & $13 \%$ & $9 \%$ & $13 \%$ & $17 \%$ \\
\hline
\end{tabular}

Fonte: A autora

Tabela 10 - Categorias de ações de Responsabilidade Social versus tipo de projetos - Respondentes do Brasil

\begin{tabular}{|c|c|c|c|c|c|c|}
\hline GERAL & $\begin{array}{l}\text { Envolvimento } \\
\text { comunitário e } \\
\text { desenvolvimento }\end{array}$ & Meio ambiente & $\begin{array}{l}\text { Práticas de } \\
\text { trabalho }\end{array}$ & Direitos humanos & $\begin{array}{l}\text { Práticas justas de } \\
\text { operação }\end{array}$ & $\begin{array}{l}\text { Questões de } \\
\text { consumidores }\end{array}$ \\
\hline $\begin{array}{l}\text { Projetos Residenciais e } \\
\text { Comerciais }\end{array}$ & $30 \%$ & $22 \%$ & $16 \%$ & $11 \%$ & $13 \%$ & $9 \%$ \\
\hline Projetos Estruturais & $24 \%$ & $24 \%$ & $16 \%$ & $9 \%$ & $13 \%$ & $13 \%$ \\
\hline Construção Civil & $28 \%$ & $18 \%$ & $21 \%$ & $9 \%$ & $15 \%$ & $9 \%$ \\
\hline Projetos Hidráulicos & $22 \%$ & $20 \%$ & $13 \%$ & $15 \%$ & $17 \%$ & $13 \%$ \\
\hline Projetos Elétricos & $24 \%$ & $22 \%$ & $13 \%$ & $9 \%$ & $20 \%$ & $11 \%$ \\
\hline Consultoria e Perícia & $20 \%$ & $17 \%$ & $20 \%$ & $10 \%$ & $20 \%$ & $13 \%$ \\
\hline $\begin{array}{l}\text { Projetos de Estruturas } \\
\text { Metálicas }\end{array}$ & $22 \%$ & $26 \%$ & $13 \%$ & $9 \%$ & $13 \%$ & $17 \%$ \\
\hline
\end{tabular}


O motivo predominante que levou as empresas a investirem em ações de responsabilidade social em seus projetos no Brasil, foi por acreditar que podem, de forma verdadeira, fazer a diferença nas comunidades dos entornos das obras. Na Ásia e na América do Norte essa mesma motivação ficou equilibrada com a meta de melhorar a imagem institucional, enquanto no Oriente Médio o percentual se iguala com o objetivo de apenas cumprir requisitos legais e/ou auditorias (Figura 20).

Figura 20 - Motivações das empresas para investir em ações de Responsabilidade Social em seus projetos

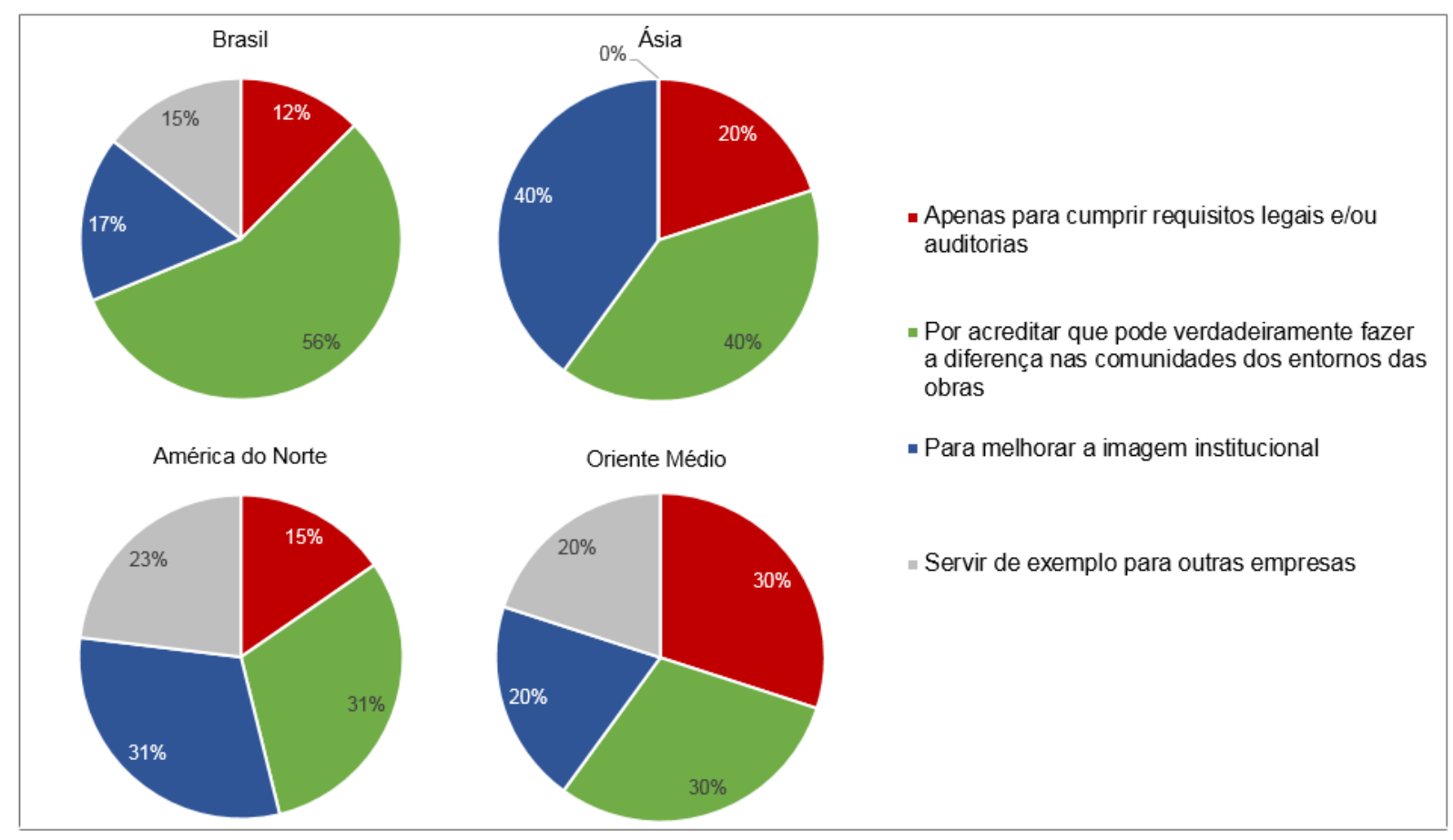

Fonte: A autora

A dificuldade mais indicada como impedimento à implementação de ações de responsabilidade social em projetos de construção civil foi a falta de interesse no tema por parte das empresas do setor da construção civil; em segundo lugar, a falta de apoio por parte dos gestores. Há um peso para falta de recursos financeiros, todavia, o motivo representa apenas $17,2 \%$ das empresas que não investem em ações sociais, conforme evidenciado na Figura 21. 
Figura 21 - Principais dificuldades para implantação de ações de Responsabilidade Social nos projetos

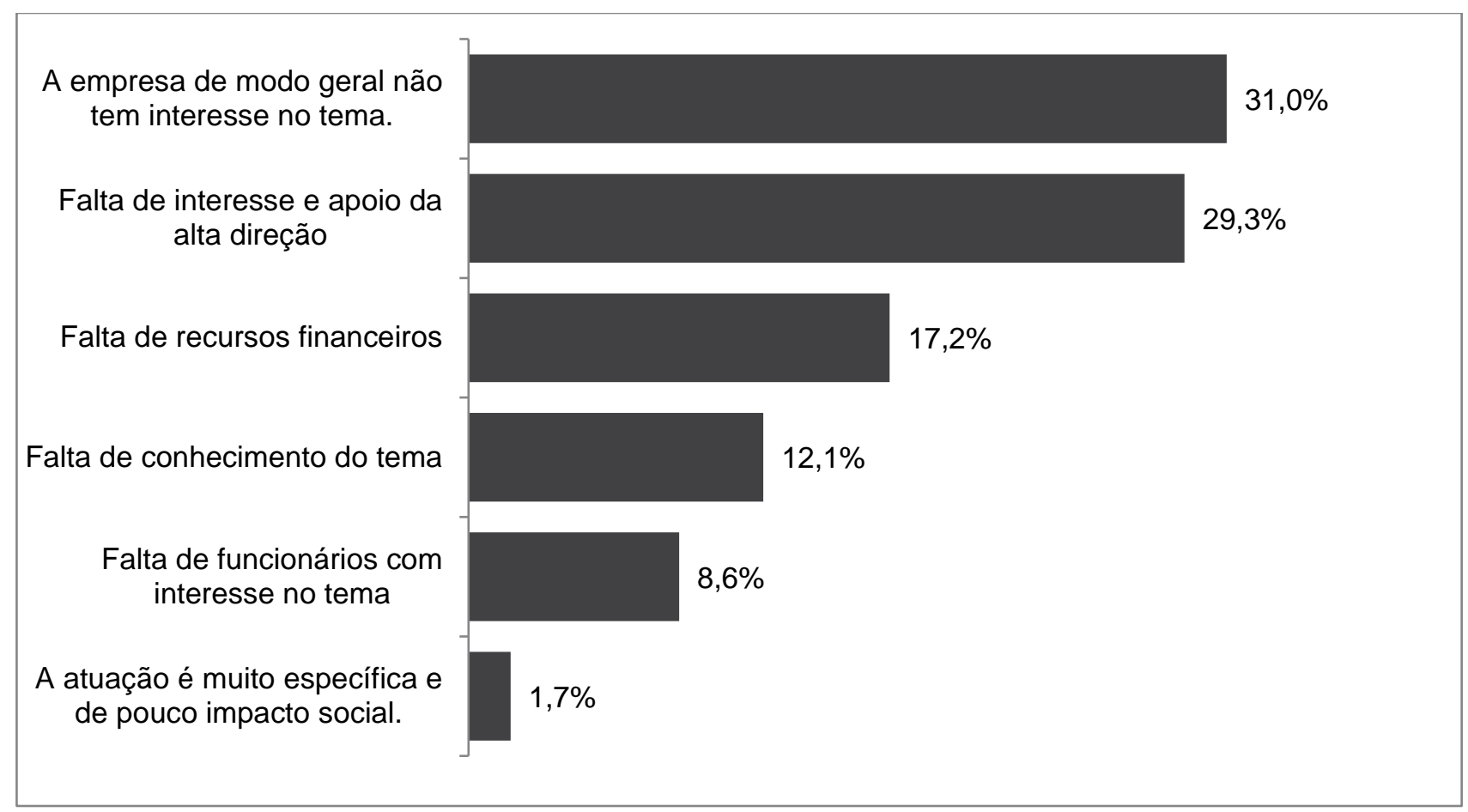

Fonte: A autora

Verificou-se que apesar de uma grande porção das empresas considerarem que as ações sociais integram a visão estratégica em seus projetos $(86 \%$ dos respondentes), conforme Figura 22, as práticas formais de inclusão do tema na empresa, como por exemplo, a existência de um comitê responsável e a inclusão das ações no orçamento e planejamento dos projetos, ainda não são realmente colocadas em prática pela maior partes das empresas, visto que em $75 \%$ dos casos a direção é diretamente responsável pelas decisões da área, ficando a cargo de um comitê em apenas $20 \%$ das empresas (Figura 25). Nota-se que existe uma relação das empresas que dizem que as ações de responsabilidade social integram sua visão estratégica com aquelas que incluem essas ações no planejamento e orçamento dos projetos, uma vez que das empresas que responderam que "sim", integração as ações de responsabilidade social à visão estratégica da companhia, 67\% delas também contemplas essas ações no planejamento e orçamento dos projetos (Figura 23), enquanto apenas $51 \%$ de todos os respondentes, o fazem. (Figura 24). 
Figura 22 - As ações de Responsabilidade Social nos projetos integram a visão estratégica da empresa?

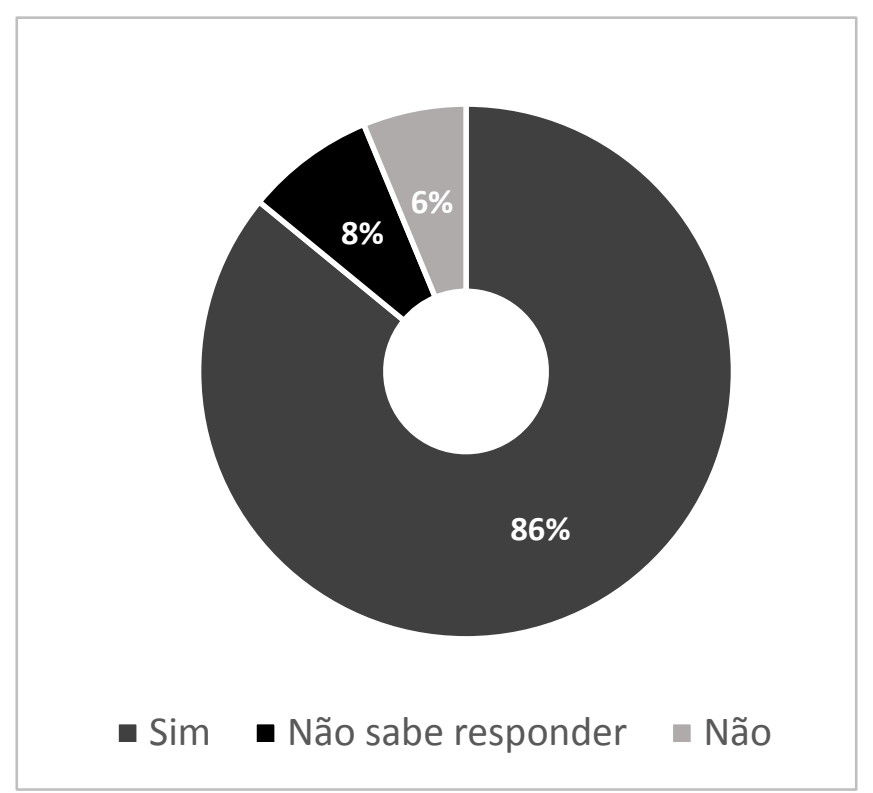

Fonte: A autora
Figura 7 - As ações de Responsabilidade Social estão contempladas no planejamento e orçamentos dos projetos? - Para empresas que responderam "Sim" sobre a integração com a visão estratégica

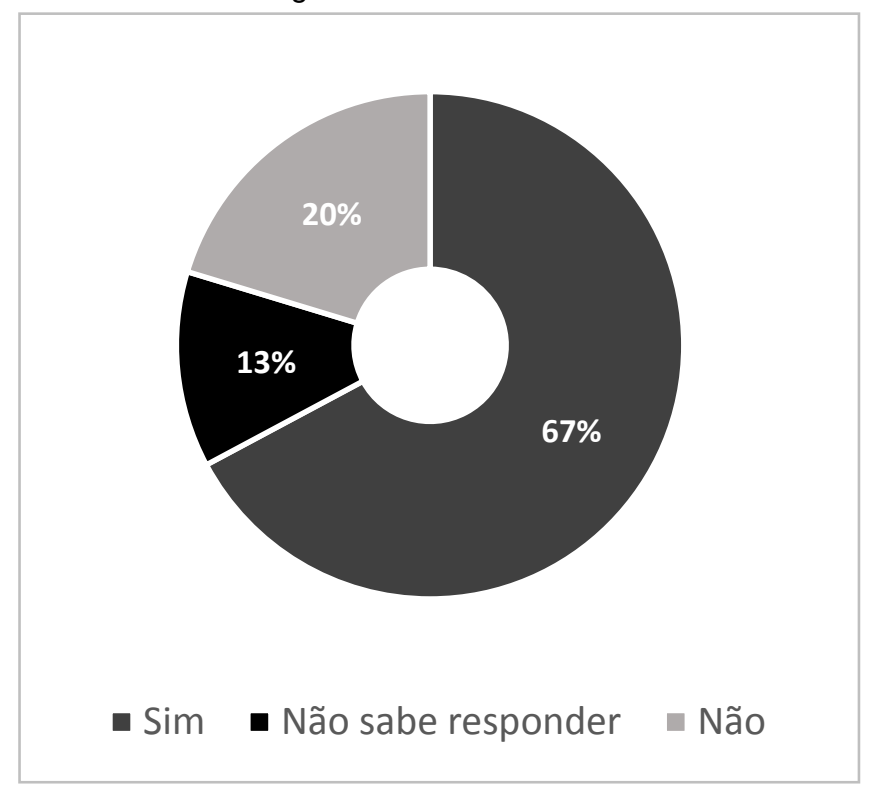

Fonte: A autora

Figura 24 - As ações de Responsabilidade Social estão contempladas no planejamento e orçamento dos projetos? - Todos os respondentes

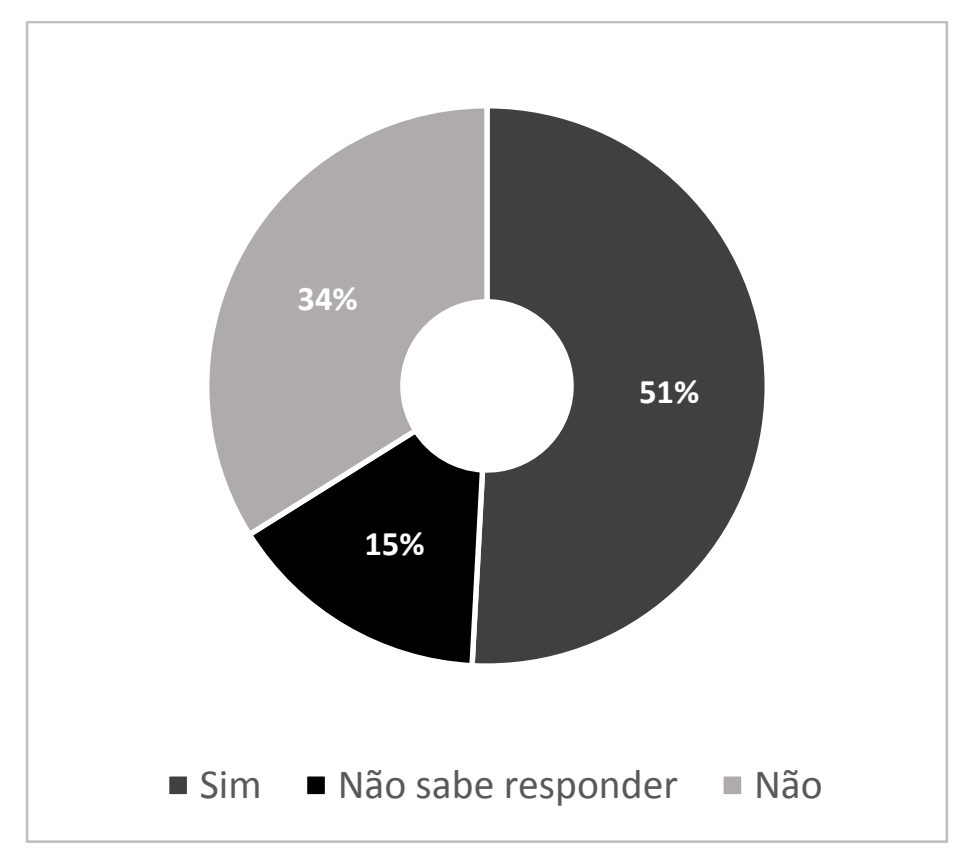

Fonte: A autora 
Figura 25 - Responsáveis por decidir as ações de Responsabilidade Social dos projetos

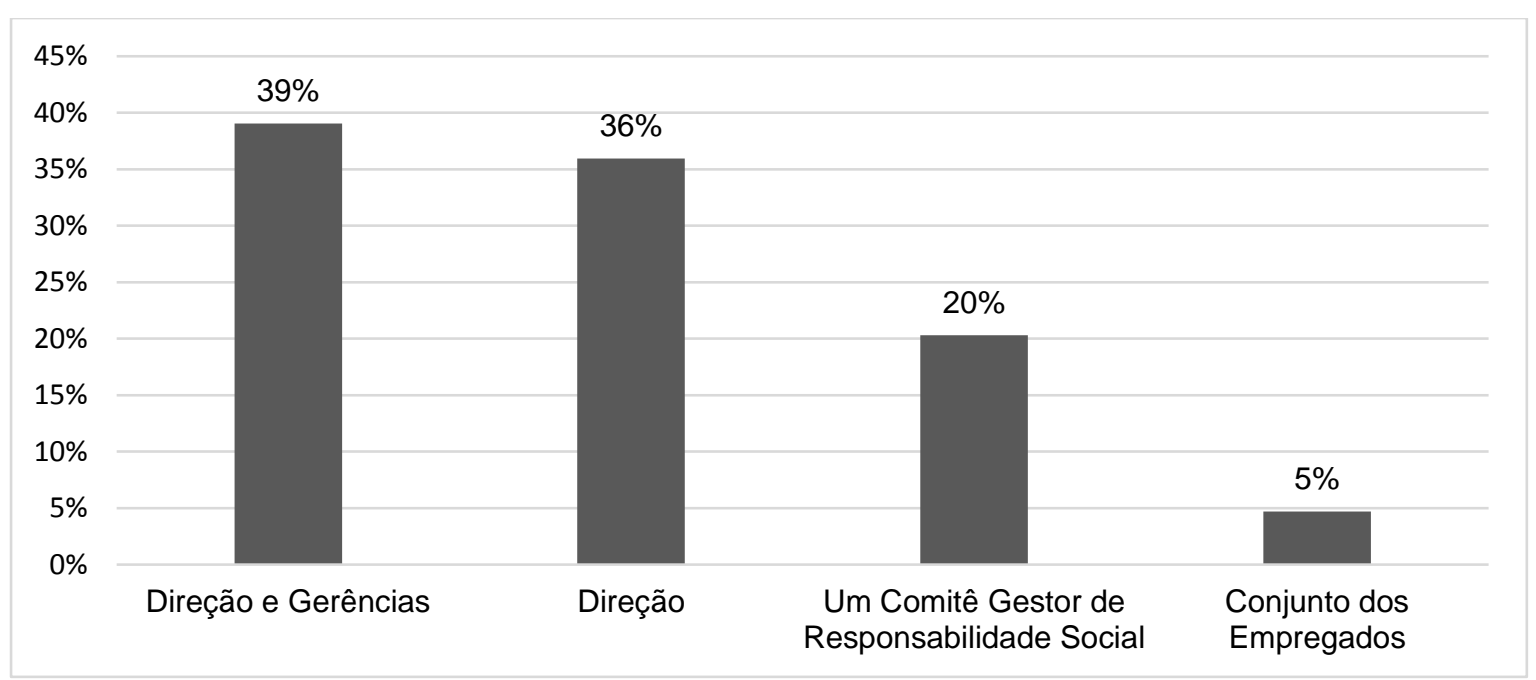

Fonte: A autora

Em relação ao quanto é gasto anualmente com ações de responsabilidade social nos projetos de construção civil, verificou-se que os investimentos mais expressivos (acima de meio milhão) representam $21 \%$ das empresas, porém as empresas que investem menos de $\mathrm{R} \$ 50$ mil somam $37 \%$ do total e há uma faixa de $19 \%$ de empresas que não investiram no ano de 2017. Além disso, 14\% investiram menos do que no ano anterior (Figuras 26 e 27).

Figura 26 - Volume de investimentos em ações de Responsabilidade Social nos projetos no ano de 2017 (em Reais)

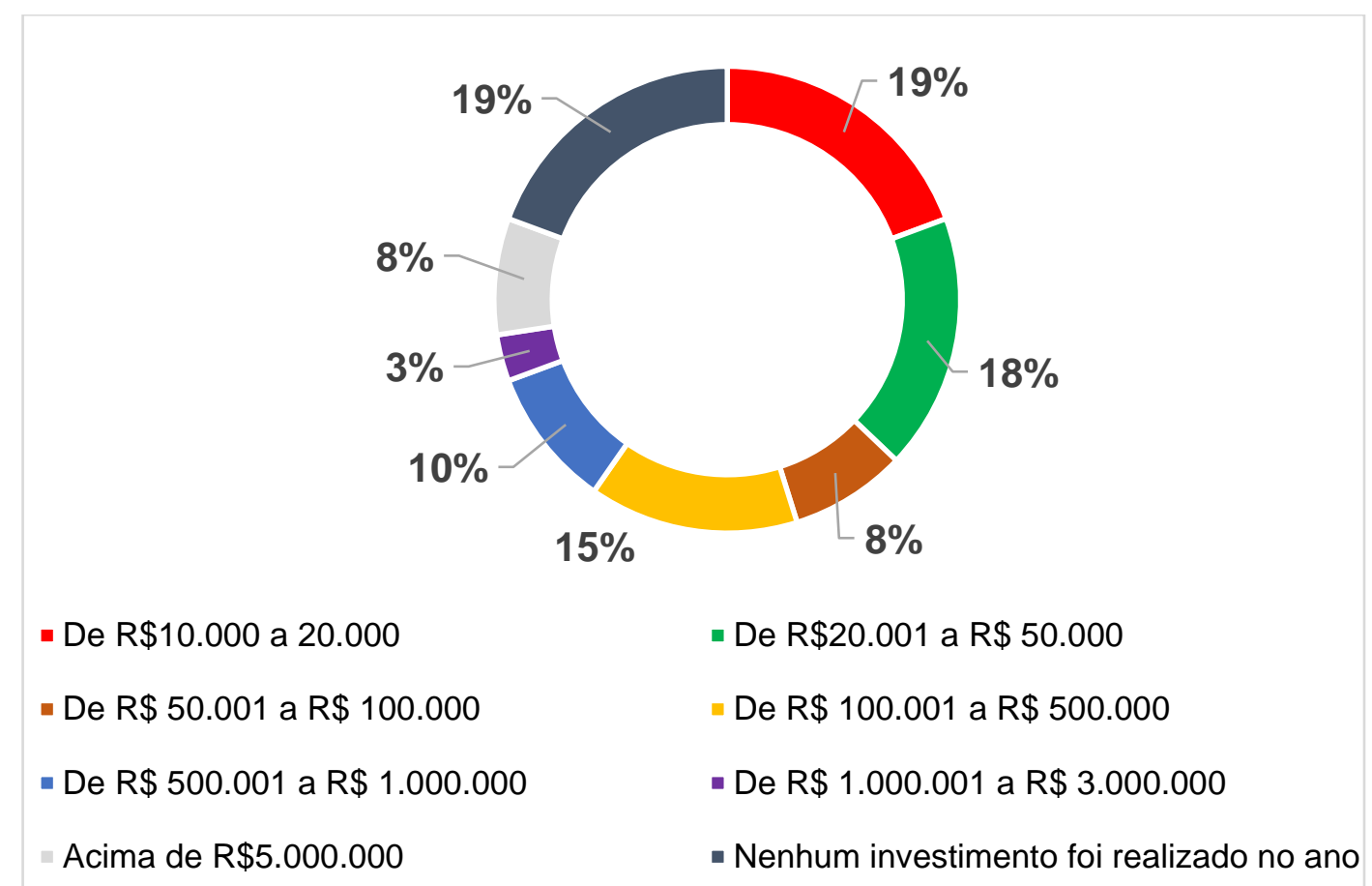

Fonte: A autora 
Figura 27 - Comparação dos volumes de investimentos com o ano de 2016

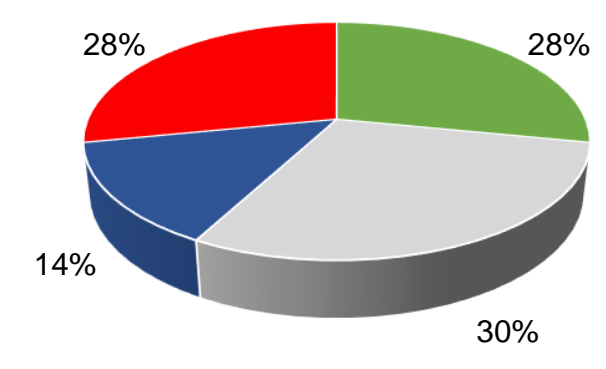

- Mais investimentos que em 2016

O mesmo volume de recursos que em 2016

- Menos recursos que em 2016

- Não sabe responder

Fonte: A autora

As principais parceiras das ações sociais nos projetos de construção civil são as ONGs e as OSCIPs. O termo ONG significa Organização Não-Governamental. Estas são também conhecidas como entidades do Terceiro Setor, o qual trabalha com ações de interesse público não vinculadas ao governo. Apesar de o termo não ter uma definição pela legislação brasileira, ele é utilizado para identificar entidades privadas sem fins lucrativos que existem sob as formas jurídicas de associação ou fundação. Uma OSCIP - Organização da Sociedade Civil de Interesse Público, além de não buscar o lucro contábil como qualquer organização pertencente ao Terceiro Setor, também é reconhecida por um ou mais organismos públicos, como Prefeituras, Estado ou Federação. Em outras palavras, toda e qualquer entidade privada que exerça atividades intermediárias entre a sociedade e o Estado, sem objetivo de lucro, poderá ser considerada uma ONG, a qual pode ter, ou não, a qualificação de OSCIP.

O próprio governo aparece como um parceiro das ações de responsabilidade social em projetos de construção civil, junto com associações de moradores; institutos e fundações empresariais; universidades; empresas; escolas; sindicatos; hospitais e centros de saúde; creches; organizações religiosas; associações de funcionários; Sesi/Senai. A Figura 28 mostra os percentuais de respostas em cada tipo de parceria. Note-se que os respondentes poderiam selecionar mais de um parceiro.

Através do coeficiente de correlação de Pearson, verificou-se que empresas que têm parceria com hospitais e clínicas de saúde também fazem parceria com creches (Coeficiente: 0,65). 
Figure 28 - Parceiros para a realização de ações de Responsabilidade Social nos projetos

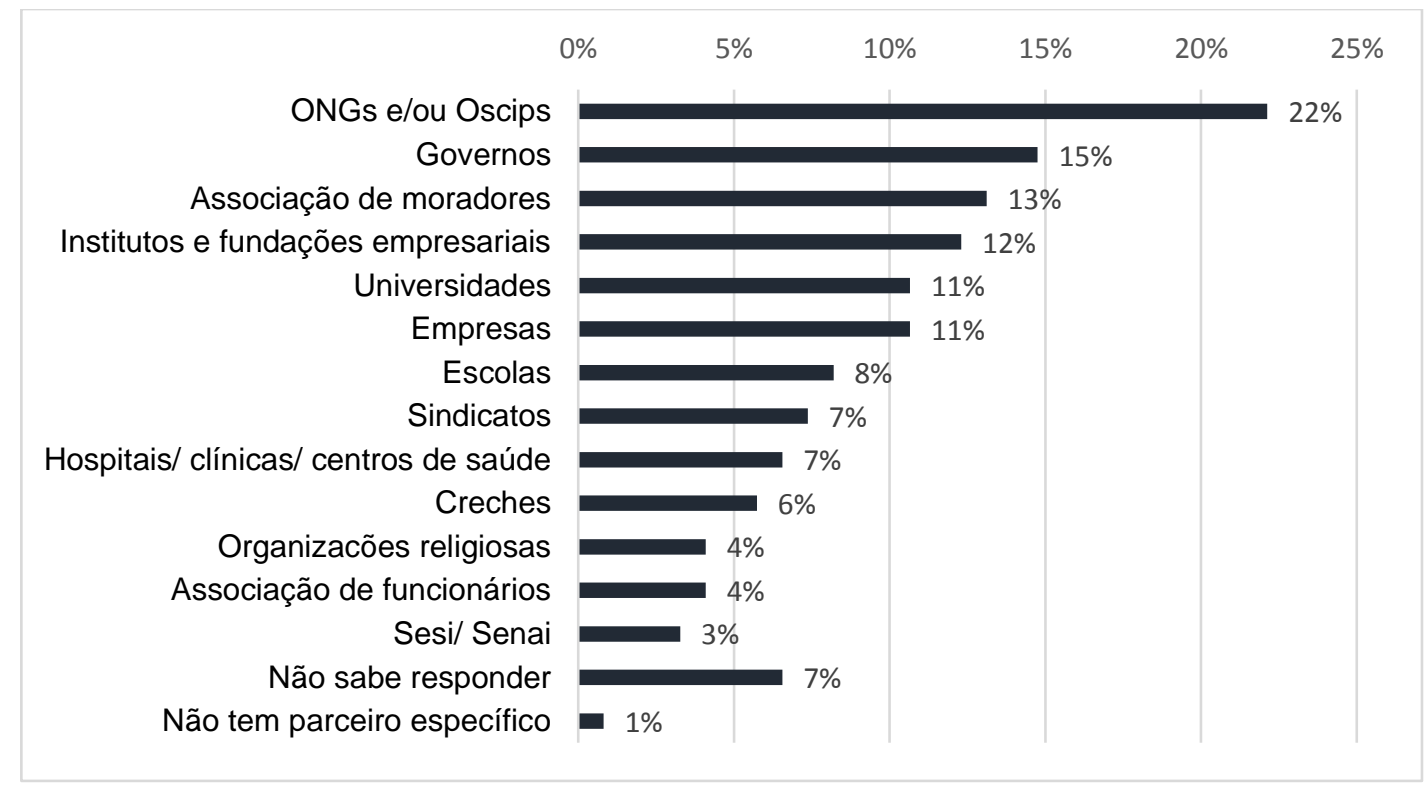

Fonte: A autora

A maior preocupação das empresas em seus projetos de construção civil é majoritariamente relacionada com a comunidade local. Suas ações, de modo geral, visam minimizar os transtornos que as obras causam (Figura 29). Há uma preferência em priorizar escolas e ONGs locais, bem como ações voltadas para os próprios colaboradores (Figura 30). Esse resultado vem de acordo com o que preconiza Costa (2002) em seu trabalho, no qual o autor relaciona as três esferas para as quais empresas privadas geralmente destinam seus investimentos sociais: (1) para o público interno da organização, sendo característica desse tipo de investimento a melhoria das condições de trabalho, estrutura salarial, alimentação fornecida e benefícios aos empregados; (2) ações focadas para o público localizado no entorno de suas atividades, como, por exemplo, a manutenção de áreas de esporte e lazer, escolas e outras instalações de provisão de políticas sociais; (3) os recursos e ações são direcionados na luta por direitos sociais, independentemente do público-alvo estar ou não ligado diretamente à empresa ou às comunidades nas quais opera. Sendo assim, pode-se dizer que as ações de responsabilidade social em projetos de construção civil, seguem o mesmo padrão das ações realizadas em empresas privadas de outros setores. 
Figura 29 - Critério para escolha dos beneficiários das ações de Responsabilidade Social nos projetos

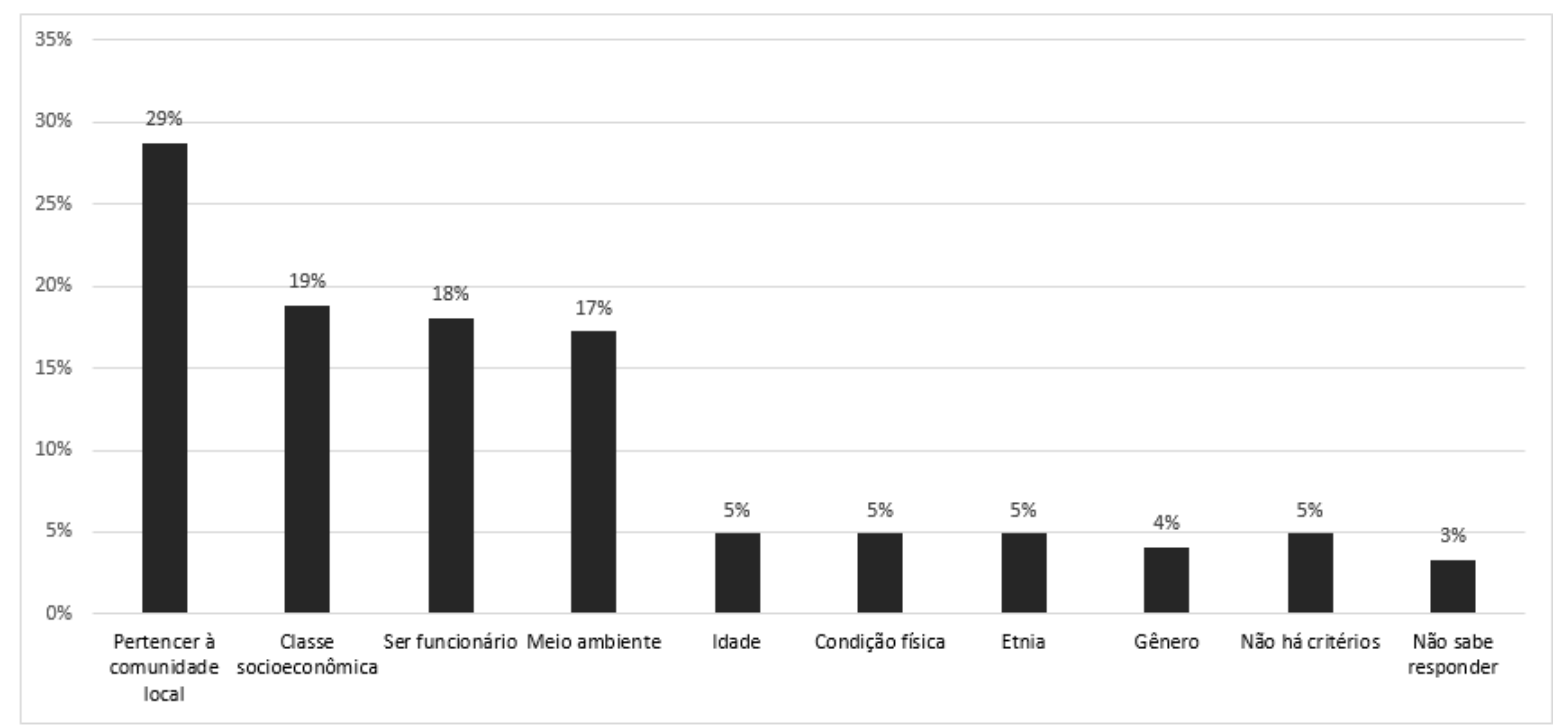

Fonte: A autora

Figura 8 - Para quem são destinadas as ações de Responsabilidade Social nos projetos

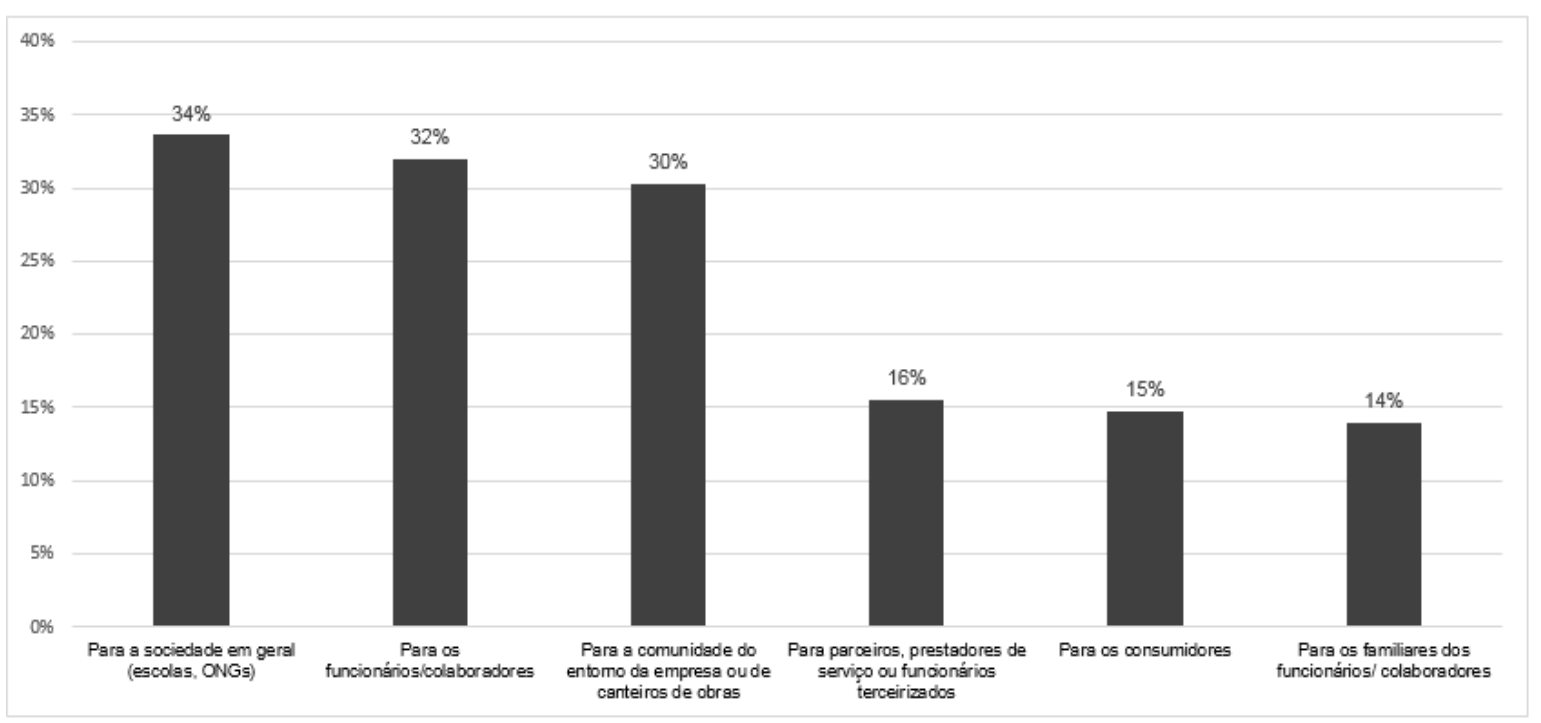

Fonte: A autora

Os coeficientes de Pearson revelam que as empresas que declaram investir em responsabilidade social para fazer diferença nas comunidades nos entornos das obras, destinam ações para escolas e ONGS (coeficiente: 0,63), e estas têm forte comunicação interna (coeficiente: 0,58) e se preocupam em melhorar a imagem institucional (coeficiente: 0,59). Adicionalmente, essas empresas costumam divulgar suas ações através da internet (coeficiente: 0,58). 
Estudos clássicos de negócios preconizam que o único propósito de uma empresa é obter lucro e devolver rendimentos aos acionistas (FRIEDMAN, 1970). No entanto, à medida que os estudos de negócios evoluíram, os acadêmicos começaram a perceber que era necessária uma abordagem mais abrangente, e assim surge a "teoria dos stakeholders". Essa teoria sugere que as corporações são responsáveis não apenas por atender às necessidades dos acionistas, mas também por outras partes interessadas, incluindo: funcionários, fornecedores, clientes, financiadores e a sociedade em geral (FREEMAN; CAVUSGIL, 1984). Muitas vezes, para o consumidor, existe um contrato implícito entre um negócio e a sociedade. A responsabilidade social nas empresas implica que estas têm um compromisso para com a sociedade. Assim, há evidências crescentes de que implementar responsabilidade social e sustentabilidade como metas e enxergar sua integração à visão estratégica do negócio como uma oportunidade e não como um fardo pode ser um dos principais impulsionadores da inovação atual e do sucesso futuro dos negócios e seus projetos (NIDUMOLU; PRAHALAD; RANGASWAMI, 2009). Além disso, há um número crescente de relatórios e programas sugerindo que os consumidores exigem iniciativas de Responsabilidade Social das empresas, e estender essas exigências aos seus projetos é uma necessidade para estes sejam competitivos e bemsucedidos.

Ainda que não exista um consenso sobre a definição de "sucesso" em projetos, (CARVALHO; RABECHINI JR., 2011) afirmam que alcançar êxitos em relação a um determinado projeto, depende do ponto de vista de quem analisa. Diferentes perspectivas e expectativas das partes interessadas vão levar a avaliações diferentes em relação ao desenvolvimento e sucesso do projeto, logo é necessário atender um "ótimo global", estabelecido por consenso entre as partes. Sendo assim os conceitos de Responsabilidade Social devem vir para integrar à noção de sucesso em projetos, uma vez que suas premissas estão inegavelmente relacionadas com questões fundamentais para os projetos de construção civil, como a gestão de riscos, de recursos humanos e stakeholders.

Umas das formas que clientes utilizam para avaliar as empresas em relação à sua atuação e qualidade de seus produtos e serviços são as certificações. Especialmente quando se fala de uma forma de mensurar o desempenho em 
sustentabilidade, é difícil fazer uma adequada avaliação. Em muitos casos desenvolver estratégias de medição de desempenho parece difícil de ser implementada. Todavia pesquisadores sugerem que uma abordagem que fornece a estrutura necessária para avaliar o desempenho de organizações e/ou projetos são as certificações, tanto em gestão ambiental (ISO 14001), saúde e segurança ocupacional (OHSAS 18001), responsabilidade social (ISO 16001 e SA 8000) e a diretriz responsabilidade social (ISO 26 000). Essas normas apresentam princípios e técnicas de gestão, elas podem ser implantadas conjuntamente, com o objetivo de alcançar qualidade nos processos produtivos, produzir com menores níveis de agressão ao meio ambiente, promovendo o desenvolvimento sustentável e preocupando-se com a qualidade de vida de seus colaboradores(ASIF; SEARCY, 2014; ELENA WINDOLPH; SCHALTEGGER; HERZIG, 2014).

Assim como é necessário se acompanhar e avaliar as estratégias e práticas empresariais e de um projeto para que estes sejam competitivos e lucrativos, também é indispensável se conhecer e utilizar indicadores para identificar necessidades e apontar deficiências das iniciativas de responsabilidade social nos projetos de construção civil.

Um dos objetivos específicos desta pesquisa foi identificar quais as referências normativas, indicadores e métodos de mensuração de desempenho social são conhecidos, implantados ou não implantados, porém que despertam o interesse de das organizações dos respondentes para aplicação em seus projetos. Os dados foram compilados e exibidos por meio da Figura 31. Ficou evidente o nível de desconhecimento em relação a todos os itens expostos, exceto as normas ISO 14.001 e 18.001, que além de mais conhecidas são também as mais implantadas nos projetos. Todos os outros indicadores e normas têm um nível baixíssimo de implantação, em média 4\%, enquanto o nível de desconhecimento em relação a estes gira em torno de $51 \%$. Já o interesse em implantar todas das normas e indicadores é de $20 \%$. Acredita-se que o alto índice de desconhecimento em relação aos sistemas de gestão, se deve ao fato de que a maioria dos respondentes atuam em áreas mais técnicas da Engenharia. Os participantes desta pesquisa, de modo geral, em sua maioria são profissionais com mais de dez anos de experiência profissional, conforme mostra a Figura 32. 
Figura 31 - Nível de conhecimento em referências normativas, indicadores e métodos de mensuração de desempenho social

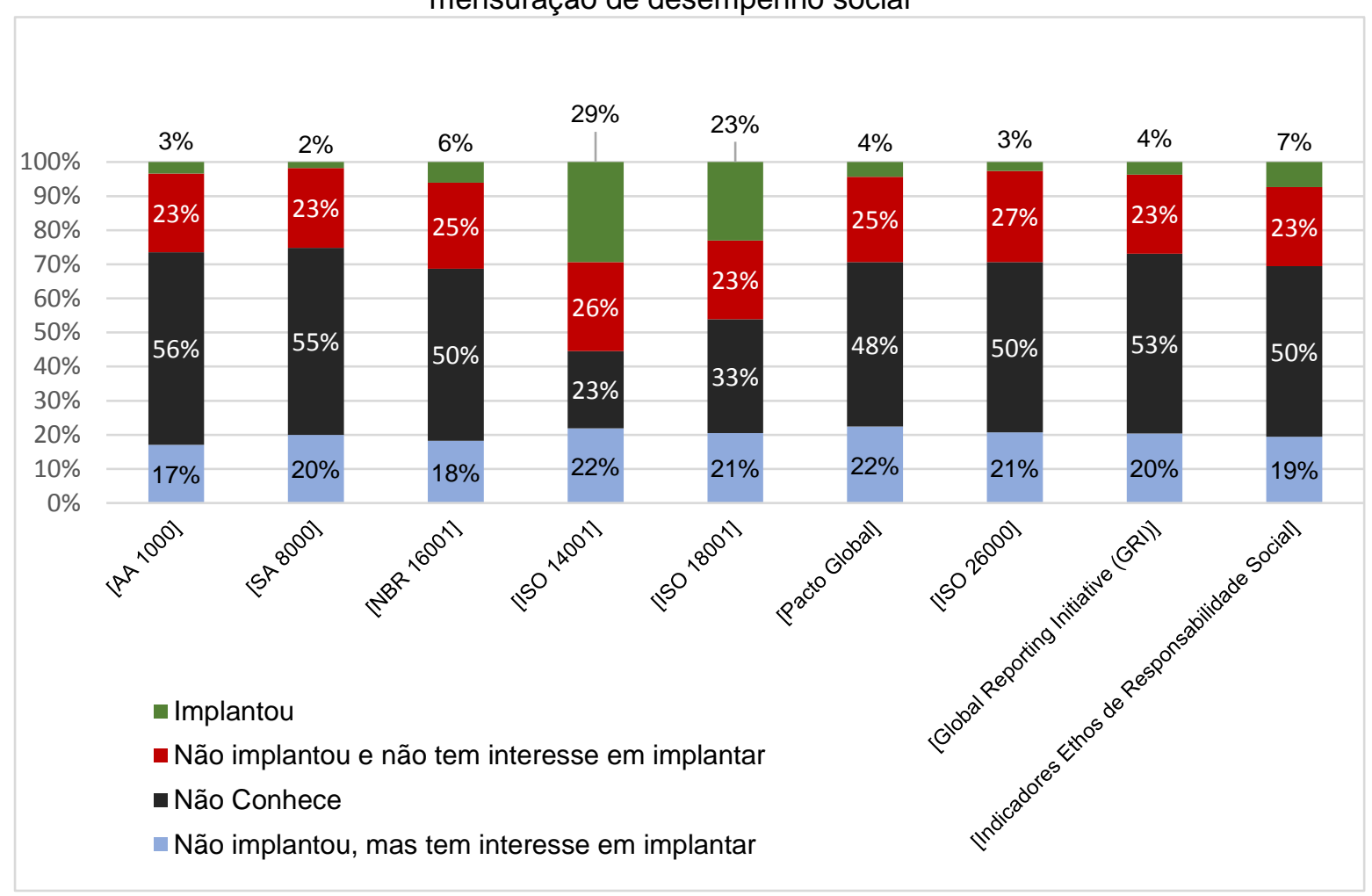

Fonte: $\bar{A}$ autora

Figura 32 - Perfil profissional dos participantes da pesquisa

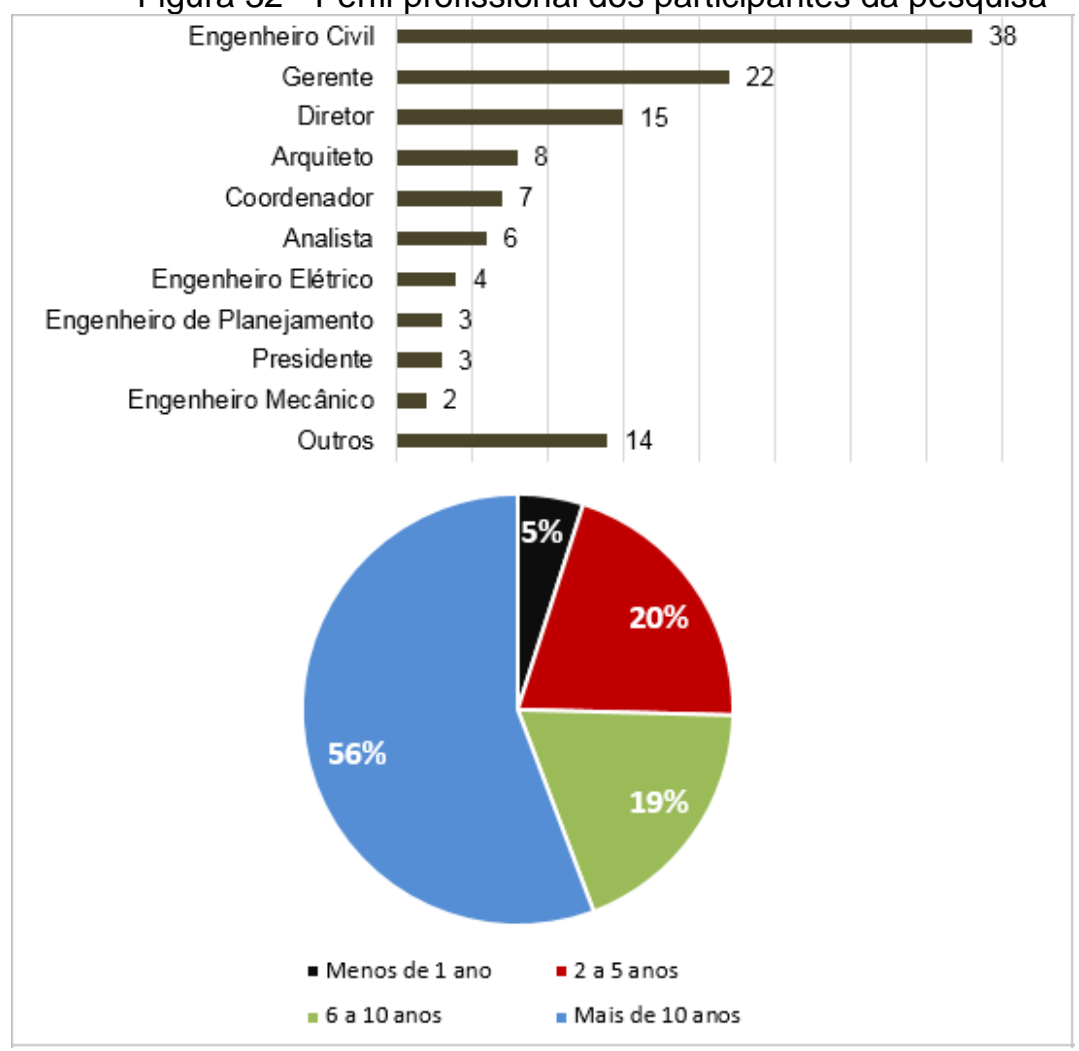

Fonte: A autora 


\section{CONSIDERAÇÕES FINAIS}

Nesse capítulo são apresentadas as considerações finais em relação aos objetivos dessa pesquisa, às contribuições e às limitações, bem como às recomendações de trabalhos futuros.

\subsection{Revisão Sistemática da Literatura}

Essa etapa da pesquisa teve como principal achado a confirmação de que o tema responsabilidade social em projetos de construção civil é um tema relevante, uma vez que o número de publicações vem crescendo continuamente desde 2008.

As abordagens metodológicas apresentadas pelos artigos foram variadas, todavia, a mais comum foi a revisão bibliográfica, porém não sistemática. Grande parte das abordagens de revisão de literatura foram de compilações de conceitos. Em seguida, a abordagem exploratória qualitativa baseada em estudo de casos, pois essa metodologia vem de encontro com a realidade de projetos de construção civil, uma vez que nessa abordagem é possível ir a campo enquanto o fato acontece para estudá-lo.

Através da análise de conteúdo, foi possível verificar que o conhecimento dentro da temática de responsabilidade social em projetos de construção permite múltiplos enfoques e metodologias. Trabalhos desenvolvidos em vários países com realidades distintas contribuíram para a evolução do tema. O Brasil, ainda que seja um país com dimensões continentais, ainda não se destacou entre os que mais contribuíram com 0 assunto.

Notou-se que os artigos encontrados seguem a lógica de projetos, no qual existe uma concepção, um planejamento, construção e operação; e que os artigos analisados, cada um deles, trata de alguma das fases do projeto (iniciação, planejamento, execução ou encerramento), estes trazem enfoques específicos e metodologias interessantes. 


\subsection{A Survey e a Contribuição da Pesquisa}

A principal contribuição da presente pesquisa foi fazer um panorama sobre como empresas ligadas a projetos de construção civil desenvolvem e operacionalizam o tema responsabilidade social em seus projetos. Por meio da survey, foi possível verificar que o termo é conhecido pela maioria dos respondentes, no entanto, que é limitado o entendimento do seu significado, estando muitas vezes restrito a um sentido comunitário e ambiental. As ações realizadas ainda estão muito focadas nos entornos das obras, porém as empresas alegam, em sua maioria, atuarem com ações de responsabilidade social nos projetos por acreditar que verdadeiramente podem fazer a diferença no local onde o projeto acontece, ou seja, as práticas seguem uma tendência empresarial mundial de atuar fortemente na comunidade onde está inserida.

Alguns pesquisadores consideram que as ações são isoladas, muito voltadas para atividades ambientais, imaturas e baseadas apenas em fazer o que é obrigatório e operacional, todavia, a pesquisa mostrou que apenas uma pequena parcela atua com o mero objetivo de atender requisitos legais e/ou auditorias. A maior parte dos respondentes acreditam que as ações de responsabilidade social nos projetos fazem parte da estratégia da empresa, porém isso se mostra incoerente quando a maior parte das empresas não possui um comitê específico para atuar no tema e deixando todas as ações a cargo da gerência e direção (que muitas vezes tem um foco no lucro e não em questões socias).

Os stakeholders dos projetos de construção civil são bastante diversos, compreendendo desde os trabalhadores das obras, comunidades nos entornos das atividades e até empresários, engenheiros e projetistas. Essa grande diversidade de pessoas com diferentes interesses e habilidades, que coordenam um conjunto de atividades desiguais, ainda que inter-relacionadas, traz uma inerente complexidade, uma gama de riscos.

Em se tratando de gestão de riscos e ações de responsabilidade social, verificouse que nenhum dos respondentes fez uma associação direta ao desenvolvimento de ações de responsabilidade social como uma forma de resguardar os projetos contra os riscos. Possivelmente, isso acontece pois falta a disseminação de outros significados de responsabilidade social. É necessário educar as partes interessadas 
dos projetos para realizar ações que vão além da filantropia com as comunidades locais.

A preocupação com a capacitação dos recursos humanos, especialmente em canteiros de obra, apareceu com grande força nessa pesquisa, evidenciando que a gestão de recursos humanos é uma área a ser dada especial atenção. É necessário preparar a mão de obra para o advento do uso de novas tecnologias. Muitos temem perder seus empregos, e isso apareceu em uma das respostas abertas, portanto fazse necessário uma gestão de recursos humanos eficiente para equilibrar essa balança.

Sendo que os projetos de construção civil são, de modo geral, impactantes na sociedade, tanto positiva quanto negativamente e trazem benefícios econômicos, gerando emprego e renda para os trabalhadores envolvidos, as questões de responsabilidade social devem ser implementadas, incluindo medidas, políticas e atividades que abordem problemas ambientais e sociais de modo estratégico. Essa deve ser uma tendência, para que os projetos sejam importantes plataformas para a indústria da construção civil desenvolver responsabilidade social.

\subsection{Limitações da Pesquisa}

Esse estudo teve limitações resultantes das metodologias escolhidas. Na etapa 1, destacam-se: a realização da revisão sistemática da literatura e a decisão de utilizar o banco de dados Web of Science, Science Direct e Scopus para a obtenção da amostra inicial. Ainda que sejam banco de dados com uma grande abrangência, ainda é possível que alguns títulos importantes não tenham sido capturados no critério de busca, para a realização da revisão sistemática da literatura.

Constataram-se as limitações do uso de questionários online, em comparação com as entrevistas face-a-face, uma vez que há uma dificuldade natural em garantir que as pesquisas sejam completadas e retornadas dentro do prazo e que as perguntas sejam corretamente compreendidas. Outra desvantagem percebida foi 0 viés associado à autosseleção dos respondentes. Todavia, mesmo com tais limitações, 
esse trabalho veio agregar detalhes empíricos sobre a questão da responsabilidade social em projetos de construção civil.

Por objetivar uma visão panorâmica sobre o tema responsabilidade social em projetos de construção civil, não houve um rigor estatístico em relação ao tamanho da amostra. Isso seguramente influenciou os resultados das correlações de Pearson.

\subsection{Sugestões de trabalhos futuros}

Dada a comprovada importância do tema responsabilidade social em projetos de construção, espera-se que esse trabalho motive o desenvolvimento de novas pesquisas dentro dessa temática. Algumas sugestões são deixadas a seguir:

1. Através da revisão sistemática de literatura identificou-se uma escassez de trabalhos com metodologias matemáticas/ experimentais. Abordagens quantitativas podem ser fomentadas, uma vez que existem poucos trabalhos com este enfoque.

2. Desenvolvimento de estudos comparativos das práticas de responsabilidade social em projetos desenvolvidos no Brasil em relação a outros países, utilizando rigor estatístico para avaliar as diferenças;

3. Avaliar a relação das ações de responsabilidade social e gestão de riscos nos projetos. 


\section{REFERÊNCIAS BIBLIOGRÁFICAS}

ACCOUNTABILITY. AA1000. Londres, Disponível:<http://www.accountability.org.uk>. Acesso em: 1/mai/2018.

ASHLEY, P. A.; QUEIROZ, A.; CARDOSO, A. J. G.; SOUZA, A. A. de; TEOdÓSIO, A. S. S.; BORINELLI, B.; VENTURA, E. C. F.; CHAVES, J. B. L.; VELOSO, L. H. M.; ALIGLERI, L.; LIMA, P. R. S.; FERREIRA, R. N. Ética e responsabilidade social nos negócios. 1. ed. São Paulo: Editora Saraiva, 2002.

AALTONEN, K.; KUJALA, J. A project lifecycle perspective on stakeholder influence strategies in global projects. Scandinavian Journal of Management, [s. I.], 2010.

AGUINIS, H.; GLAVAS, A. What We Know and Don't Know About Corporate Social Responsibility: A Review and Research Agenda. Journal of Management, [s. I.], v. 38, n. 4, p. 932-968, 2012.

ASSOCIAÇÃO BRASILEIRA DE NORMAS TÉCNICAS - ABNT. NBR 16001 (2012). Responsabilidade social - Sistema de gestão - Requisitos. Rio de Janeiro.

ASSOCIAÇÃO BRASILEIRA DE NORMAS TÉCNICAS - ABNT. NBR 26000 (2010). Diretrizes sobre Responsabilidade social. Rio de Janeiro.

ASSOCIAÇÃO BRASILEIRA DE NORMAS TÉCNICAS - ABNT. NBR 16001 (2012). Responsabilidade social - Sistema de gestão - Requisitos. Rio de Janeiro.

AREND, R. J. A heart-mind-opportunity nexus: Distinguishing social entrepreneurship for entrepreneurs. Academy of Management Review, [s. I.], v. 38, n. 2, p. 313-315, 2013.

ASIF, M.; SEARCY, C. Towards a standardised management system for corporate sustainable development. TQM Journal, [s. I.], 2014.

BARANDICA, J. M. et al. Estimation of $\mathrm{CO} 2$ emissions in the life cycle of roads through the disruption and restoration of environmental systems. Ecological Engineering, [s. I.], v. 71, p. 154-164, 2014.

BARRAKET, J. et al. Understanding Legitimacy Formation in Multi-Goal Firms: An Examination of Business Planning Practices among Social Enterprises. Journal of Small Business Management, [s. I.], v. 54, p. 77-89, 2016.

BARTHORPE, S. Implementing corporate social responsibility in the UK construction industry. Property Management, [s. I.], 2010.

BECKETT, R.; JONKER, J. AccountAbility 1000: a new social standard for building sustainability. Managerial Auditing Journal, [s. I.], 2002.

BOWEN, H. R. Social responsibilities of the businessman, 1953. Disponível em: $<$ http://www.scopus.com/inward/record.url?eid=2-s2.0-

84945349131\&partnerID=tZOtx3y1> 
BROWER, J.; MAHAJAN, V. Driven to Be Good: A Stakeholder Theory Perspective on the Drivers of Corporate Social Performance. Journal of Business Ethics, [s. I.], v. 117, n. 2, p. 313-331, 2013.

CAIADO, R.G.G. Diretrizes para maturidade da gestão de risco em projetos de construção. Dissertação apresentada ao Curso de Pós-Graduação em Engenharia Civil. Universidade Federal Fluminense, Niterói, março de 2015.

CARROLL, A. B. The Pyramid of Corporate Social Responsibiity: Toward the Morai Management of Organizational Stakeholders. Business Horizons, [s. I.], p. 39-48, 1991.

CARROLL, A. B. Carroll's pyramid of CSR: taking another look. International Journal of Corporate Social Responsibility, [s. I.], v. 1, n. 1, p. 3, 2016. Disponível em: <http://jcsr.springeropen.com/articles/10.1186/s40991-016-0004-6>

CARVALHO, M. M.; FLEURY, A.; LOPES, A. P. An overview of the literature on technology roadmapping (TRM): Contributions and trends. Technological Forecasting and Social Change, [s. I.], v. 80, n. 7, p. 1418-1437, 2013.

CARVALHO, M. M.; RABECHINI JR., R. Fundamentos Em Gestao De Projetos: Construindo Competencias Para Gerenciar Projetos. [s.I: s.n.].

CBIC - CÂMARA BRASILEIRA DA INDÚSTRIA DA CONSTRUÇÃO. Banco de Dados. Disponível em: <http://www.cbicdados.com.br/menu/emprego/rais-ministeriodo-trabalho>. Acesso em: 01/01/2019.

CHEN, L. H.; LIAW, S. Y.; LEE, T. Z. Using an HRM pattern approach to examine the productivity of manufacturing firms - An empirical study. International Journal of Manpower, [s. I.], 2003.

CLELAND, D. I.; IRELAND, L. R. Project management: strategic design and implementation. [s.I: s.n.].

DAHLSRUD, A. How corporate social responsibility is defined: An analysis of $\mathbf{3 7}$ definitions. Corporate Social Responsibility and Environmental Management, [s. I.], v. 15, n. 1, p. 1-13, 2008.

DAVIS, K. Understanding the social responsibility puzzle. Business Horizons, [s. I.], 1967.

DAVIS, K. The Case for and Against Business Assumption of Social Responsibilities. Academy of Management Journal, [s. I.], v. 16, n. 2, p. 312-322, 1973.

DE JONG, J. A.; LEENDERS, F. J.; THIJSSEN, J. G. I. HRD tasks of first-level managers. Journal of Workplace Learning, [s. I.], 1999.

DE VAUS, D. Survey Research. In: Research Methods for Postgraduates: Third Edition. [s.l: s.n.].

DOLNICAR, S.; POMERING, A. Consumer Response to Corporate Social Responsibility Initiatives: An Investigation of Two Necessary Awareness States. 
ANZMAC Conference, [s. I.], n. December, p. 1-9, 2007.

ECOLOGIA. Handbook for Implementers of ISO 26000, Global Guidance Standard on Social Responsibility. Hand book for Implementers of ISO 26000, [s. I.], n. May, p. 35, 2011.

EGRI, C. P.; RALSTON, D. A. Corporate responsibility: A review of international management research from 1998 to 2007. Journal of International Management, [s. I.], v. 14, n. 4, p. 319-339, 2008.

EHSAN, N. et al. Risk management in construction industry. In: 2010 3RD INTERNATIONAL CONFERENCE ON COMPUTER SCIENCE AND INFORMATION TECHNOLOGY 2010, Anais... [s.l: s.n.]

ELENA WINDOLPH, S.; SCHALTEGGER, S.; HERZIG, C. Implementing corporate sustainability. Sustainability Accounting, Management and Policy Journal, [s. I.], 2014.

ESCHENBACH, R. C.; ESCHENBACH, T. G. Understanding Why Stakeholders Matter. Journal of Management in Engineering, [s. I.], 1996.

FERREIRA, C. dos S.; GEROLAMO, M. C. Análise da relação entre normas de sistema de gestão (ISO 9001, ISO 14001, NBR 16001 e OHSAS 18001) e a sustentabilidade empresarial. Gestão \& Produção, [s. I.], v. 23, n. 4, p. 689-703, 2016. Disponível em: <http://www.scielo.br/scielo.php?script=sci_arttext\&pid=S0104530X2016000400689\&lng=pt\&tlng=pt>

FORTUNATO, T. L. S. R. Modelo de Gestão de Risco em Obras de Escavação de Túneis em Rocha. Técnico Lisboa. Dissertação para obtenção do Grau de Mestre em Engenharia Civil. Janeiro de 2013.

FREDERICK, W. C. From CSR1 to CSR2. Business \& Society, [s. I.], v. 33, n. 2, p. 150-164, $1994 . \quad$ Disponível em: <http://journals.sagepub.com/doi/10.1177/000765039403300202>

FREEMAN, R. E. Strategic management: A stakeholder approach. [s.I: s.n.].

FREEMAN, S.; CAVUSGIL, S. T. Strategic management. A stakeholder approach. Journal of International Marketing, [s. I.], 1984.

FRIEDMAN. The Social Responsibility of Business is to Increase its Profits, by Milton Friedman. 1970.

GAVIRIA-MARIN, M.; MERIGÓ, J. M.; BAIER-FUENTES, H. Knowledge management: A global examination based on bibliometric analysis. Technological Forecasting and Social Change, [s. I.], v. 140, p. 194-220, 2019. Disponível em: <https://linkinghub.elsevier.com/retrieve/pii/S0040162517304055>. Acesso em: 8 abr. 2019.

GEORGE, F. et al. Stakeholder management on construction projects. AACE International ..., [s. I.], 2000.

GHISELLINI, A.; THURSTON, D. L. Decision traps in ISO 14001 implementation 
process: Case study results from Illinois certified companies, 2005.

GHOBADIAN, A.; MONEY, K.; HILLENBRAND, C. Corporate Responsibility Research: Past-Present-Future. Group \& Organization Management, [s. I.], v. 40, n. 3 , p. 271-294, 2015.2 Disponível em: <http://gom.sagepub.com/cgi/doi/10.1177/1059601115590320>

GIANNARAKIS, G.; LITINAS, N.; SARIANNIDIS, N. Evaluation of corporate social responsibility performance standards. African Journal of Business Management, [s. I.], v. 5, n. 17, p. 7367-7374, 2011. Disponível em: $<$ http://www.academicjournals.org/AJBM>

GÖBBELS, M.; JONKER, J. AA1000 and SA8000 compared: a systematic comparison of contemporary accountability standards. Managerial Auditing Journal, [s. I.], v. 18, n. 1, p. 54-58, 2003.

GOMES, S. F. Auditoria aos relatórios de sustentabilidade das empresas portuguesas: uma visão sobre o estado da arte e a percepção dos Revisores Oficiais de Contas. 2012. Tese de Doutorado.

GLOBAL COMPACT - UNITED NATIONS. Quem somos. Disponível em:<https://www.unglobalcompact.org/what-is-gc> Acesso em: 10/01/2019.

GLOBAL REPORTING INITIATIVE - GRI. Quem somos. Disponível em: <http s://www.globalreporting.org/languages/Portuguesebrazil/Pages/default.aspx>. Acesso em: 20/10/2018.

GRAY, R. et al. Social and environmental disclosure and corporate characteristics: A research note and extension. Journal of Business Finance and Accounting, [s. I.], 2001.

GREENPEACE (2009), "Poisoning the pearl river". Disponível em: www.greenpeace.org/international/en/publications/reports/poisoning-the-pearl/. Acesso em:10/jan/2019

HAHN, R. ISO 26000 and the standardization of strategic management processes for sustainability and corporate social responsibility. Business Strategy and the Environment, [s. I.], v. 22, n. 7, p. 442-455, 2013.

HAHN, R.; KÜHNEN, M. Determinants of sustainability reporting: A review of results, trends, theory, and opportunities in an expanding field of research, 2013.

HARTMANN, A.; REYMEN, I. M. M. J.; VAN OOSTEROM, G. Factors constituting the innovation adoption environment of public clients. Building Research and Information, [s. I.], v. 36, n. 5, 2008.

HOLME, L \& WATTS, R. WBCSD - World Business Council for Sustainable Development. Making Good Business Sense, [s. I.], p. 3, 1999. Disponível em: $<$ http://www.wbcsd.org/work-program/business-role/previous-work/corporate-socialresponsibility.aspx>

HUEMANN, M.; KEEGAN, A.; TURNER, J. R. Human resource management in the 
project-oriented company: A review. International Journal of Project Management, [s. I.], 2007.

HUSSAIN, N. et al. Systematic Reviews and Meta-Analysis. In: Evidence-Based Orthopedics. [s.l: s.n.]. p. 25-29.

INSTITUTO ADVB, "14a Pesquisa Nacional sobre Responsabvbilidade Social e Práticas Sustentáveis nas empresas - 2013" . Disponível em: <http://www.institutoadvb.org.br/download/14-pesquisa.pdf> Acesso em: 01/jan/2019

INSTITUTO ETHOS. INSTITUTO ETHOS. Conceitos Básicos e Indicadores de Responsabilidade Social Empresarial. Disponível em http:///www3.ethos.org.br. Acesso em 20/10/2018.

JORGENSEN, T. H. Towards more sustainable management systems: through life cycle management and integration. Journal of Cleaner Production, [s. I.], v. 16, n. 10, p. 1071-1080, 2008.

JAMALI, D. A stakeholder approach to corporate social responsibility: A fresh perspective into theory and practice. Journal of Business Ethics, [s. I.], 2008.

JIANG, R. J.; BANSAL, P. Seeing the Need for ISO 14001. Journal of Management Studies, [s. I.], v. 40, n. 4, p. 1047-1067, 2003. Disponível em: <http://doi.wiley.com/10.1111/1467-6486.00370>

JONES, M. T. Missing the forest for the trees: A critique of the social responsibility concept and discourse. Business and Society, [s. I.], 1996.

KARLSEN, J. T. Project stakeholder management. EMJ - Engineering Management Journal, [s. I.], 2002.

KARTAM, N. A.; KARTAM, S. A. Risk and its management in the Kuwaiti construction industry: A contractors' perspective. International Journal of Project Management, [s. I.], 2001.

KARLSEN, J. T. Project stakeholder management. EMJ - Engineering Management Journal, [s. I.], 2002.

KARKOTLI, Gilson Rihan. RESPONSABILIDADE SOCIAL: uma estratégia empreendedora. 2004. 216 f. Tese (Doutorado em Engenharia de Produção) - PósGraduação em Engenharia de Produção, UFSC, Florianópolis.

KEEBLE, J. J.; TOPIOL, S.; BERKELEY, S. Using Indicators to Measure Sustainability Performance at a Corporate and Project Level. In: JOURNAL OF BUSINESS ETHICS 2003, Anais... [s.l: s.n.]

KERR, J.; ROUSE, P.; DE VILLIERS, C. Sustainability reporting integrated into management control systems. Pacific Accounting Review, [s. I.], 2015.

KOLK, A.; PINKSE, J. Stakeholder Mismanagement and Corporate Social Responsibility Crises. European Management Journal, [s. I.], v. 24, n. 1, p. 59-72, 2006.

LAM ., P. T. I. et al. Environmental management system vs green specifications: How do they complement each other in the construction industry? Journal of 
Environmental Management, [s. I.], v. 92, n. 3, p. 788-795, 2011.

LAM, P. T. I. et al. Factors affecting the implementation of green specifications in construction. Journal of Environmental Management, [s. I.], v. 91, n. 3, p. 654-661, 2010.

LEE, B.; CASSELL, C. Employee and social reporting as a war of position and the union learning representative initiative in the UK. Accounting Forum, [s. I.], 2008.

LIN, X.; HO, C. M. F.; SHEN, G. Q. P. Who should take the responsibility? Stakeholders' power over social responsibility issues in construction projects. Journal of Cleaner Production, [s. I.], v. 154, p. 318-329, 2017.

LIU, J. et al. Sustainability in hydropower development - A case study, 2013.

LOOSEMORE, M.; BRIDGEMAN, J. Corporate volunteering in the construction industry: Motivations, costs and benefits. Construction Management and Economics, [s. I.], v. 6193, n. May, p. 1-13, 2017.

LOOSEMORE, M.; LIM, B. T. H. Linking corporate social responsibility and organizational performance in the construction industry. Construction Management and Economics, [s. I.], v. 35, n. 3, p. 90-105, 2017.

Loosemore, M. and Phua, F. Corporate Social Responsibility in the Construction Industry: Doing the Right Thing? Routledge, London, UK..2011

LOZANO, R.; HUISINGH, D. Inter-linking issues and dimensions in sustainability reporting. Journal of Cleaner Production, [s. I.], v. 19, n. 2-3, p. 99-107, 2011.

LOWE D. Commercial Management: Theory and Practice. Wiley-Blackwell. 2013.

MA, $H$. et al. The societal governance of megaproject social responsibility. International Journal of Project Management, [s. I.], 2017.

MATTEN, D.; CRANE, A. Corporate citizenship: Toward an extended theoretical conceptualization. Academy of Management Review, [s. I.], v. 30, n. 1, p. 166-179, 2005.

MAVIN, S. et al. Developing "new commons" between HRD research and practice: Case studies of UK universities. Journal of European Industrial Training, [s. I.], 2007.

MONEVA, J. M.; RIVERA-LIRIO, J. M.; MUÑOZ-TORRES, M. J. The corporate stakeholder commitment and social and financial performance. Industrial Management \& Data Systems, [s. I.], v. 107, n. 1, p. 84-102, 2007. Disponível em: <http://www.emeraldinsight.com/doi/10.1108/02635570710719070>. Acesso em: 8 dez. 2016.

MONTEIRO FILHA, D. C.; COSTA, A. C. R.; ROCHA, É. R. P. Perspectivas e desafios para inovar na construção civil. BNDES Setorial, [s. I.], 2010.

MUKAKA, M. M. Statistics corner: A guide to appropriate use of correlation coefficient in medical research. Malawi Medical Journal, [s. I.], 2012. 
NAÇÕES UNIDAS. As buildings and construction sector grows, time running out to cut energy use and meet Paris climate goals | UN Environment. [s.d.]. Disponível em: <https://www.unenvironment.org/news-and-stories/pressrelease/buildings-and-construction-sector-grows-time-running-out-cut-energy>. Acesso em: 11 mar. 2019

NADAE, Jeniffer de. Sistemas de gestão integrados como indutor para a sustentabilidade: uma análise do impacto no desempenho das organizações baseado no Triple Bottom Line. 2016. Tese (Doutorado em Engenharia de Produção) - Escola Politécnica, Universidade de São Paulo, São Paulo, 2016.

NIDUMOLU, R.; PRAHALAD, C. K.; RANGASWAMI, M. R. Why sustainability is now the key driver of innovation. Harvard Business Review, [s. I.], 2009.

OLANDER, S.; LANDIN, A. Evaluation of stakeholder influence in the implementation of construction projects. International Journal of Project Management, [s. I.], 2005.

ORECCHINI, F. The ISO 14001 certification of a machine-process. Journal of Cleaner Production, v.8, n.1, p. 61 -68, fev. 2000.

OTHMAN, I.; IDRUS, A.; NAPIAH, M. Effectiveness of Human Resource Management in Construction project. In: 2011 NATIONAL POSTGRADUATE CONFERENCE - ENERGY AND SUSTAINABILITY: EXPLORING THE INNOVATIVE MINDS, NPC 2011 2011, Anais... [s.l: s.n.]

PACKENDORFF, J. Inquiring into the temporary organization: New directions for project management research. Scandinavian Journal of Management, [s. I.], 1995.

PATEL, A. M. et al. A Study of Risk Management Techniques for Construction Projects in Developing Countries. International Journal of Innovative Technology and Exploring Engineering, [s. I.], 2013.

PHILLIPS, R. Some key questions about stakeholder theory. Ivey Business Journal, 1-6, 2004.

PMI. Project Management Institute. A Guide to the Project Management Body of Knowledge (PMOBOK Guide). Sixth ed. Project Management Institute, Inc. Pensilvânia, USA, 2018.

RECHENTHIN, D. Project safety as a sustainable competitive advantage. Journal of Safety Research, [s. I.], v. 35, n. 3, p. 297-308, 2004.

ROWLEY, J.; SLACK, F. Conducting a literature review. Management Research News, [s. I.], v. 27, n. 6, p. 31-39, 2004. Disponível em: $<$ http://www.emeraldinsight.com/doi/10.1108/01409170410784185>

SAID, R.; ZAINUDDIN, Y.; HARON, H. The relationship between corporate social responsibility disclosure and corporate governance characteristics in Malaysian public listed companies. Social Responsibility Journal, [s. I.], 2009.

SARKIS, J.; MEADE, L. M.; PRESLEY, A. R. Incorporating sustainability into contractor evaluation and team formation in the built environment. Journal of 
Cleaner Production, [s. I.], v. 31, p. 40-53, 2012.

SERTYESILISIK, B. A preliminary study on the regenerative construction project management concept for enhancing sustainability performance of the construction industry. International Journal of Construction Management, [s. I.], 2017.

SETHI, S. P.; ROVENPOR, J. L. The Role of NGOs in Ameliorating Sweatshop-like Conditions in the Global Supply Chain: The Case of Fair Labor Association (FLA), and Social Accountability International (SAI). Business and Society Review, [s. I.], v. 121, n. 1, p. 5-36, 2016.

SHEN, L. et al. Project feasibility study: the key to successful implementation of sustainable and socially responsible construction management practice. Journal of Cleaner Production, [s. I.], v. 18, n. 3, p. 254-259, 2010.

SILLS, S. J.; SONG, C. Innovations in Survey Research: An Application of WebBased Surveys. Social Science Computer Review, [s. I.], v. 20, n. 1, p. 22-30, 2002.

SILVA Jr., Q. Diagnostico de responsabilidade social nas empresas do setor de edificações do projeto construindo futuro. Dissertação de mestrado, Universidade Federal do Paraná, Curitiba, PR, Brasil (2008).

SILVA, V. F. Análise de risco na construção - guia de procedimentos para gestão. Mestrado Integrado em Engenharia Civil - 2009/2010 - Departamento de Engenharia Civil, Faculdade de Engenharia da Universidade do Porto, Porto, Portugal, 2009.

SLOTTE, V.; TYNJÄLÄ, P.; HYTÖNEN, T. How do hrd practitioners describe learning at work? Human Resource Development International, [s. l.], 2004.

SOUZA, F. Responsabilidade social da construção - Um panorama da atuação social da indústria da construção, São Paulo, 2011.

SZYMAŃSKI, P. Risk management in construction projects. In: PROCEDIA ENGINEERING 2017, Anais... [s.l: s.n.]

TABASSI, A. A.; BAKAR, A. H. A. Training, motivation, and performance: The case of human resource management in construction projects in Mashhad, Iran. International Journal of Project Management, [s. I.], 2009.

TAN, Y.; SHEN, L.; YAO, H. Sustainable construction practice and contractors' competitiveness: A preliminary study. Habitat International, [s. I.], v. 35, n. 2, p. 225-230, 2011.

TATSIONI, A.; IOANNIDIS, J. P. A. Meta-analysis. In: International Encyclopedia of Public Health. [s.l: s.n.].

TEOD, S. Parcerias Tri-Setoriais em Políticas Sociais: Em Busca de Modelos Explicativos de sua Complexidade na Esfera Pública. Anpad, [s. I.], 2009.

TINOCO, H. Responsabilidade social em construção civil. Boletim técnico. Asociación Latinoamericana de Control de Calidad, Patologia y Recuperación de Estructuras - ALCONPAT Int., 2012. 
TSAI, C. Y.; CHANG, A. S. Framework for developing construction sustainability items: the example of highway design. Journal of Cleaner Production, [s. I.], v. 20, n. 1, p. 127-136, 2012.

TSAI, W.-H. et al. An Activity-Based Costing decision model for life cycle assessment in green building projects. European Journal of Operational Research, [s. I.], v. 238, n. 2, p. 607-619, 2014.

TURK, A. M. The benefits associated with ISO 14001 certification for construction firms: Turkish case. Journal of Cleaner Production, [s. I.], v. 17, n. 5, p. 559-569, 2009.

UTTING, P.; REED, D.; MUKHERJEE-REED, A. Business regulation and non-state actors: Whose standards?: whose development? Routledge studies in development economics, [s. I.], p. 346, 2012. Disponível em: <http://site.ebrary.com/lib/alltitles/docDetail.action?doclD=10545483>

VAN ECK, N. J.; WALTMAN, L. Software survey: VOSviewer, a computer program for bibliometric mapping. Scientometrics, [s. I.], v. 84, n. 2, p. 523-538, 2010. VISSER, W. Revisiting Carroll's CSR pyramid. Corporate citizenship in developing countries, [s. I.], p. 29-56, 2005.

WADDOCK, S. Parallel universes: Companies, academics, and the progress of corporate citizenship. Business and society Review, [s. I.], v. 109, n. 1, p. 5-42, 2004. Disponível em: <http://doi.wiley.com/10.1111/j.00453609.2004.00002.x\%5Cnhttp://onlinelibrary.wiley.com/doi/10.1111/j.0045-

3609.2004.00002.x/full>

WALK, MICHAEL, J.; RUPP, A. A. Pearson product-moment correlation coefficient. In: Encyclopedia of Research Design. [s.I: s.n.].

WATTS, G.; DAINTY, A.; FERNIE, S. Making Sense of CSR in Construction : Do Contractor and Client Perceptions Align? In: PROCEEDINGS 31ST ARCOM CONFERENCE, 7-9 SEPTEMBER 2015 2015, Anais... [s.l: s.n.]

WRIGHT, P. M.; BOSWELL, W. R. Desegregating HRM: A review and synthesis of micro and macro human resource management research, 2002.

WRIGHT, P. M.; MCMAHAN, G. C. Theoretical Perspectives for Strategic Human Resource Management. Journal of Management, [s. I.], 1992.

XU, Y. Review of Global business citizenship: A transformative framework for ethics and sustainable capitalism., 2008. Disponível em: <http://ovidsp.ovid.com/ovidweb.cgi?T=JS\&PAGE=reference\&D=psyc6\&NEWS=N\& $\mathrm{AN}=2008-16461-006>$

YANG, J. et al. Exploring critical success factors for stakeholder management in construction projects. Journal of Civil Engineering and Management, [s. I.], v. 15, n. 4, 2009.

ZADEK, S. The path to corporate responsibility, 2004.

ZENG, S. X. et al. Social responsibility of major infrastructure projects in China. 
International Journal of Project Management, [s. I.], v. 33, n. 3, p. 537-548, 2015.

ZENG, S. X.; SHI, J. J.; LOU, G. X. A synergetic model for implementing an integrated management system: an empirical study in China. Journal of Cleaner Production, [s. I.], v. 15, n. 18, p. 1760-1767, 2007.

ZHAO, Z.-Y. et al. A corporate social responsibility indicator system for construction enterprises. Journal of Cleaner Production, [s. I.], v. 29, p. 277-289, 2012.

ZUO, J. et al. Sustainability policy of construction contractors: A review. Renewable and Sustainable Energy Reviews, [s. I.], v. 16, n. 6, p. 3910-3916, 2012.

ZUO, J.; ZHAO, Z. Y. Green building research-current status and future agenda: A review, 2014. 


\section{APÊNDICE A - Questionário sobre "Responsabilidade Social em Projetos de Construção Civil” - Em Português}

\section{Contribua! Pesquisa sobre Responsabilidade Social em Projetos de Construção Civil}

Por atuar na área da construção civil, poderia contribuir com uma pesquisa sobre Responsabilidade Social neste setor?

Sua opinião é muito importante para traçar o perfil das atividades sociais de empresas deste setor. Se trata de um questionário anônimo e de rápido preenchimento (cerca de 8 minutos).

O resultado desta pesquisa será divulgado através de uma dissertação de mestrado da Universidade de São Paulo (USP) sob orientação do professor Dr. Silvio Burrattino Melhado.

Caso queira receber o resultado da pesquisa daqui a alguns meses, deixe seu e-mail no final do questionário.

Grata,

Michelle Coutinho

1. Já ouviu falar de responsabilidade social empresarial? *

Mark only one oval.

$\operatorname{Sim}$

Não

2. Por responsabilidade social empresarial, você entende ações ligadas a... *

Check all thatapply.

Envolvimento comunitário e desenvolvimento

Meio ambiente

Práticas de trabalho

Direitos humanos

Práticas justas de operação

Questões deconsumidores

Other:

3. Nos PROJETOS desenvolvidos por sua empresa, são realizadas ações de responsabilidade social? *

Mark only one oval.

\section{Sim Skip to question5.}

Não Skip to question 4. 
4. Qual o principal motivo para a falta de desenvolvimento de ações de responsabilidade social nos projetos desenvolvidos por sua empresa? *

Mark only one oval.

A empresa de modo geral não tem interesse no tema. Skip to question 19.

Falta de recursos financeiros. Skip to question 19.

Falta de funcionários com interesse no tema. Skip to question 19.

Falta de interesse e apoio da alta direção. Skip to question 19.

Other:

Skip to question 19.

5. Descreva as ações de responsabilidade social realizadas nos PROJETOS desenvolvidos por sua empresa: *

6. Quais motivos levaram a empresa a investir em ações de responsabilidade social em seus diferentes PROJETOS? *

Check all that apply.

Apenas para cumprir requisitos legais e/ou auditorias.

Por acreditar que pode verdadeiramente fazer a diferença nas comunidades dos entornos das obras.

Para melhorar a imagem institucional.

Servir de exemplo para outras empresas.

Other:

7. Para quem são direcionadas as ações de responsabilidade social? *

Check all that apply.

Para os funcionários/colaboradores

Para a sociedade em geral (escolas, ONGs)

Para a comunidade do entorno da empresa ou de canteiros de obras

Para os familiares dos funcionários/ colaboradores

Para parceiros, prestadores de serviço ou funcionários terceirizados

Para os consumidores

Other: 
8. Quais critérios são utilizados para definir os beneficiários das ações sociais dos PROJETOS desenvolvidos por sua empresa? *

Check all that apply.

Classe socioeconômica

Ser funcionário

Idade

Condiçãofísica

Pertencer à comunidade local

Gênero

Meio ambiente

Etnia

Não há critérios

Não saberesponder

9. Estimar os valores gastos em atividades de responsabilidade social nos PROJETOS de sua empresa no ano de 2017: *

Mark only one oval.

Nenhum investimento foi realizado em 2017

De $R \$ 10.000$ a $R \$ 20.000$ no ano

De $R \$ 20.001$ a $R \$ 50.000$ no ano

De $R \$ 50.001$ a $R \$ 100.000$ no ano

De $R \$ 100.001$ a $R \$ 500.000$ no ano

De $R \$ 500.001$ a $R \$ 1.000 .000$ no ano

De $R \$ 1.000 .001$ a $R \$ 3.000 .000$

De $R \$ 3.000 .001$ a $R \$ 5.000 .000$

Acima de $\mathrm{R} \$ 5.000 .000$

10. Quem são os parceiros para realização de ações de responsabilidade social nos PROJETOS desenvolvidos por sua empresa? *

Check all that apply.

Sesi/ Senai

Sindicatos

ONGs e/ou Oscips (Organizações da Sociedade Civil de Interesse Público)

Escolas

Hospitais/ clínicas/ centros de saúde

Creches

Institutos e fundações empresariais

Universidades

Associação de moradores

Associação de funcionários

Governos

Não sabe responder

Other: 
11. Em 2017 as ações de Responsabilidade Social dos PROJETOS receberam mais investimentos, menos ou o mesmo volume de recursos que em 2016? *

Mark only one oval.

Mais investimentos que em 2016

O mesmo volume de recursos que em 2016

Menos recursos que em 2016

Não sabe responder

12. As atividades relacionadas à responsabilidade social nos diferentes PROJETOS, integram a visão estratégica da empresa? *

Mark only one oval.
$\operatorname{Sim}$
Não
Não sabe responder

13. Quem toma as decisões mais importantes sobre as ações de responsabilidade social dos PROJETOS de sua empresa? *

Mark only one oval.

Direção

Direção e Gerências

Conjunto dos empregados

Um Comitê Gestor de Responsabilidade Social

Other:

14. As ações de responsabilidade social estão contempladas no processo de planejamento e orçamento de cada PROJETO de sua empresa? *

Mark only one oval.
$\operatorname{Sim}$
Não
Não sabe responder

15. A empresa divulga as ações de responsabilidade social realizadas em seus diferentes PROJETOS? *

Mark only one oval.
$\operatorname{Sim}$
Não
Não sabe responder 
16. Quais as formas de divulgação das ações de responsabilidade social dos diferentes PROJETOS de sua empresa? *

Check all that apply.

As ações não são divulgadas

Comunicação interna

Site da empresa

Por releases para a imprensa

Por material divulgados junto aos beneficiários

Relatório anual

Other:

17. A empresa possui políticas formais de compras de "materiais ecológicos" ou "ambientalmente certificados" para o desenvolvimento de seus projetos de construção civil? *

Mark only one oval.

$\operatorname{Sim}$

Não

Não sabe responder

18. A sua empresa realiza pesquisa junto a seus clientes para saber se ele entende como diferencial a organização atuar em programas de responsabilidade social e/ou ambiental e se a escolhe por isto? *

Mark only one oval.

$\operatorname{Sim}$

Não

Não sabe responder

19. Com relação às normas, orientações e indicadores, a sua empresa: *

Mark only one oval per row.

\begin{tabular}{|c|c|c|}
\hline Implantou & $\begin{array}{l}\text { Não implantou, mas } \\
\text { tem interesse em } \\
\text { implantar }\end{array}$ & $\begin{array}{l}\text { Não implantou e não } \\
\text { tem interesse em } \\
\text { implantar }\end{array}$ \\
\hline
\end{tabular}

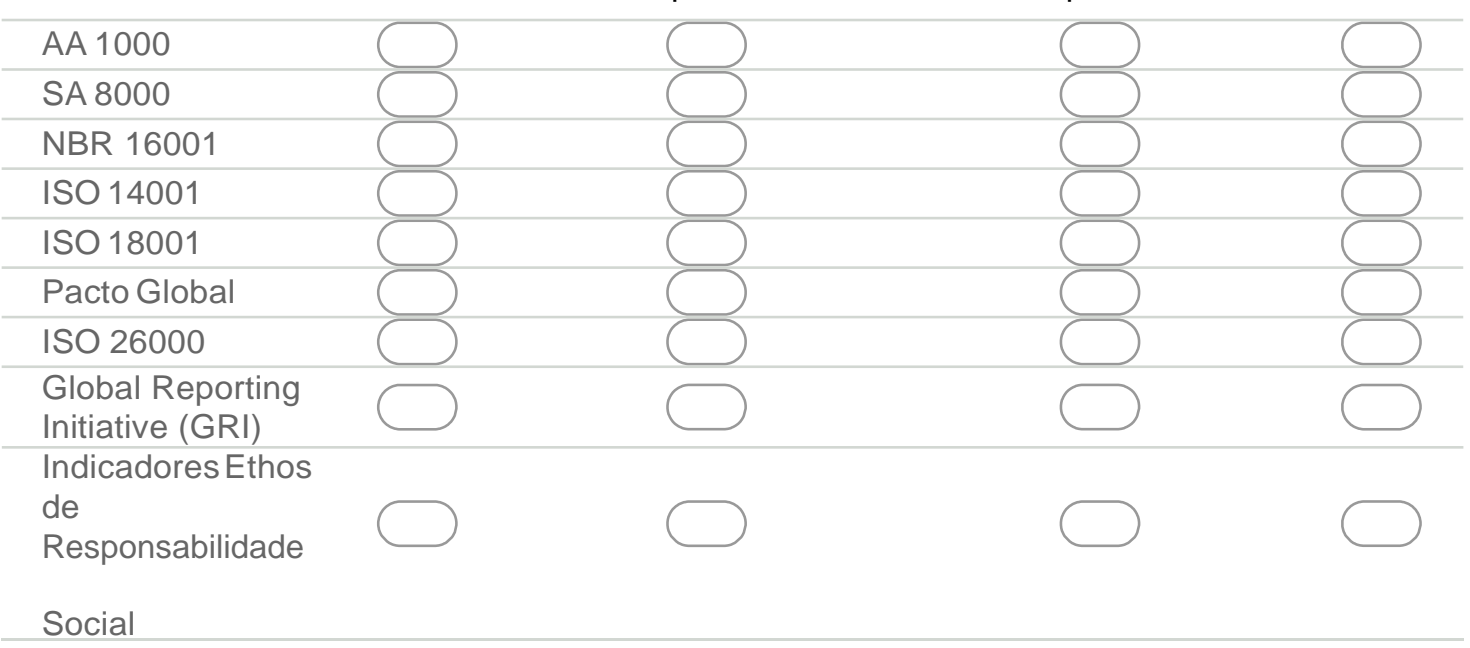


20. A empresa estimula seus colaboradores a realizar trabalho voluntário? * Mark only one oval.
$\operatorname{Sim}$
Não
Não sabe responder

\section{Caracterização da empresa respondente}

\section{Número de funcionários: *}

Mark only one oval.
Até 9 funcionários
De 10 a 49 funcionários
De 50 a 99 funcionários
De 100 a 499 funcionários
Mais de 500 funcionários

22. Em quais mercados/segmentos a sua empresa atua? * Check all that apply.

Projetos Elétricos

Projetos Hidráulicos

Projetos de Estruturas Metálicas

Projetos Residenciais e Comerciais

Projetos Estruturais

Fornecedores de materiais para a construção civil

$\square$ Other: 
23. Local da empresa?

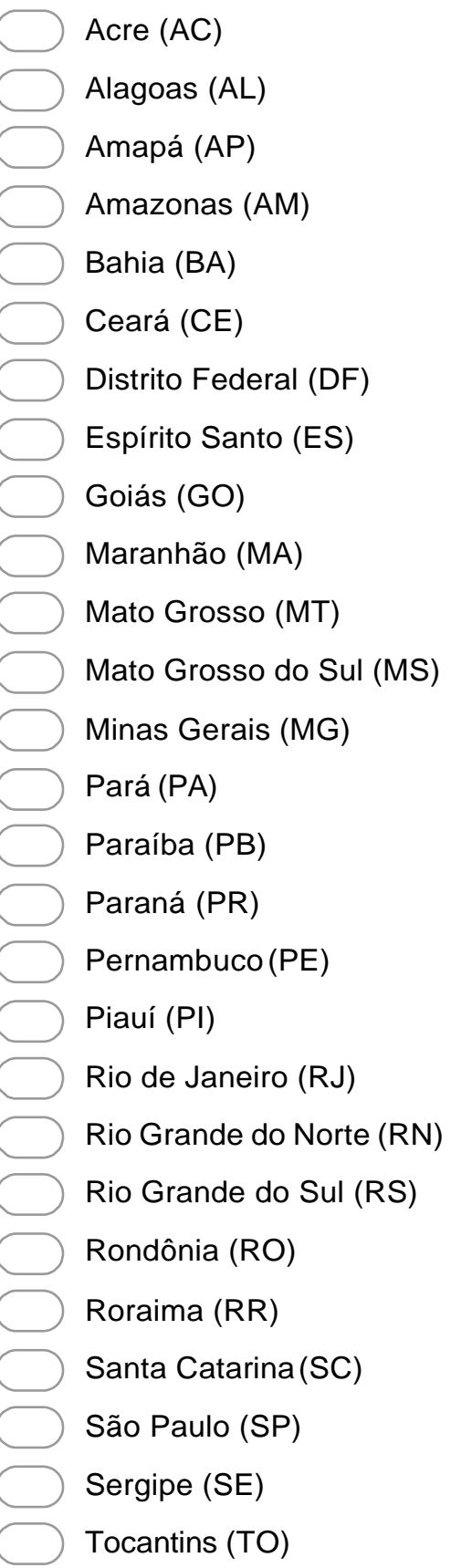

24. Cargo ocupado pelo respondente: * Mark only one oval.

Analista

Arquiteto

Coordenador

Diretor

Engenheiro Civil

Engenheiro Elétrico

Engenheiro Mecânico

Engenheiro de Planejamento

Gerente

Presidente

Other: 
25. Tempo de experiência profissional do respondente: *
Menos de 1 ano 2
a 5 anos
6 a 10 anos Mais
$\Longrightarrow$ de 10 anos

26. Gênero do respondente:

Mark only one oval.
Masculino
Feminino

27. Nome da empresa (opcional)

28. e-mail (opcional)

Powered by

:: Google Forms 


\section{APÊNDICE B - Questionário de Pesquisa em espanhol}

\section{Responsabilidad social en proyectos de construcción civil}

¡Participa en la investigación sobre responsabilidad social en Proyectos de Construcción Civil! Su opinión es muy importante para trazar el perfil de las actividades sociales de empresas de este sector.

El resultado de esta investigación será divulgado a través de una disertación de maestría de la Universidad de São Paulo (USP).

Gracias,

Michelle Coutinho

* Required

1. ¿Escuchó hablar sobre responsabilidad social empresarial? Mark only one oval.<smiles>O=[N+]([O-])c1ccccc1</smiles>

2. Por responsabilidad social empresarial, usted entiende acciones ligadas a ... * Marque todas las alternativas que considere apropiadas.

Check all that apply.

Participación comunitaria y desarrollo

Medio ambiente

Prácticas de trabajo

Derechos humanos

Prácticas justas de operación de la empresa

$\square$ Cuestiones de consumidores

$\square$ Other:

3. En los PROYECTOS desarrollados por su empresa, se realizan acciones de responsabilidad social? *

Mark only one oval.

$\square$ Sí Skip to question 5.
No Skip to question 4.

4. ¿Cuál es el principal motivo para la falta de desarrollo de acciones de responsabilidad social en los proyectos desarrollados por su empresa? *

Mark only one oval.

La empresa en general no tiene interés en este tema. Skip to question 19.

Falta de recursos financieros. Skip to question 19.

Falta de funcionarios con interés en este tema. Skip to question 19.

Falta de interés y apoyo de la alta dirección. S Skip to question 19.

Other: 
5. Describa las acciones realizadas de responsabilidad social en los PROYECTOS que su empresa desarrolla: *

6. ¿Qué motivos llevaron a la empresa a invertir en acciones de responsabilidad social en sus diferentes proyectos? *

Check all that apply.

Sólo para cumplir requisitos legales y / o auditorías

Por creer que puede realmente hacer la diferencia en las comunidades de los entornos de las obras
$\square$ Para mejorar la imagen institucional
Ser ejemplo para otras empresas
$\square$ Other:

7. ¿A quién se dirigen las acciones de responsabilidad social? *

Check all that apply.

Para los empleados / colaboradores

Para la sociedad en general (escuelas, ONG)

Para la comunidad del entorno de la empresa o de los canteros de obra

Para los familiares de los empleados / colaboradores

Para los socios, los proveedores de servicios o los empleados tercerizados

$\square$ Para los consumidores

$\square$ Other:

8. ¿Qué criterios se utilizan para definir los beneficiarios de las acciones sociales de los proyectos desarrollados por su empresa? *

Check all that apply.

Clase socioeconómica

Ser empleado

Edad

Estado físico

Pertenencer a la comunidad local

Género

Medio ambiente

Etnia

No hay criterios

No sabe responder 
9. Estimar los valores gastados en actividades de responsabilidad social en los PROYECTOS de su empresa en el año 2017: *

Mark only one oval.

Ninguna inversión se realizó en 2017

De 10.000 USD a 20.000 USD en el año

De 50.001 USD a 100.000 USD en el año

De 100.001 USD a 500.000 USD en el año

De 500.001 USD a 1.000.000 USD en el año

De 1.000.001 USD a 3.000.000 USD en el año

De 3.000.001 USD a 5.000.000 USD en el año

Más de 5.000.000 USD en el año

10. ¿Quiénes son los socios/colaboradores para la realización de acciones de responsabilidad social en los PROYECTOS desarrollados por su empresa? *

Check all that apply.

\section{Sindicatos}

ONGs y/o Oscips (Organizaciones de la Sociedad Civil de Interés Público)

Escuelas

Hospitales / clínicas / centros de salud

Guarderías

Institutos y fundaciones empresariales

U Universidades

Asociación de vecinos

Asociación de funcionarios

Gobiernos

Empresas

Organizaciones religiosas

No sabe responder

Other:

11. ¿En 2017 las acciones de Responsabilidad Social de los PROYECTOS recibieron más inversiones, menos o cantidad igual al año 2016? *

Mark only one oval.

Más inversiones que en 2016

El mismo volumen de recursos que en 2016

Menos recursos que en 2016

No sabe responder

12. ¿Las actividades relacionadas con la Responsabilidad Social integran la visión estratégica de la empresa? *

Mark only one oval. 
13. ¿Quién toma las decisiones más importantes sobre las acciones sociales de los proyectos de la empresa? *

Mark only one oval.

Dirección

Dirección y Gerencias

Conjunto de los empleados

Un Comité Gestor de Responsabilidad Social

Other:

14. ¿Las acciones de responsabilidad social están contempladas en el proceso de planificación y presupuesto de cada PROYECTO de la empresa? *

Mark only one oval.
$\bigcirc$ Sí
No
No sabe responder

15. ¿La empresa divulga las acciones de responsabilidad social realizada en relación a sus diferentes PROYECTOS? *

Mark only one oval.
Sí
No
No sabe responder

16. ¿Cuáles son las formas de divulgación de las acciones sociales de los diferentes PROYECTOS de su empresa? *

Check all that apply.

Comunicación interna

Página Web de la empresa

Por comunicados de prensa

Por material divulgado junto a los beneficiarios

Informe anual

$\square$ Other:

17. ¿La empresa tiene políticas formales de compras de "materiales ecológicos" o "ambientalmente certificados" para el desarrollo de sus proyectos de construcción civil? *

Mark only one oval.
Sí
No
No sabe responder 
18. ¿La empresa investiga a sus clientes para saber si ellos entienden como un diferencial la compañia actuar con responsabilidad social y/o Ambiental en sus proyectos, y si por este motivo la empresa es elegida en relación a sus competidores? *

Mark only one oval.
Sí
No
No sabe responder

19. Con respecto a las normas y orientaciones, su empresa: *

Por favor seleccione 2 columnas: "Conoce o no conoce" e "Implantó / No implantó con o sin interés"

Mark only one oval per row.

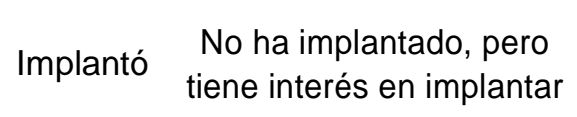

No ha implantado y no tiene interés en implantar

ISO 14001

20. ¿La empresa estimula a sus colaboradores a realizar trabajo voluntario? *

Mark only one oval.
Sí
No
No sabe responder

\section{Caracterización de la empresa respondiente}

\section{Número de empleados: *}

Mark only one oval.
Hasta 9 empleados
De 10 a 49 empleados
De 50 a 99 empleados
De 100 a 499 empleados
Más de 500 empleados 
22. ¿En qué mercados / segmentos su empresa actúa? *

Check all that apply.

$\square$ Proyectos Eléctricos

Projetos Hidráulicos

Proyectos Residenciales y Comerciales

$\square$ Proyectos Estructurales

Proveedores de materiales para la

construcción Other:

\section{País de la empresa: *}

Mark only one oval.

Argentina

Bolivia

Chile

Colombia

Costa Rica

Cuba

Ecuador

El Salvador

España

Guatemala

Honduras

México

Nicaragua

Panamá

Paraguay

Perú

Puerto Rico

República Dominicana

Uruguay

Venezuela

24. Cargo ocupado por el respondiente: *

Mark only one oval.

Analista

Arquitecto

Director

Ingeniero civil

Ingeniero Eléctrico

OptIngeniero mecánico

Ingeniero de Planificación

Gerente

Presidente 
25. Tiempo de experiencia laboral del respondiente: *

Mark only one oval.

$$
\begin{aligned}
& \text { Menos de } 1 \text { año } 2 \text { a } 5 \text { años } \\
& 6 \text { a } 10 \text { años Más de } 10 \text { años }
\end{aligned}
$$

26. Género del encuestado:

Mark only one oval.

$\bigodot_{\text {Femenino }}$ Masculino

27. Nombre de la empresa (opcional):

28. e-mail (opcional):

Powered by

: Google Forms 


\section{Social Responsibility in Civil Construction Projects}

Participate in research on social responsibility in Civil Construction Projects!

Your opinion is very important to trace the profile of the social activities of companies in this sector. The results of this research will be published through a master's dissertation from the University of São Paulo (USP).

Thankful,

Michelle Coutinho

${ }^{*}$ Required

1. Have you heard of corporate social responsibility? *

Mark only one oval.

Yes

No

2. For corporate social responsibility, you understand actions related to ... *

Check all the alternatives you deem appropriate

Check all that apply.

Community involvement and development

Environment

Work practices

Fair operating practices

Consumer issues

Other:

3. Are social responsibility actions carried out in PROJECTS developed by your company? * Mark only one oval.
Yes Skip to question 5.
No Skip to question 4.

4. What is the main reason for the lack of development of social responsibility actions in the projects developed by your company? *

Mark only one oval.

The company in general has no interest in the topic. Skip to question 19.

Lack of financial resources. Skip to question 19.

Lack of employees with an interest in the topic. Skip to question 19.

Lack of interest by senior management. Skip to question 19.

Other:

Skip to question 19. 
5. Describe the social responsibility actions carried out in PROJECTS developed by your company: *

6. 2. What reasons led the company to invest in social responsibility actions in its different PROJECTS? *

Check all that apply.

Only to comply with legal requirements and / or audits.

Believing that it can truly make a difference in the communities around the work sites.

To improve the institutional image.

To be an example for other companies.

Other:

7. 3. To whom are the social responsibility actions directed? * Check all thatapply.

Foremployees

For society in general (schools, NGOs)

For the community around the company or construction sites

For the relatives of employees / collaborators

For partners, service providers or outsourced employees

For consumers

Other:

8. 4. What criteria are used to define the beneficiaries of the social actions of PROJECTS developed by your company? *

Check all that apply.

Socioeconomic class

Being an employee

Age

Physical condition

Belonging to the local community

Gender

Environment

Ethnicity

There are no criteria

I do not know 
9. Estimate the values spent on social responsibility activities in your company PROJECTS in 2017: *

Mark only one oval.

No investment was made in 2017

10,000 USD to 20,000 USD in the year

21,001 USD to 50,000 USD in the year

50,001 USD to 100,000 USD in the year

100,001 USD to 500,000 USD in the year

500,001 USD to $1,000,000$ USD in the year

$1,000,001$ USD to $3,000,000$ USD in the year

$3,000,001$ USD to $5,000,000$ USD in the year

More than 5,000,000 USD in the year

10. Who are the partners to carry out social responsibility actions in projects developed by your company? *

Check all that apply.

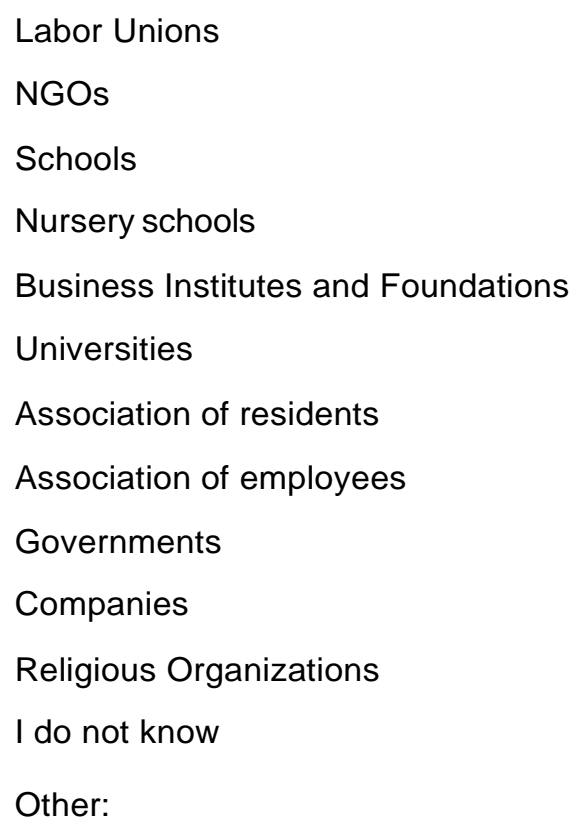

Other:

11. In 2017 did the social responsibility actions of projects receive more investments, less or equal volume compared to 2016? *

Mark only one oval.

More investments than in 2016

The same volume of resources as in 2016

Less resources than in 2016

I do not know

12. Do the activities related to social responsibility in the different PROJECTS integrate the strategic vision of the company? *

Mark only one oval.

Yes

No

I do not know 
13 Who makes the most important decisions about the social action of the company's PROJECTS? *

Mark only one oval.

Director

Director and Managers

Employees

A Social Responsibility Management Committee

Other:

14. Are social responsibility actions included in the planning and budgeting process of each company PROJECT? *

Mark only one oval.
$\bigcirc$ Yes
No
I do not know

15. Does the company disclose its social responsibility actions carried out in relation to its different PROJECTS? *

Mark only one oval.

Yes

No

I do not know

16. What are the way the social actions are disclosed? *

Check all that apply.

The actions are not disclosed

Internal communication

Company Website

By press releases

By material disclosed to the beneficiaries

Annual report

Other:

17. Does the company have formal procurement policies for "green" or "environmentally certified" materials? *

Mark only one oval.

Yes

No

I do not know 
18. Does your company carry out consumer research to check if clients recognize the organization for having social and/or environmental responsibility programs and choose them for this reason? *

Mark only one oval.
Yes
No
I do not know

19. Regarding to standards and guidelines, your company *

Mark only one oval per row.

It is not implemented,
but I have an interest in
implementing
implemented Is not implemented
implementing

20. Does your company encourage employees to volunteer? *

Mark only one oval.
$\bigcirc$ Yes
No
I do not know

\section{Characterization of the respondent company}

\section{Number of company employees *}

Mark only one oval.

Up to 9 employees

10 to 49 employees

50 to 99 employees

100 to 499 employees

Over 500 employees 
22. In which markets / segments does your company operate? *

Check all that apply.

Electric projects

Hydraulic Projects

Metal Structures Projects

Residential and Commercial Projects

Structural Projects

Suppliers of building materials

Other:

23. Company Location (country) *

24. Position occupied by the respondent: *

Check all that apply.
$\square$ Analyst
Architect
Director
Civil Engineer
Electric Engineer
Mechanical Engineer
Planning Engineer
Manager
President
Other:

25. Time of work experience: *

Mark only one oval.
Less than 1 year
2 to 5 years
6 to 10 years
More than 10 years

26. Gender:

Mark only one oval.
Male
Female

27. Company name (optional):

28. e-mail (optional) 


\section{APÊNDICE D - Link para a planilha de dados originais} do link:

A planilha com os dados originais está disponível para download através https://drive.google.com/file/d/18gotft6L8FEzpHPYsy_qab9I5Xo3BBDr/view?us $\mathrm{p}=$ sharing 